
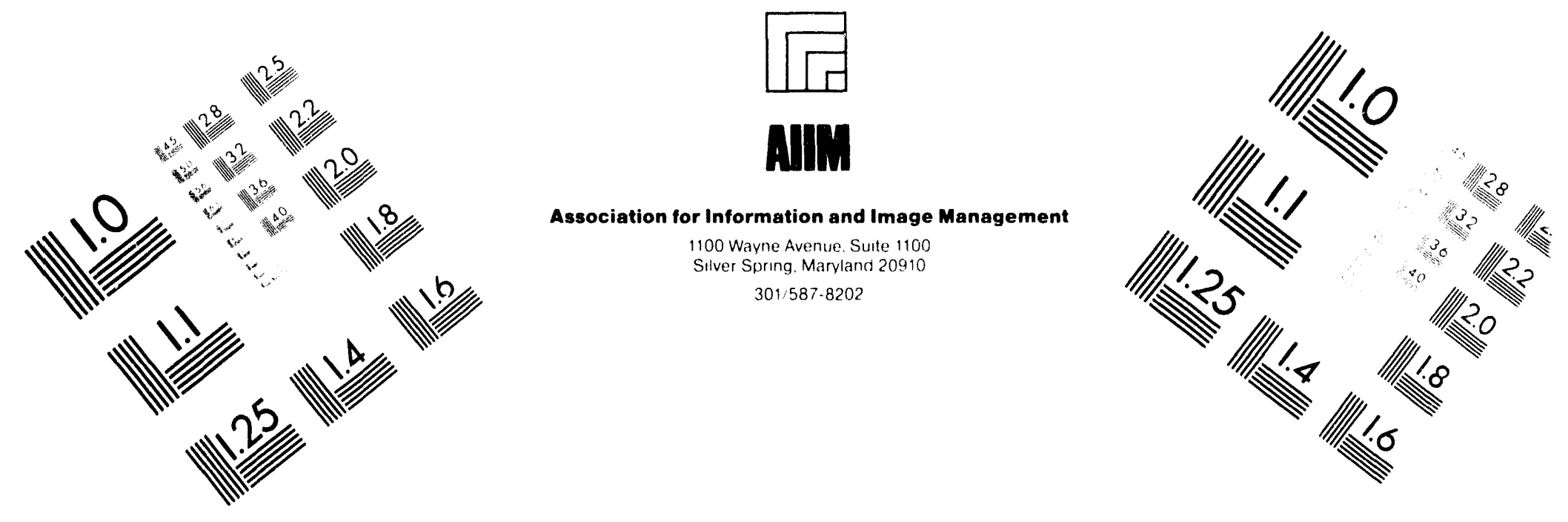

\title{
Centimeter
}

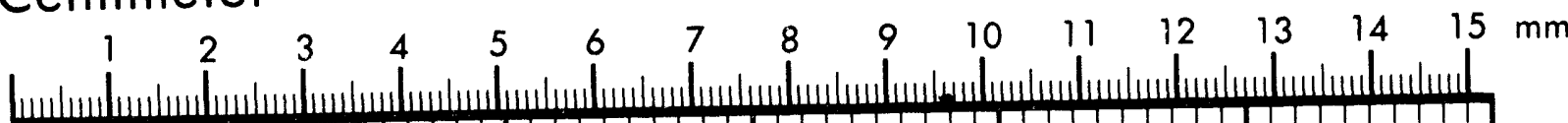

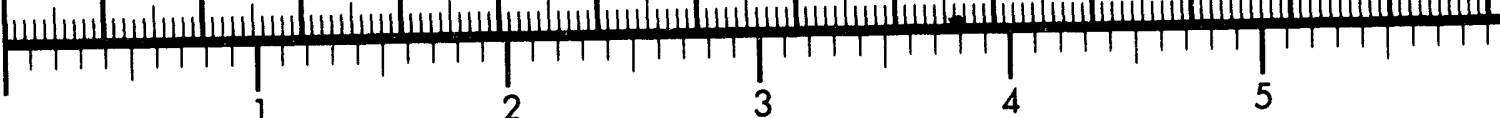

Inches
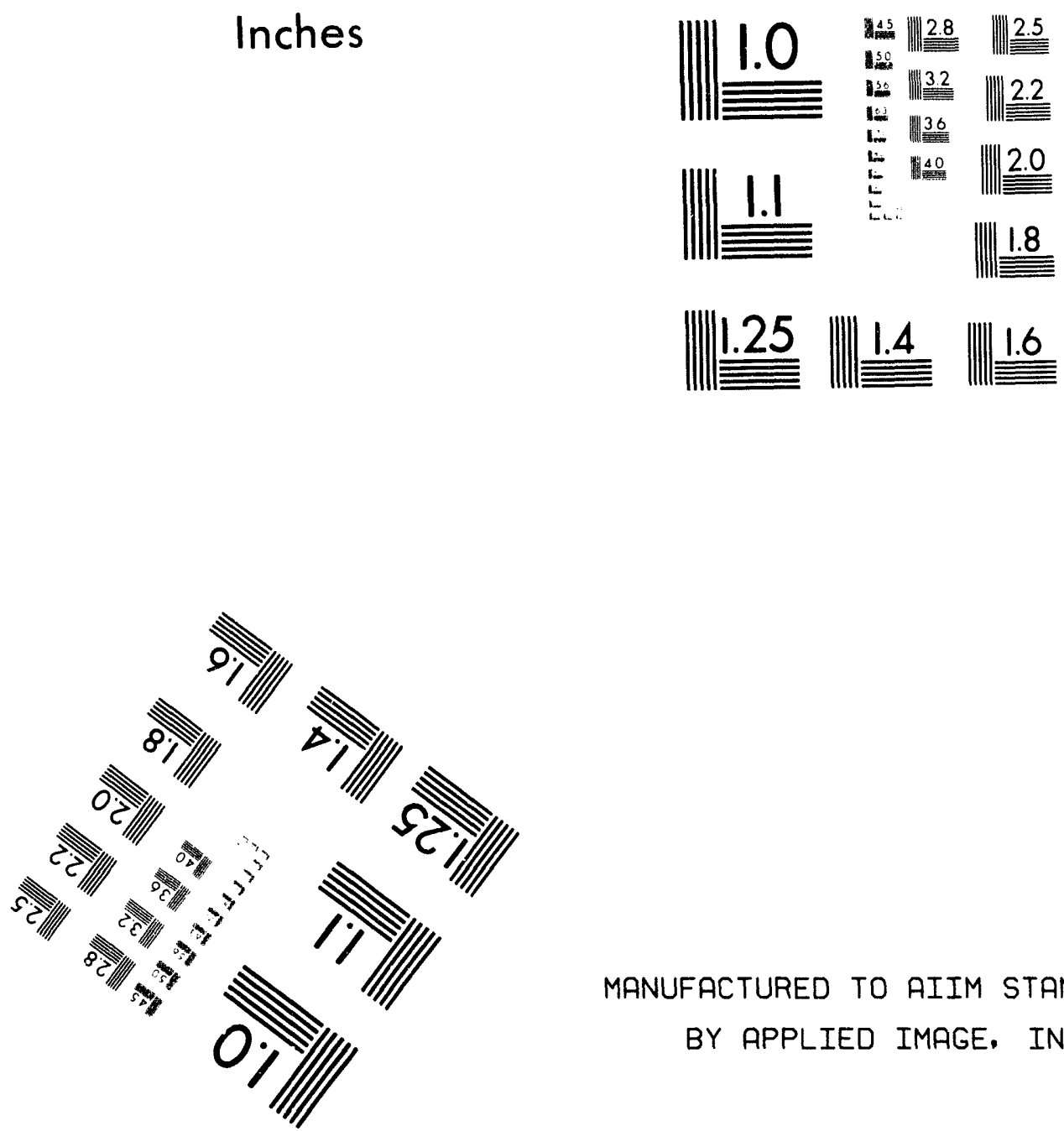

MANUFACTURED TO AIIM STANDARDS

BY APPLIED IMAGE, INC.

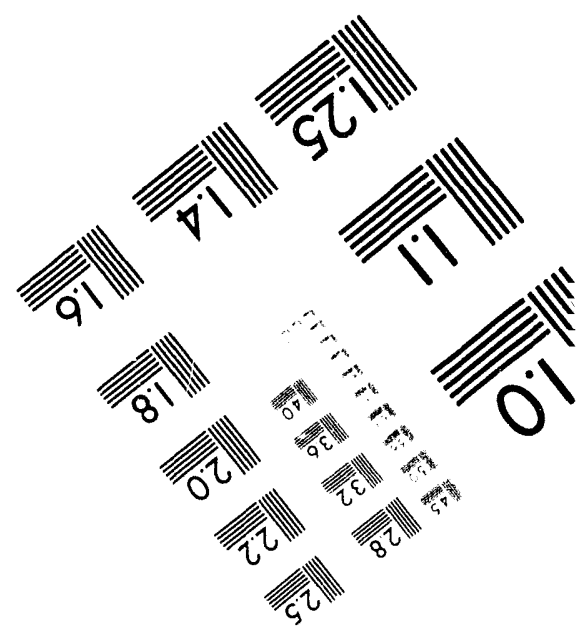



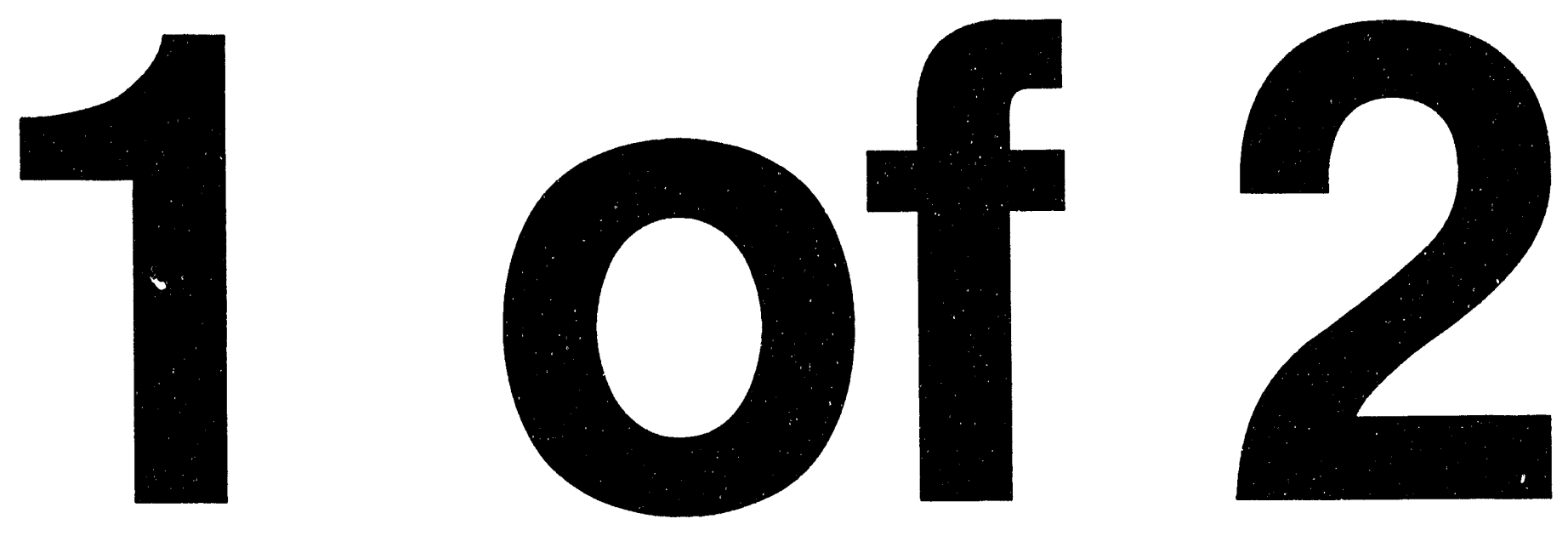


\section{Summary of Comments Received on Staff Draft Proposed Rule \\ on Radiological Criteria for Decommissioning}

Manuscript Completed: June 1994

Date Published: August 1994

Prepared by

J. Caplin, G. Page, D. Smith, C. Wiblin

Advanced Systems Technology, Inc.

932 Hungerford Drive

Rockville, Md 20850

\section{Prepared for}

Division of Regulatory Applications

Office of Nuclear Regulatory Research

U.S. Nuclear Regulatory Commission

Washington, DC 20555-0001

NRC FIN J6039

\section{MASTER}




\begin{abstract}
The Nuclear Regulatory Commission (NRC) is conducting an enhanced participatory rulemaking to establish radiological criteria for the decommissioning of NRC-licensed facilities. The NRC obtained comments on the scope, issues, and approaches through a series of workshops (57 FR 58727), Generic Environmental Impact statement (GEIS) scoping meetings (58 FR 33570), a dedicated electronic bulletin board system (58 FR 37760), and written submissions. A summary of workshop and scoping-meeting comments was published as NUREG/CR-6156. On February 2, 1994, the Commission published in the Federal Register (59 FR 4868) a notice that the NRC staff had prepared a "staff draft" proposed rule on radiological criteria for decommissioning. Copies of the staff draft were distributed to the Agreement states, participants in the earlier meetings, and other interested parties for comment. This report summarizes the comments identified from the 96 docketed letters received on the staff draft. No analysis or response is included in this report. The comments reflect a broad spectrum of viewpoints. Two subjects on which the commenters were in general agreement were (1) that the enhanced participatory rulemaking should proceed, and (2) that the forthcoming GEIS and guidance documents are needed for better understanding of the draft rule.
\end{abstract}


1 INTRODUCTION.

1.1 Background.

1.2 Overview of Comments

2.1 Definjtions, $\$ 20.1003$.

2.1.1 Background Radiation.

2.1.2 Critical Group.

2.1.3 Decommission

2.1.4 Readily Removable.

2.1.5 Residual Radioactivity

2.1.6 Site Specific Advisory Board (SSAB)

2.1.7 Other Issue Related Comments.

2.2 Scope, $\$ 20.1401$.

2.2.1 Previously Submitted/Approved Plans.

2.2.2 Finality.

2.2.3 Other Issue Related Comments

2.3 Concepts, $\$ 20.1402$.

2.3.1 Radiological Goal/Limit.

2.3.2 National/International Consensus Standards . . . . 11

2.3 .3 Demonstrating Compliance . . . . . . . . . . 12

2.3.4 Effective Use of Resources. . . . . . . . . . 13

2.3.5 Technical Basis for Criteria Vs. Non-Technical/ Political Basis. . . . . . . . . . . . . 14

2.3 .6 Other Issue Related Comments. . . . . . . . . 15

2.4 General Provisions, $\$ 20.1403$. . . . . . . . . . . 16

2.4.1 Calculations of TEDE to 1000 Years . . . . . . . 16

2.4 .2 As LCW As Reasonably Achievable (ALARA)
Analysis. . . . . . . . . . . . . . . . 17

2.4.3 Removal/Storage of Residual Radioactivity. . . . . 18

2.4 .4 Other Issue Related Comments . . . . . . . . . 19

2.5 Radiological Criteria for Unrestricted Use, $\$ 20.1404$. . 20

2.5.1 Goal - Indistinguishable from Background . . . . . 20

2.5 .2 TEDE of 3 to $15 \mathrm{mrem} /$ year. . . . . . . . . . 20

2.5.3 Other Issue Related Comments. . . . . . . . . 21

2.6 Criteria for License Termination Under Restricted Conditions, \$20.1405.

2.6.1 Acceptability Criteria . . . . . . . . . . . 22

2.6 .2 Institutional Controls. . . . . . . . . . . 23

2.6 .3 Financial Assurance . . . . . . . . . . . . 24

2.6 .4 Maximum TEDE of $100 \mathrm{mrem} /$ year. . . . . . . . . 25

2.6 .5 Other Issue Related Comments. . . . . . . . . 25 
2.7 Notification and Public Participation, $\$ 20.1406 . \quad . \quad . \quad . \quad 25$

2.7 .1 Public Notifications. . . . . . . . . . . . . 25

2.7 .2 Use of Site Specific Advisory Board. . . . . . . 26

2.7 .3 Other Issue Related Comments . . . . . . . . . . 27

2.8 Site Specific Advisory Board, $\$ 20.1407$. . . . . . . . . 27

2.8 .1 Need for Board . . . . . . . . . . . . . . . 27

2.8 .2 Responsibilities/Activities . . . . . . . . . 28

2.8 .3 Membership . . . . . . . . . . . . . . . 28

2.8 .4 Independence and Support . . . . . . . . . . . 29

2.8 .5 Reporting/Use of Recommendations. . . . . . . . 30

2.8 .6 Other Issue Related Comments. . . . . . . . . 30

2.9 Minimization of Contamination, $\$ 20.1408$. . . . . . . . 31

2.9 .1 General . . . . . . . . . . . . . . . . 31

2.9 .2 Acceptability Criteria. . . . . . . . . . . 31

2.9 .3 Backfit Analysis . . . . . . . . . . . . . 31

2.9 .4 Appropriateness in Part 20 . . . . . . . . . . . . . 32

2.9 .5 Other Issue Related Comments . . . . . . . . . 32

2.10 Implementation . . . . . . . . . . . . . . . . . . . . . 32

2.10 .1 Regulatory Guidance/Better Explanation of Rule's Provisions. . . . . . . . . . . . . 32

2.10.2 Compatibility/Consistency With Federal/state Requirements . . . . . . . . . . . . . . . 33

2.10.3 Need for Cost Analysis of Requirements. . . . . . 34

2.10 .4 Clarity . . . . . . . . . . . . . . . . . . . . . 35

2.10 .5 Flexibility. . . . . . . . . . . . . . . . . . . 35

2.10 .6 Other Issue Related Comments . . . . . . . . . . 36

2.11 Miscellaneous. . . . . . . . . . . . . . . . . . . . . . 36

\section{Appendices}

Appendix A Text of Rule from staff Draft

$A-1$

Appendix B Commenter Listing

$\mathrm{B}-1$

Appendix C Comment References 


\section{FOREWORD}

The Nuclear Regulatory Commission (NRC) is conducting an enhanced participatory rulemaking to establish radiological criteria for the decommissioning of NRC-licensed facilities. The NRC obtained comments on the scope, issues, and approaches for this rulemaking through a series of seven workshops held from January through May 1993; eight meetings in four cities on the proposed scope of the Generic Environmental Impact Statement (GEIS); a dedicated electronic bulletin board system which was established for disseminating information and obtaining comments on the rulemaking; and letters in response to notices in the Federal Register inviting comments. Copies of the summaries of comments received from this process, published as NUREG/CR-6156, and an NRC "staff draft" proposed rule were distributed to the NRC's Agreement States, participants in the earlier workshops and meetings, and othex interested parties for comment. A notice of availability of NUREG/CR-6156 and the staff draft rule was published in the Federal Register, and the documents were placed on the electronic bulletin board.

The purpose of this report is to summarize comments contained in letters received from interested persons regarding the staff draft proposed rule.

This report contains information that is being considered by the NRC in developing radiological criteria for the decommissioning of NRC licensed facilities. The results, approaches, and methods described in this NUREG/CR-6250 are provided for information only. Publication of this report does not necessarily constitute NRC approval of, or agreement with, the comments summarized herein.

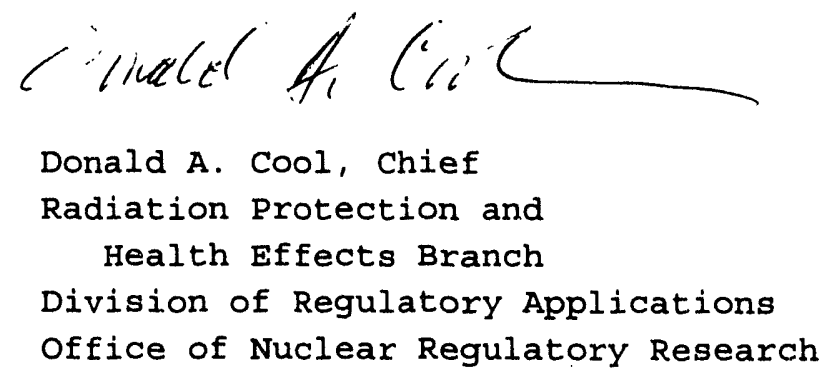




\section{INTRODUCTION}

\subsection{Background}

On June 27, 1988, the Commission published in the Federal Register (53 FR 24018) a final rule on general requirements for decommissioning nuclear facilities. The amended regulations addressed decommissioning planning needs, timing, assurance of the availability of funds for decommissioning, and environmental review requirements. That rule did not cover acceptable levels of residual radioactivity for decommissioned facilities. The Commission indicated that specific requirements on how clean a nuclear facility must be to qualify for decommissioning would be dealt with later in a separate action.

On December 11, 1992, the Commission published in the Federal Register (57 FR 58727) a notice that it was preparing to initiate rulemaking on establishing radiological criteria for the decommissioning of NRC-licensed facilities. The notice listed a schedule for seven workshops throughout the United states during 1993, in Chicago, San Francisco, Boston, Dallas, Philadelphia, Atlanta, and Washington, D.C. ${ }^{1}$ On June 18, 1993, The Commission published in the Federal Register (58 FR 33570) a notice that public meetings on the scope of the Generic Environmental Impact statement would be held during July 1993 in Washington, D.C., San Francisco, CA, Oklahoma City, OK, and Cleveland, OH. The purpose of the workshops and scoping meetings was to solicit comments from affected interests on the scope, issues, and approaches that must be addressed in establishing radiological criteria for decommissioning to determine the extent to which radioactive contamination must be removed or reduced in lands and structures before a license for a nuclear facility can be terminated. Written comments on approaches and issues also were solicited. Those comments received were summarized in NUREG/CR-6156 and were used by the staff in preparing the "staff draft."

On February 2, 1994, the Commission published in the Federal Register (59 FR 4868) a notice that the NRC staff had prepared a draft proposed rule on radiological criteria for decommissioning. The draft provided requirements for two levels of clean up. One level of clean up was for release of the site for unrestricted use. The other level was for clean up of the site with certain restrictions attached governing its future use. This draft was identified as the "staff draft." The staff draft (Appendix A contains the text of the rule) and NUREG/CR-6156 were distributed to the Agreement states, participants in the earlier meetings, and other interested parties for comment.

At the time of issuance of the staff draft, neither the Generic Euvironmental Impact statement (GEIS) nor guidance for implementing the draft rule were available for public review.

\footnotetext{
1. The workshops were held as follows: Jan. 27\&28-Chicago, IL; Feb. 23\&24-San Francisco, CA; Mar. 12-Boston, MA; Mar. 23\&24-Dallas, TX; Apr. 13\&14-Philadelphia, PA; Apr. 29\&30-Atlanta, GA; May 6\&7-Washington, D.C.
} 


\subsection{Overview of Comments}

There were 1,075 comments categorized from the 96 docketed letters ${ }^{2}$ received on the staff draft. Copies of these letters are available for inspection or copying for a fee in the NRC Public Document Room, 2120 L street, NW (Lower Level), Washington, D.C. Commenters and their addresses are listed in Appendix B.

The comments were organized in accordance with the issues and sub-issues identified in Sectior 2. For purposes of organization, this summary of comments on the staff draft uses the outline of the proposed rule to the extent possible. The summaries are presented with identifying comment numbers, listed in parenthesis, for each issue. Some comments were summarized in more than one issue; there were 1,533 uses of the 1,075 comments. The source of each comment can be identified as to its origin (docket number), commenter, and the page number where the comment begins in the docketed letter. Multiple use of a comment in various issues can also be identified. This information is in Appendix $\mathrm{C}$.

These comments were similar to those summarized in NUREG/CR-6156 with respect to the wide range of expressed views. The commenters strongly favored enhanced participatory rulemaking and said that the GEIS and the guidance documents are needed in order to understand the basis for the rule and how it would be implemented.

2 There were 100 numbers assigned to this docket of which three were duplicates of earlier letters and one number was inadvertently skipped. 


\section{SUMMARIES OF COMMENTS PER ISSUE}

\subsection{Definitions, \$20.1003}

\subsubsection{Background Radiation}

Some commenters said that there is a need for further guidance on, or better explanation of the use of, the definition of background radiation (101, 185, $626,820)$.

Some public interest and environmental interest groups did not want to include fallout in the definition of background radiation $(158,486,626,636,648$, 782).

Three commenters suggested wording that they believe would clarify, without substantially changing, the proposed definition of background radiation (479, 817,1094 ).

Three commenters either disagreed with or identified potential problems in including radon in the definition of background radiation $(595,782,855)$. However, another commenter agreed that radon should continue to be included as it now is in the proposed definition (938).

Two commenters said that to include radon in the definition of background radiation might be incompatible with other requirements in the proposed rule $(185,595)$.

\subsubsection{Critical Group}

Some commenters objected to the use of a critical group or to the use of an averaged value of exposure to the members of a critical group in evaluating radiation exposures $(126,160,421,618,628,785,947)$, and some added that only a "maximally exposed individual" should be considered $(126,618,947)$. other commenters supported the use of averaged exposures of the members of a critical group $(310,418)$.

Some commenters said that the most "vulnerable" or "susceptible" people should be considered in calculating the critical-group average $(152,512)$.

Several commenters said that there is a need for more clarification or guidance in selecting and using the critical group or in the calculation of exposure to the average member of the critical group $(418,449,453,713,867,995,999)$. Another recommended replacing the concept "average member of the critical group" with "hypothetical maximally exposed individual" (23). 
One commenter said that the physical restrictions on the site should be taken into consideration when characterizing the critical group in decommissioning to a resuricted use (136).

\subsubsection{Decommission}

Some environmental groups, individuals, and states agreed with including decommissioning to restricted use in the definition of decommissioning (496, $962,1010)$. Other environmental groups disagreed, and believed the definition should include only decommissioning to unrestricted use $(423,631)$.

One commenter said that the definition of decommissioning should make it clear that decommissioning includes some pre-shutdown planning, engineering, and regulatory review (475).

One commenter noted that the definition of decommissioning in 10 CFR 50.2 would have to be changed to conform to the proposed new definition in 10 CFR part 20, (915).

\subsubsection{Readily Removable}

One commenter did not understand the meaning of "detergent" in the definition Readily Removable (328).

One commenter objected to the definition of readily removable contamination as not requiring sufficient decontamination (635).

One comnenter said that there should be some clarification of the definition Readily Removable for guidance on determining methods that would result in acceptable volumes of waste for subsequent disposal (810).

\subsubsection{Residual Radioactivity}

Several commenters said that the definition Residual Radioactivity should be rewritten to exclude radioactive materials off site that result from discharges that are permitted under the regulations during normal operations $(214,445$, $540,571,759)$. One commenter said that the definition should include all onsite or off-site radioactive materials that result from licensed activities (645), and one said that the statement of considerations should "include a discussion of radioactive materials discharges, including precipitation and reconcentration issues" (14).

Two commenters suggested changes to the definition Residual Radioactivity that would avoid including as residual radioactivity technologically-enhanced NORM, building materials, or other ubiquitous naturally-occurring radioactive materials $(184,301)$. 
One commenter said that the definition of residual radioactivity might conflict with that for background radiation (185).

One commenter suggested that the wording of the definition of residual radioactivity be changed to include radioactive materials possessed by the licensee and not only those used by the licensee (821).

\section{1 .6 Site Specific Advisory Board (SSAB)}

One commenter objected to the definition of the Site Specific Advisory Board as requiring the board both to be constituted by and to advise the licensee (655).

\subsubsection{Other Issue Related Comments}

Two commenters said that there is a need for clarification of the definition of "total effective dose equivalent" $(67,1095)$. Others noted the need for a definition for "cumulative TEDE" and were either uncertain of its meaning (706) or wanted an explanation of its distinction from "TEDE" (1032).

One commenter said that the phrase "net public or environmental harm" should be defined "in terms of risk, damage, costs, benefits, and more objective terms," but suggested no actual wording for such a definition (303).

Three commenters said that "significant" in proposed 10 CFR 20.1401(c) should be defined $(448,715,872)$; two of them said that it should be defined similarly to "significantly" in the Council of Environmental Quality's regulation in 40 CFR $1508.27,(715,872)$.

Two commenters said that "unrestricted use" should be defined (714, 872).

One commenter said that in decommissioning to restricted use the "document creating the use restriction" should define "affected parties" as including others besides the critical group (999).

One commenter said to provide a "more sufficient definition of ALARA," but did not suggest any specific wording that would be "more sufficient" (1081).

\subsection{Scope, \$20.1401}

\subsubsection{Previously Submitted/Approved Plans}

Some industry commenters agreed that sites previously decommissioned or approved for decommissioning should be exempted from the requirements of the proposed rule $(121,238,360,790,860,975)$, and some of them suggested that the exemption should be extended to licensees with plans submitted, or substantially complete, for decommissioning but not yet approved, e.g., by setting an 
implementation date for the rule one to two years after its adoption (463, 690, 789).

Some individuals, environmental groups, and one state said that the proposed rule should apply to all sites and that sites previously decommissioned or approved for decommissioning should not be exempted $(95,161,375,658,667$, 1005). One commenter said that the proposed requirements should be used to evaluate decommissioning plans in the interim before the proposed rule is promulgated (378).

One federal agency suggested that it might be "instructive" to compare the siteby-site criteria used for previous decommissionings with the criteria of the proposed rule (360).

\subsubsection{Finality}

Many commenters said that the scope of the rule should provide more assurance of finality of decommissioning for licensees and some suggested the need for specific criteria or clarifying wording to be added to the scope concerning the conditions that would require the revisiting of a decommissioned site (16, 53, $239,248,252,277,297,361,419,543,675,717,813,874,902,934,984$, 1089). One said that the use of site Specific Advisory Boards would prevent finality (879). Another said that a de facto limit, or "goal", that is set too low to verify by measurements will make final closure practically impossible (1056).

Many commenters agreed with the intent of the scope not to require additional cleanup for sites that conform to the proposed decommissioning criteria (66, 72, $91,121,218,427,559,560,646,694,771,790,798)$. In addition, one said that the scope should reference specific sections of the rule (484), and two said that the scope should provide for further decontamination at sites released for restricted use when the restrictions are "proven to be ineffective" (717, 874 ).

Some commenters said the standard should have more stringent requirements for attaining finality, with continued legal responsibility for licensees and less latitude for exposures over "background" $(167,201,466,495,656,668,673$, 864). One commenter asked what the responsibilities of the NRC and the licensee are for sites that "will never be remediated" (444).

Other comments were: Finality for previously decommissioned sites might have to be evaluated by comparing previously used criteria with those of the proposed rule (178); finality for sites decommissioned to restricted use might be linked to requirements for further cleanup if cleanup technology improves (179); criteria for additional site cleanup should not be "adopted unilaterally by the NRC," but should come out of "a public process" (937); for finality the scope's grandfathering should extend to sites decommissioned under the SAFSTOR option (288); and requiring reconsideration of materials previously buried on site is "unfair" because it affects finality of the previous action (367). 


\subsubsection{Other Issue Related Comments}

Several commenters supported the exemption of mill tailings sites from the proposed decommissioning ruie and said that the exemption should also be extended to other source materials licensees, e.g., uranium recovery sites, because they are adequately covered under the requirements of 10 CFR Part 40 or in EPA standards that should be "transferred" to 10 CFR Part 40, (225, 233, 240, $305,342,346)$. One commenter said that the applicability of the standard to sites contaminated with uranium or thorium needs clarification (935). One commenter said that the NRC shouldn't single out thorium sites as likely candidates for restricted release (936).

Some commenters expressed general agreement with the scope of the rule (500, $547,568,615)$. Some agreed that there should not be a separate standard for radon $(61,181,249,295,581,938)$, and one agreed that materials previously disposed of on site should be included in decommjssioning (183). A commenter supported decommissioning to unrestricted use but opposed decommissioning to restricted use (1067).

One commenter questioned the legal basis for requiring a ditional cleanup after license termination (447), and one said that the NRC should identify the areas in which it has regulated non-radiological hazards (477). One commenter said the NRC should limit the focus of the rule to radiological issues at this time and address questions such as mixed wastes later (763); while another said that the rule should "consider coordination" of radiological and non-radiological "impacts" (1066).

Other comments were: The NRC should clarify that, at sites with more than one facility, the decommissioning criteria apply to the entire site and not to each facility individually (664); another commenter questioned the reason for exempting mill tailings in the scope of the proposed rule (703); and two commenters said that the NRC should distinguish between naturaily-occurring radionuclides and NORM enhanced by processing $(705,831)$. One commenter said that decommissioning is the same as deregulation of residual levels of radioactive materials to levels below regulatory concern (155). One commenter said that the rule should allow licensees to decommission inactive facilities without requesting the termination of the license (271). The EPA said that the draft proposed rule's lack of provisions for recycle/reuse of materials from decommissioned sites is "...a significant omission that should be corrected..." $(1084)$. 


\subsection{Concepts, \$20.1402}

\subsubsection{Radiological Goal/Limit}

A number of commenters from various groups generally agreed with having a risk based standard that sets out radiation dose limits and goals, and applies the ALARA principle, although they often differed on the numerical values to use for the limits and goals $(50,84,273,338,414,462,544,670,671,959,991$, 1077). Some commenters, mostly environmental or public interest groups or individuals, said that the numerical values of the proposed goal and limits were set too high, usually because they favor a standard that would allow no radiation exposures above those received from naturally-occurring background radiation $(22,98,138,159,164,166,397,490,495,612,665)$. Others, mostly industrial, technical, medical, or academic commenters, believed that these limits and the goal are set too low $(26,39,57,244,273,296,304,309,553$, $638,639,700,750,859,871,876,892,967,974,980,1001,1047)$ because the standard would be infeasible of compliance, would not be consistent with scientific consensus recommendations, state standards, or other current regulatory requirements, or would waste resources in an effort to remediate small risks.

About 20 percent of the commenters opposed the inclusion of radiological goals in the regulation, but supported radiological limits $(13,96,117,118,146$, $206,213,242,268,294,508,599,609,614,621,720,726,728,757,762,779$, $870,877,885,933,977,1047,1055,1060)$; one urged "the use of a universal standard, based on a single dose level" (563). Commenting environmental groups generally wanted the limit to be the same low value as the goal, i.e., "zero," making the goal unnecessary. Other commenters thought a goal value unnecessary or undesirable, e.g., because it would become a de facto limit or because the ALARA principle applied to a limit achieves the same purpose.

Comments on these topics are further summarized in other sections of this report, e.g., $\$ \$ 2.3 .2,2.3 .3,2.3 .4$, and 2.4 .2 .

Some commenters favored the proposed goal $(69,278,468,1012)$. Some believed that the numerical value of the proposed goal was set too low $(32,206,308$, $345,282,356,384,511,545,551,562,709,723,868,924,1075)$. A few commenters suggested specific values for the goal: Three said it should be 5 $\mathrm{mrem} / \mathrm{y}(85,282,345)$, one suggested $5.56 \mathrm{mrem} / \mathrm{y}(356)$, and one suggested a range of 15 to $25 \mathrm{mrem} / \mathrm{y}(562)$. One commenter said that the proposed concept of goal should be reworded to exclude any associated numerical value (887), and that the goal should not be set on a "per radionuclide" basis (881); another said that the objective of minimizing total risk should take precedence over any numerical goal (961). One commenter said that the proposed goal of $3 \mathrm{mrem} / \mathrm{y}$ is untenable "in residential scenarios" if radon is included in the definition of background radiation (595). Some commented that a goal of indistinguishable from background would increase the types and volumes of waste $(710,783,841)$. One commenter said that the proposed rule's conditions for applying the goal 
concept are contradictory and equate to a "zero dose standard for nuclear power plants" (264). One commenter recommended a concentration based "screening level" below which no further assessment is necessary, instead if a $3 \mathrm{mrem} / \mathrm{y}$ goal (347).

Some commenters agreed with the proposed limits for decommissioning to unrestricted use $(68,70,728,957,986)$, and some with the proposed 1imits for decommissioning to restricted use $(582,964,1015)$. A number of commenters, usually from environmental or public interest groups, said that the numerical values for the proposed limits were set too high for unrestricted use (96, 146, $150,260,266,428,464,466,609,657,659,684,893)$ or for restricted use (154, 165, 607, 993, 1078). Many industry, scientific, technical, or medical group commenters or individuals said that the proposed values for the limits were set too low $(117,137,205,210,260,261,283,314,339,343,376,380$, $480,501,504,506,539,549,558,640,688,773,776,833,955,963,998)$. One commenter said that, instead of having generic dose limits, numerical limits should be determined on a site-specific basis (828, 842) as a "justifiable fraction" of $100 \mathrm{mrem} / \mathrm{y}(836)$. One commentex said that a $100 \mathrm{mrem} / \mathrm{y} 1 \mathrm{imit}$ should be applied both to operating and to decommissioned facilities (875). And one said that a risk-based objective of $10^{-4}$ is the largest that should be considered acceptable as a linit (507).

Commenters also suggested various numerical values for dose limits for the decommissioning rule: One suggested $0.03 \mathrm{mrem} / \mathrm{y}$ (659), others suggested 3 $\mathrm{mrem} / \mathrm{y}(96,146,428), 4 \mathrm{mrem} / \mathrm{y}(501), 10 \mathrm{mrem} / \mathrm{y}(614,621,760,779,788), 25$ $\mathrm{mrem} / \mathrm{y}(289,343,833,965), 30 \mathrm{mrem} / \mathrm{y}(24,205,210,260,266,640,761), 50$ $\mathrm{mrem} / \mathrm{y}(993), 100 \mathrm{mrem} / \mathrm{y}(117,137,261,275,286,548,549,558,688,773,909$, 1006), $500 \mathrm{mrem} / \mathrm{y}(929,980)$. One commenter suggested a range of 1 imits of 25 to $30 \mathrm{mrem} / \mathrm{y}(376)$, and another suggested 10 to $30 \mathrm{mrem} / \mathrm{y}$ (751). One commenter said that a site-specific TEDE rate of $10-30 \mathrm{mrem} / \mathrm{y}$ greater than the regional average background is "essentially equivalent to background and without demonstrable increased risk" (1050). One commenter said that having requirements set at various low levels, such as 15 or $25 \mathrm{mrem} / \mathrm{y}$, would create a mistaken impression that there is some real difference among these regulatory limits (968). Ore commenter suggested limits of $10 \%$ over background where background is high (over $1000 \mathrm{mr}$ [sic]) to 100 z over background in the "lowest radiation zones" (775). One commenter recommended sublimits within the 15 mrem/y proposed limit (71).

Some commenters suggested the use of some version of the radiological criteria for decommissioning as recommended by the Health Physics society of $100 \mathrm{mrem} / \mathrm{y}$ TEDE to any member of the public from all nonmedical manmade sources combined, with a screening level of $25 \mathrm{mrem} / \mathrm{y}$ mean TEDE to the critical population group for a single site, and another screening level of $5 \mathrm{mrem} / \mathrm{y}$ mean TEDE to the critical population group below which no further assessment is required (235, $265,314,339,374,480,506,638,746,888,890,891,919,926,1049,1057)$.

Some commenters agreed with the proposed requirement that the radiological criteria should apply to the average member of a critical group (552, 576, 649), 
while others said they should apply to "a maximally exposed individual" (102, 883), "the maximum exposed individual in the general public" $(768,788)$, or to the "maximum possible population dose" (914).

One commenter said that in setting the radiological criteria there is an inconsistency in the NRC's consideration of individual and collective doses which "should be fully addressed" (794). Another commenter said there might be an inconsistency between the proposed dose limits and the limit of $75 \mathrm{mrem} / \mathrm{y}$ to the thyroid in 10 CFR 61.41, (1004, 1009); while one said that, instead of the proposed goal or limit, to consider using thw "performance assessment goal [s] " of $10 \mathrm{CFR}$ Paxt 61 of $0.25 \mathrm{mSv}$ [sic] to the whole body or to any body organ except for $0.75 \mathrm{mSv}$ [sic] to the thyroid (1019).

One commenter recommended that the radiological criteria be set out as "soil and air contaminant limits for radionuclides" (471). Others thought that dose limits were more appropriate than "arbitrary" soil concentration limits (82.8) and that a consistent, uniform "target" for residual radioactivity is needed $(830,978)$.

One commenter said that lifetime cancer risks from radiation exposures should be limited the same way as are those from chemical agents (971); but others said that it is unsound to treat radiation risks and chemical risks identically (251, 311). Still others said that, depending on the assumptions used, a $10^{-4}$ risk might equate to $2 \mathrm{mrem} / \mathrm{y}$ rather than to $3 \mathrm{mrem} / \mathrm{y}$ (978) or that the NRC's limit of $15 \mathrm{mrem} / \mathrm{y}$ might be an order of magnitude greater than the EPA's risk limit $(982,1085)$.

One commenter said that the dose limits and goals should include contributions from all nonbackground radiation doses whether or not from sources licensec by the NRC (811); another supported a single dose-limit criterion that inciues ali pathways $(340)$. One commenter agreed that the proposed radiological criteria would protect the environment as well as people (298), but another disagreed with national and international consensus that radiological risk standards that protect humans will also protect the environment (1069). One commenter said that considering exposures from natural background radiation in determining exposure limits is consistent with NCRP positions (309). One commenter noted that setting radiological criteria relative to background would make the "cleanup guidelines" site specific rather than generic for "certain situations" (1041).

One commenter said that the proposed $3 \mathrm{mrem} / \mathrm{y}$ goal and $15 \mathrm{mrem} / \mathrm{y}$ limit need further "justification" both because they might be too low (169) or because the $15 \mathrm{mrem} / \mathrm{y}$ limit might be too high (171). The same commenter was uncertain about the application of the $3 \mathrm{mrem} / \mathrm{y}$ goal in decommissionings to restricted use (177). One commenter said that it would be "helpful" if the statement of considerations for the proposed rule were to discuss both the benefits and the drawbacks of having a single set of radiological decommissioning criteria for all types of licensees (344), and that the NRC should discuss the selection of the $3 \mathrm{mrem} / \mathrm{y}$ goal and the $15 \mathrm{mrem} / \mathrm{y}$ limit in more detail $(343,376)$. One commenter said that the GEIS should discuss the relationship between the 3 
mrem/y goal and ALARA considerations (718). One commenter did not understand whether the conditions for restricted use in proposed section 20.1402 are to be applied collectively or independently (949).

\subsubsection{National/International Consensus standards}

Some commenters said that it is important for the NRC to follow expert national and international scientific/technical consensus recommendations or standards (24, 544, 742, 1045), and one noted that the NRC's proposed use of a dose-based standard, rather than a risk-based standard, is consistent with ICRP/NCRP recommendations (26). One commenter noted the ICRP/NCRP recommendations requiring that remedial actions do more good than harm, and that societal costs and risks be balanced against societal benefits to assure that net societal benefit is maximized (1048).

Some commenters objected to the proposed standards as more stringent than ICRP/NCRP recommendations require or are otherwise inconsistent with them (24, $750,773,833,888,892,1044,1047)$, and some said the proposed standards lack a sound technical basis [see section 2.2.5] $(263,558,638,859)$. Several commenters said that the NRC should adopt a $100 \mathrm{mrem} / \mathrm{Y}$ public dose limit, with the ALARA principle applied, as recommended by the ICRP $(49,56,117,263,339$, $508,549,562,638,746,761,773,842,891,892)$, and two noted that the ICRP would apply this limit to all facilities whether operating or decommissioned (56, 117). Some commenters said that if the NRC does not adopt this limit, it should adopt the Health Physics Society's recommended adaptation of the limit [see section 3.1] $(282,289,773)$, and two proposed changing the proposed limit from $15 \mathrm{mrem} / \mathrm{y}$ to $25 \mathrm{mrem} / \mathrm{y}$ as recommended by the Health Physics Society (339, 965). One commenter said that the NRC should consider using background variation values of 10 to $30 \mathrm{mrem} / \mathrm{y}$ as recommended by the Health Physics Society (520). One commenter believed that the proposed $15 \mathrm{mrem} / \mathrm{y}$ limit is too high because the National Academy of Sciences has "concluded" that there is no "safe" threshold of exposure to ionizing radiation (163). One commenter disagreed with national and international consensus that radiological risk standards that protect human health will also protect the environment (1069).

Some commenters said that the NRC's proposed use of the radiation dose to the average member of a critical group is consistent with well-established ICRP/NCRP standards $(27,28,418,746)$, and one added that it is appropriate not to consider collective dose $(890)$. Other commenters said that the ICRP's type of ALARA analysis that considers collective dose had not been followed in developing the proposed rule $(393,822,834,844,853)$, and that the NRC should consider the costs associated with adopting limits below those recommended by the ICRP (401).

One commenter said that some individuals might have self-serving interests in promoting the idea that very small radiation doses are more harmful than they actually are (46), and one said that basing required actions on ICRP recommendations would avoid wasting money and disposal capacity on wastes that pose no public risk (575). 


\subsubsection{Demonstrating Compliance}

Many commenters questioned the technical feasibility of demonstrating compliance with the proposed decommissioning requirements $(2,62,78,169,209,243,246$, $259,268,279,354,372,377,470,515,551,720,729,738,741,748,751,803$, $825,857,868,878,904,979,1018,1037)$. Some raised questions about determining background radiation $(2,243,723)$, particularly where uranium is present $\{243,246,354)$. One said that it is inappropriate to base the proposed criteria on the LPA's superfund risk level of $10^{-6}$ because these entail detection levels that preclude demonstration of compliance (247). Another said that such a risk limit should be used but did not suggest how to demonstrate compliance with it (503).

Some commenters recommended that the proposed rule use a limit of $30 \mathrm{mrem} / \mathrm{y}$ because it would be difficult to demonstrate compliance with the proposed 15 $\mathrm{mrem} / \mathrm{y}$ limit $(31,260,761,1052)$. Another commenter noted that it would be especially difficult to demonstrate compliance with the proposed goal of 3 mrem/y $(85,1056)$. Several commenters remarked that demonstrating compliance with the proposed radiological criteria would be not only difficult but costly and wasteful of resources without real benefit or enforceable $(84,279,387$, $401,515,545,555,577,829,924,1018)$.

Commenters said that compliance should be demonstrated by means other than calculation from models (369), that model inputs are overconservative (388, 880), and that measurements should be required for demonstrating compliance $(527,596,660,698,796)$. One commenter said that TEDE calculations should be restricted to the first 500 years because there are no practical measurements that can validate calculations over longer periods (313). One commenter said that demonstration of compliance should include assessments of surface water and groundwater (157), and another said that it should include drilling of test wells to assess groundwater (619) and "spot monitoring" for some years after decommissioning (632). A commenter said that the proposed rule "abdicates responsibility" for making measurements (594) and wanted technical assistance grants for "citizen and state or local groups" to hire "our own" contractors to make independent measurements for demonstrating compliance (596). One commenter said "one cannot measure millirems" to "verify directly that the interpretation [sic] '15 millirems' [sic] has been met" (151), another said that alpha particles are "impossible to measure" (617).

Several commenters said thet the NRC should issue guidance for licensees on practical means of demonstrating compliance with the radiological criteria (35, $53,63,402,570,765)$, and one requested such guidance on background measurements (41). Several commenters said that guidance on demonstrating compliance with the radiological criteria should be made available for public review before it is adopted $(128,642,686,793,857)$.

Two commenters recommended that alternatives to dose limits be used in demonstrating compliance, e.g., concentration of radioactive materials per unit volume or radioactivity per unit area $(7,1033)$. Another said that it is 
technically sound for the NRC to consider the precursors of radon, rather than a separate standard for radon, in determining compliance with the rule (61); while another said that including radon in the definition of background will cause problems in demonstrating compliance with a $3 \mathrm{mrem} / \mathrm{y}$ goal (855).

One commenter said that site-specific factors to be considered in determining compliance should be limited to "unique characteristics of the site and waste" (74) and that it is not clear that background radiation is a site-specific condition, because the $15 \mathrm{mrem} / \mathrm{y}$ limit is a measured increment over the background radiation level at any site (75). One commenter said that "default criteria" might be useful if applied only to "uncomplisated situations" (707). Another commenter suggested establishing a dose limit below which contributions to dose do not have to be determined, e.g.; 1/10 the proposed limit (1040). One commenter thought that the new rule should incorporate performance requirements similar to those for the closure of burial ground sites in 10 CFR Part 61 (1071).

A couple of commenters said that it is not clear who (among the NRC, Agreement States, licensees, and SSABS) makes the final decision on whether or not compliance has been demonstrated (10) or when the conditions for allowing decommissioning to restricted use have been met (15).

\subsubsection{Effective Use of Resources}

Numerous commenters (mostly licensees, scientific/technical and medical groups, and individuals) said that the application of the radiological criteria of the proposed rule would result in excessive expenditures of resources without commensurate benefit $(13,29,206,208,212,226,279,371,382,387,396,500$, $515,539,544,545,553,599,639,744,752,761,772,783,787,829,848,873$, $922,952,960,1001,1018,1044,1053,1075)$. Some said that the criteria would require costly and time-consuming laboratory measurements instead of practical field-monitoring techniques $(62,279,387,401,515,554)$. Two said that resources would be wasted particularly by source materials licensees $(227,780)$. others said that any proposed criteria should be cost beneficial in conformance with Executive Order $122866(276,918)$. One commenter recommended an assessment "screening level" of $5 \mathrm{mrem} / \mathrm{Y}$ TEDE to prevent wasting public resources on detailed assessment of extremely low risks unlikely of further cost-effective reduction (1054).

Some commenters said that requiring impractical or extreme criteria for decommissioning, such as the return of a site to "original" condition, e.g., regardless of the effect on a critical habitat, would not be effective use of resources $(671,778,797,861,927,979,1016)$. Others said that it would be more cost effective to decommission to restricted use than to meet the proposed criteria for unrestricted use $(482,701)$.

Two commenters said that overconservative radiation dose criteria based on untrue hypotheses would waste limited resources on requirements that produce no public benefit $(40,45)$, and another said that the proposed regulatory criteria 
would cause the wasteful diversion of resources from successful programs (537). One commenter recommended issuance of guidance to licensees at the same time as the rule to reveal the costs of demonstrating compliance (79).

Some commenters suggested that the proposed regulations be compatible with standards of other regulatory agencies in order to have consistent regulation and conserve resources $(25,547,976)$; another stated that state or local agencies that adopt a more stringent standard than the NRC's should be required to fund any resulting additional costs (33). One commenter stated that the NRC should regulate so that licensees and not taxpayers would have to bear all the costs of decommissioning (167); another said that it is "economically just" to expect operators to clean ias close to background as feasible" (489).

One commenter stated that making licensees responsible tor establishing and supporting site specific advisory boards is not an efiective use of licensees' rescurces (228). Anotiler said that the role of SSABs should be better "defined" to avoid the imposition of requirements that would waste resources (643).

One commenter said that, for effective use of resources, large volumes of slightly contaminated soil with a few "hot spots" should be regarded as if homogeneously contaminated (674).

\subsubsection{Technical Basis for Criteria Vs. Non-Technical/Political Basis}

Many commenters (mostly from industry or scientific/technical or medical groups and individuals) suggested that the basis for the proposed standard is political, arbitrary, technologically unfounded or inadequate, or inconsistent with other current criteria $(1,3,43,56,58,234,253,263,283,296,306$, $376,504,539,554,638,800,837,859,862,875,926,929,933,963,974,980$, 981, 994, 998, 1047). One commenter said that the public should be made aware that the basis is political and not technical (42). Some said that the radiological criteria result from the NRC's desire for political correctness (43, 293), and ignore epidemiological data that justify higher dose limits (116, 553).

One commenter said that the NRC should apply the two-tiered safety philosophy which the NRC and the courts have recognized (913).

Some commenters said that the proposed criteria were based on erroneous assumptions of harm at low radiation dose rates, and that there is a "preponderance" of evidence that beneficial effects are more likely, or that the non-threshold theory of dose-effect relationships is incorrect and conservative $(44,469,473)$. One commenter urged that the criteria should be based on nonthreshold dose-effect assumptions (680). One commenter said that, even if higher dose limits are supported scientifically, lower limits should be adopted to satisfy "the public" (487); yet another said that the criteria should reflect 
valid information and reasoned assessment, regardless of the "sincerity or intensity of public interest" (865). One commenter stated that the NRC should consider certain environmentally-sensitive/cultural issues as well as technical issues (e.g., Native American interests) in developing its standards (491). One commenter said that the rule should "consider coordination" of radiological and non-radiological "impacts" (1066).

One commenter said that if "background based" goals and limits are not used, the "uncertainties, economic criteria, and technological issues built into the rule" should be discussed (505). Another said that a strong technical basis for the rule is more important than agreement on the criteria with other federal agencies (943).

One commenter said that there should be an unbiased scientific reappraisal of the harmful and beneficial effects of low-dose radiation (48).

One commenter provided detailed technical analyses, in support of its recommendations, in several position statements relevant to the radiological criteria for decommissioning: (1) Radiation dose Limits for the General Public, Part II, (2) Radiation Standards for site Cleanup and Restoration, and (3) Return to Background (an interpretation of the variability of natural radiation doses as it relates to cleanup standards) (1046).

\subsubsection{Other Issue Related Comments}

In describing the limit, one commenter suggested replacing "which is indistinguishable from background" with "an incremental dose of $15 \mathrm{mrem} / \mathrm{y}$ " (76).

One commenter agreed with the need to establish a "clear and consistent" decommissioning regulation (269). One commenter cautioned that the issue of environmental damage caused by unnecessarily restrictive decommissioning standards suggests that site by site exemption from generic standards would often be required (1026). One recommended the deletion of all of proposed $\$$ 20.1402 and the placement of its requirements into regulatory guidance (459).

One commenter said that establishing a $3 \mathrm{mrem} / \mathrm{y}$ goal relying on a nonthreshold risk/dose assumption is legally insufficient according to the U.S. Supreme Court's "Benzene" decision (312). One commenter stated that the linear nonthreshold dose/risk model "provides a definitive assurance on cancer and genetic risks from low level radiation" (407); another said that cancer risk from exposure to 100 (or 500 ) mrem/y of ionizing radiation is "reasonably believed to be zero" (1000). One commenter said that the NRC should state how a change in the dose/risk relationship would affect decommissionings (379).

One commenter did not want the NRC to consider any decomuissioning if the annual TEDE could exceed $100 \mathrm{mrem} / \mathrm{y}(446)$. One said that the goal should be "a maximum hazard" of $3 \mathrm{mrem} / \mathrm{y}(426)$; another said that any limits above $3 \mathrm{mrem} / \mathrm{y}$ are "loopholes" (493). One commenter did not agree with the proposed "dose levels" (550). 
A commenter said that the NRC appropriately recognizes that some sites can not be decommissioned (856). Another said that it is appropriate, as proposed, to deal with mixed wastes separately (610). Two commenters said that chemical toxicity should also be addressed $(747,971)$, while one said that it is appropriate not to address nonradiological hazards (832). One commenter said that accounting for radon through precursors, as proposed, would be acceptable provided the limit is raised to $100 \mathrm{mrem} / \mathrm{y}$ (597).

One commenter said that best-available-technology and return-to-background are not useful concepts for decommissioning "guidance" (770).

One commenter believed that the proposed criteria will not protect the environment because animals "cannot read signs and obey restrictive lawis" (417). One commenter said the federal government is responsible by law for "full cleanup" (623). One commenter said that determinations of "applicable environmental risks" must be site specific and that "generic risk" assessments do not consider "...scenarios and values unique to indigenous peoples..."(1070).

\subsection{General Provisions, \$20.1403}

\subsubsection{Calculations of TEDE to 1000 Years}

Some commenters supported the 1000-year time frame for applying dose limits (313, 796). Others said that longer or shorter time frames should be used. of those supporting a longer time frame, one said there should be more "justification" for a shorter time (816), others recommended a time of 100,000 years (622) or some indefinitely long time (687). Those recommending shorter time frames said that, for "realistic" or "nonspeculative" estimates, times of about 100 years should be used $(896,923)$, and one recommended a 500-year period for calculating total effective dose equivalent (313). One commenter suggested the use of a time period for assessing collective dose "not to exceed one lifetime" (822). One commenter said that the statement of considerations should make clear that there is no expectation that control on restrictions could be guaranteed for more than a few hundred years (93).

One commenter said that other NRC regulations referenced in the proposed rule, such as those requiring financial assurance, extend only through the duration of the license - generally less than 100 years - and can not be applied to a 1000-year period (847); another said that the proposed 1000-year time frame might be inconsistent with the period used for estimating doses in 10 CFR Part 61, (1011). One commenter said that the NRC should state that the 1000-year time frame for modeling at near background doses is meaningless rather than may be virtually meaningless (333).

Some commenters suggested a need for guidance on how the dose estimates to 1000 years should be made $(110,410)$; others said that guidance was needed on "average member of the critical group" (453) and on identifying the greatest exposure group (995) for 1000-year estimates. 
One commenter said that the rule should require the dose estimates for the year of maximum dose and should not require validation by actual measurements as proposed (903). Another commenter stated that the requirement to validate calculation of the greatest annual TEDE by actual measurements was confusing (452).

One commenter said the 1000-year dose from "the disposal option" should also be calculated for risk comparison (420). Another recommended consideration of whether a single 1000 -year "cutoff" value provides sufficient "flexibility" for all types of decommissionings (425).

One commenter stated that a probabilistic model is more appropriate than a deterministic model for a 1000-year time frame (852). And one commenter said that remediation to "natural background" should be required because some radioactive materials last more than a thousand years (166).

\subsubsection{As Low As Reasonably Achievable (ALARA) Analysis}

A number of commenters agreed with incliding requirements for application of the ALARA principle in the regulation $(92,273,316,572,721,772,961,1006)$. Others opposed including ALARA requirements in the regulation or recommended against applying them as proposed $(151,691,718,772,883)$.

Some commenters proposed that the ALARA principle be applied in conjunction with a limit of $100 \mathrm{mram} / y(286,545,548,746,894,928)$. One suggested, "If ALARA exceeds 100 mrems [sic] per year, use 100 mrem per year as the dose limit," and, "If ALARA is less than 100 mrem per year, use ALARA as determined for the analysis" (842). Several commenters stated that requiring remediation to a 3 $\mathrm{mrem} / \mathrm{y}$ goal or to any single specified amount would thwart the purpose of ALARA analysis, e.g., by establishing a de facto limit (212, 330, 348, 621, 762, 829), and several said that a single limit combined with an ALARA requirement is sufficient for the regulation $(213,508,728,744,752,762,788,823,921$, 933 ).

Some commenters said that application of the ALARA principle at low doses is "meaningless," unreasonable or without practical use below a "screening level" of 10 to $30 \mathrm{mrem} / \mathrm{y}(267,391,515,545,572,638,888,921,1051)$ or $5 \mathrm{mrem} / \mathrm{y}$ (1054, 1057). Some noted that a $15 \mathrm{mrem} / \mathrm{y}$ limit may not be AluAR (889, 955, 981), and two said that a $15 \mathrm{mrem} / \mathrm{y}$ limit (566) or the proposed radiological criteria (1044) are inconsistent with ICRP recommendations. Some commenters said that minimization of total risk should take precedence over returning a site to background levels $(278,961,967)$.

Several commenters stated that decommissioning risks should be weighed against public benefit and included in ALARA analyses: including risks to workers, public risks, risks from non-radiological hazardous materials, and risks and costs of moving and disposing of wastes $(88,292,366,465,565,685,699,819$, $906,957,1014)$. One said that all risks should be considered (988) and one 
said that risk balancing should include deferring cleanup to allow time for radioactive decay $(465)$.

One commenter endorsed provisions for including public participation in ALARA determinations (961); another said that the NRC should consider the need for a more formal public involvement in determining ALARA when the $3 \mathrm{mrem} / \mathrm{y}$ goal cannot be met $(174)$.

Some commenters said that more guidance is needed on how to perform ALARA analyses $(170,450,826,844)$, and one said that benefit and cost should be weighed in a "qualitative sense" (764).

One commenter said that "realistic" ALARA analyses should be limited to a period of 100 years (923). And one said that the NRC and not the SSABs should be the "ultimate arbiter" on ALARA issues in decommissionings (458). One commenter noted that allowing cleanup to different ALARA-determined dose rates, while not a "health protection concern," could be a "significant public relations issue" (1038).

Some commenters stated that collective doses should be considered in ALARA analyses as do the NCRP/ICRP $(393,822,834,853)$.

\subsubsection{Removal/storage of Residual Radioactivity}

Some commenters called for more guidance or "specificity" on ways to comply with the proposed requirements for removal or storage of radioactive materials (51, 215, 456, 810, 1090). Several commenters said that some aspects of the draft regulation needed further explanation or were unclear or "inadequate" with respect to removal, storage or disposal of radioactive materials $(325,329,403$, $440,710,743,801,802,841,941,1063,1064)$. Some suggested procedures for classifying or removing waste $(629,674)$.

Some commenters agreed with the proposed requirement that licensees evaluate previously-buried radioactive wastes as part of decommissioning (109, 152, 183, 525, 651); others, mostly licensees, disagreed with having to reconsider wastes disposed of earlier in accordance with regulatory requirements $(255,363,367$, 676,813 !)

Some commenters advocated or suggested schemes for long-term on-site waste storage $(222,519,591)$. Some said the NRC should not terminate licenses and should continue to require monitoring of sites after decommissioning in case some additional contamination "might be detected" later (162, 632). One recommended adoption of requirements similar to those for LLRW facilities at sites where exposures could exceed $100 \mathrm{mrem} / \mathrm{y}$ in unrestricted areas (437). One said that all radioactivity [sic] from licensed activities should be "contained" (156). One recommended sequestering and monitoring of radioactive wastes on site in perpetuity, except as might otherwise be required for sites on or near sacred tribal land (202). Two said not to include materials confined in 
NRC/EPA-approved disposal cells in determining TEDE if institutional controls are not in effect $(589,777)$.

One commenter stated that disposal options other than disposal at LLRW facilities are needed (180). Another said that without a disposal option for the "thorium problem" decommissioning is "rendered moot" (219) or creates costly disposal problems (221). Still others recommended either modifying the proposed disposal requirements for uranium mills (227) or exempting uranium mills from the rule $(240)$.

Commenters said that a requirement to remove all residual radioactivity would result in a proliferation of small waste disposal sites $(255,363)$, or could be technically achievable but impractical (1016). One said that decommissioning to restricted use will reduce the amount of waste sent to disposal sites (845). And one commenter said that the rule should require that wastes for disposal at LLRW sites be "kept to a minimum" (711).

One commenter agreed with considering reuse/recycle of materials case-by-case (587), and another said to allow recycling whenever possible (863).

One commenter suggested that "all readily removable activity" be defined (51). one commenter thinks that the proposed rule does not require a site-specific analysis (814). One commenter said, "...we demand a far stricter standard" (656). One commenter said to eliminate proposed paragraph 20.1403 (c) and said that all residual radioactivity must be recovered in decontamination (692).

\subsubsection{Other Issue Related Comments}

One commenter stated that the draft proposed rule is responsive to comments made at the NRC workshops and scoping meetings (19). Another commenter said that the proposed rule adequately protects the environment and that special environmental or cultural issues can be handled case-by-case (82). One commenter stated that longer clean up time entails greater public risk (633). Another commenter recommended that the critical group be selected on the basis of reasonable future site use, whether unrestricted or restricted (689). One commenter suggested including in the rule criteria for continuing licensing and for decommissioning to restricted use (737). The rule should not include accounting for discharges that $10 \mathrm{CFR}$ Part 20 permits for normal operations, absent identified reconcentration problems (769). One commenter recommended deletion of the last phrase in proposed paragraph $20.1405(\mathrm{~b})$ and adding a reference to 10 CFR 50.75 in proposed paragraph 20.1405(c), (905).

In support of its recommendations, one commenter appended a detailed discussion of needs for performance assessment, facility design, and facility siting, particularly as related to the cultural, religious, and treaty rights concerns of indigenous peoples (1072). 


\subsection{Radiological Criteria for Unrestricted Use, $\$ 20.1404$}

\subsubsection{Goal - Indistinguishable from Background}

Some commenters noted an inconsistency in $10 \mathrm{gic}$ in the requirement that both conditions of proposed paragraph 20.1404 (a) be met simultaneously (52, 123, 216). Two commenters suggested resolution of this problem: one by eliminating paragraph 20.1404(a) (2), (52); the other by changing the rule to require that either condition be met, rather than that both conditions be met (e.g., by changing "and" at the end of condition 20.1404 (a) (1) to "or"), (216).

Some commenters agreed with the proposed goal $(464,468,973)$; one agreed provided that the goal be "interpreted as a minimum and not an average" (359). others disagreed with the proposed application of a goal as inconsistent with an objective of minimizing overall risk $(234,257,830,961)$, and some were concerned that the goal would become a de facto limit $(257,384,641)$.

of the commenters who said that the gual was set too high, some said the goal/limit should be set at zero attributable to licensed activities (94, 164, $389,661,693,702)$, and one said the goal should be eliminated and made the limit (146).

Other commenters said that the goal was sct too low, and was unrealistic, vague, or lacked a technical basis $(244,824,846,868,924,929,977)$, and one specified that a TEDE rate of $10-30 \mathrm{mrem} / \mathrm{y}$ greater than regional average background is "essentially equivalent to background and without demonstrable increased risk" (1050). In addition, some said that the proposed rule did not take proper account of naturally-occurring radioactive materials in applying the goal or the limit $(244,434,738)$. Others stated that the goal and limit could result in excessive cleanup if applied to operationally permitted off-site discharges $(262,270,571)$. Some commenters questioned the ability to measure and verify a goal value of $3 \mathrm{mrem} / \mathrm{y}(169,434,837,924,1075)$.

One commenter said that the rule should clearly state the precedence that special environmental, socioeconomic, or cultural factors take over the proposed goal (966).

One commenter suggested that the phrase "in excess of natural background levels" be substituted for "which is indistinguishable from background" (1096).

\section{5 .2 TEDE of 3 to $15 \mathrm{mrem} /$ year}

Some commenters supported the proposed goal and limit $(70,86,127,930)$. One suggested that the proposed $15 \mathrm{mrem} / \mathrm{y}$ limit should be applied to "a maximally exposed individual" (127). 
Some commenters (mostly among public interest and environmental groups and individuals) disagreed stating that the proposed goal and limit were set too high $(22,147,150,163,211,488)$. Others (mostly scientific/technical, medical, or industrial groups or individuals) disagreed stating that the proposed goal and $15 \mathrm{mrem} / \mathrm{y}$ limit were set too low $(1,29,709,773,824,833$, 836, 871), politically derived or not scientific (1, 967), not cost effective $(29,206,391,545,554,572,848,955,981)$, unachievable $(29,206,545,967)$, and not measurable or verifiable $(169,709,729,751,803)$. Some said the goal would become a de facto limit $(206,212,751)$.

Some commenters said the goal was unnecessary and recommended the use of a single limit $(599,621,757)$. Others suggested different limits or goals such as a limit of $100 \mathrm{mrem} / \mathrm{y}(773,892$, 921) with a goal of $25-30 \mathrm{mrem} / \mathrm{y}(31)$, or suggested consideration of $10-30 \mathrm{mrem} / \mathrm{y}$ "equivalent to background" (751). One suggested that a limit of $10 \mathrm{mrem} / \mathrm{y}$ would be "workable" (621). One suggested, as an alternative to the $15 \mathrm{mrem} / \mathrm{y}$ limit, that derived volume or area concentration limits should be specified (6).

One commenter suggested defining "reasonable" in ALARA analysis as some specific percentage of the total decommissioning cost to meet the $15 \mathrm{mrem} / \mathrm{y}$ limit (53). Another said that the proposed criteria were "vague" on ALARA determinations between the $3 \mathrm{mrem} / \mathrm{y}$ goal and the $15 \mathrm{mrem} / \mathrm{y}$ limit, and that more "specificity" was needed to prevent the goal from becoming a de facto limit (170). Some said that the limit/goal deserved more "justification" or "analysis" $(171,347)$. Some said that the proposed goal/limits should not be used to "quantify ALARA" $(699,889)$.

One commenter suggested a need for more public "involvement" when the $3 \mathrm{mrem} / \mathrm{y}$ goal cannot be met (174). And one said to "clarify" the "comparison" between "background" and the proposed goal/limits (627).

\subsubsection{Other Issue Related Comments}

Some commenters agreed that the rule should provide for decommissioning both to unrestricted use and to restricted use $(81,236)$, and one recommended that a 100 $\mathrm{mrem} / \mathrm{y}$ limit should apply to both types (688).

One commenter suggested that the NRC specify in the rule or in guidance that only "plausible future use scenarios" be considered in decommissioning to unrestricted use (964). 


\subsection{Criteria for License Termination Under Restricted Conditions, \$ 20.1405}

\subsubsection{Acceptability Criteria}

Some commenters agreed with the concept of decommissioning to restricted use $(81,201,341,349,496,582,643,735,771,827,964)$. Others disagreed (111, $154,159,162,167,650,716,1067)$.

Some commenters said that more guidance is needed on some of the terms in the criteria for decommissioning to restricted use and on their applications (15, 804, 951). Some said that terms such as "prohibitively expensive," "technically achievable," and "net public harm" are problem "loopholes" (97, 910). One commenter suggested changing "are not technically achievable" in proposed paragraph 20.1405 (a) to "cannot be justified by cost-benefit analysis" (321); another suggested changing "technically achievable" to "reasonably achievable" (898). One sajd to delete such terms and instead to require the application of the AlARA principle to a $100 \mathrm{mrem} / \mathrm{y}$ limit (928). One commenter suggested that for sites decommissioned to restricted use, "perhaps 3 mrem [sic] above background would be acceptable" (613).

One commenter said that the proposed $15 \mathrm{mrem} / \mathrm{y}$ limit would result in most decommissionings ending with some restricted use (55). Two commenters said that the rule should clarify that no exemption is required for the restricted-use decommissioning option if the acceptability criteria are met, and that the rule should include exemptions allowing decommissioning to restricted use when the acceptability criteria cannot be met $(59,582)$.

Some commenters stated that the proposed criteria require the use of unrealistic assumptions about, or do not adequately consider, future site use (281, 326). Some said to change the criteria to avoid such unrealistic considerations (925, 964). One commenter recommended requiring the use of realistic assumptions in selecting the critical group in decommissioning to restricted use (136).

Other comments on this subject included the following:

The discussion of "mechanisms" of use restrictions such as land-use restrictions is "very limited" $(362,365)$.

Additional information should be provided with respect to financial penalties and "compensation to the community" where the proposed standard is not met (381).

The regulations should require restriction of use if harm can be scientifically demonstrated "at these low doses" (413).

The rule should apply regardless of cost (663). 
The proposed acceptability criteria for restricted use should be clear on whether the NRC would allow disposal rather than long-term storage of thorium and uranium "materials" (220).

Do not allow any use of sites "released under restrictions" (111).

\subsubsection{Institutional Controls}

Some commenters supported the proposed system for decommissioning to restricted use with institutional controls $(349,430,701,827)$, while others opposed it (907, 931). One said that additional controls "will not be popular with industry" (451).

Some commenters recommended not to specify TEDE requirements if institutional controls become ineffective $(585,776)$, or not to require materials stored in NRC/EPA approved cells to be included in calculating TEDE when institutional controls over restricted use become ineffective $(60,589)$. Some said that if there is such a TEDE limit, it should be greater than $100 \mathrm{mrem} / \mathrm{y}$ on a sitespecific basis $(60,585,776)$. Other commenters stated that the actual use restrictions should be site specific $(925,1002)$ and more detail is required on the restricted-use "scenario" (940).

One commenter questioned whether the licensee, rather than a third party, should be made responsible for maintaining institutional controls (105), while another said that those potentially "impacted" by the loss of institutional controls should be made responsible for enforcing site restrictions (931). One commenter said that if continuing institutional controls must be maintained as required for an operating site there "is no value to this cnncept" (582).

Commenters said that the requirements for institutional controls must be enforceable (176) or that they might not be adequately sustainable $(441,522$, $656,1093)$. Others suggested specifying a time for reassessment of institutional controls (307) or when such controls might no longer be required $(472,1007)$.

Commenters said that institutional controls will probably involve both "active" and "passive" land use controls (514), the availability of land use restrictions is dependent upon how the public can participate in the decommissioning (535), that land use restrictions may lack "clear regulatory and statutory authority" (517), land use restrictions should be set out specifically in records of title (532) and be consistent with local ordinances (534). One commenter suggested some cases where it would be more appropriate, and others where it would be less appropriate, to apply land use restrictions "in lieu of cleanup to the regulatory limit" (529). One commenter recommended revising the rules to define the extent licensees may "take credit" for institutional controls for up to 100 years $(736)$.

One commenter said that provisions governing financial assurance were unnecessary because most institutional controls would require "little additional 
funding" (467). Another said that physical restrictions are as effective as institutional restrictions (689).

Other comments on this topic include the following:

Specify that the $15 \mathrm{mrem} / \mathrm{y}$ limit of paragraph 20.1405 (b) does not apply to "site radiation workers" (336).

Criteria should be more "realistic" for institutional controls over sites that will continue to be used for electric power generation (528).

Include notices to "future residents" as a type of institutional control (1098).

Some commenters asked for more definition, explanation, or guidelines for institutional controls $(130,326,432,526,818,1034)$. One recommended that the term "affected parties" be defined in "the document creating the use restrictions" (999).

\subsubsection{Financial Assurance}

Some commenters supported the staff rule requirement for licensees' liability for providing financial assurance $(204,349,509,532,661)$. Others opposed the proposed requirements for financial assurance (129) or said they were unnecessary (467).

One commenter said that the NRC should state that it recognizes that "inappropriate fund collection" is an "undesirable burden on the public" (referencing Executive order 122866) (918). Others suggested establishment of a "timeframe" for providing financial assurance $(472,932)$ and use of realistic assumptions about future site use in decisions on financial assurance (897). One commenter finds the requirements for financial assurance "gratifying" (201), but others said that self-insurance should not be an acceptable financial assurance mechanism $(179,1027)$.

Commenters recommended adding more specific details in proposed paragraph 20.1405 (c) as to financial assurance (131, 847); for example, add provisions similar to those in the Resource Conservation and Recovery Act (RCRA) regulations (131). One stated that the NRC should consider whether guidance on minimum funding amounts is necessary (472).

Other comments on this subject included the following:

Provide for liability for further cleanup if technology improves to make such cleanup possible (179).

Alternative $i$ ii should be deleted from proposed paragraph 20.1405 (c), (455). 


\subsubsection{Maximum TEDE of $100 \mathrm{mrem} /$ year}

Some commenters endorsed the proposed maximum TEDE of $100 \mathrm{mrem} / \mathrm{y}(86,582)$. Others disagreed $(154,165,607)$, and some suggested other provisions, including use a "lower" maximum dose for long-lived isotopes (182), and specification of a maximum TEDE of $30 \mathrm{mrem} / \mathrm{y}(77), 15 \mathrm{mrem} / \mathrm{y}(616)$, or $50 \mathrm{mrem} / \mathrm{y}$ (993) in place of $100 \mathrm{mrem} / \mathrm{y}$.

One commenter recommended a fraction of the proposed $100 \mathrm{mrem} / \mathrm{y}$ for any individual site to reserve the total of $100 \mathrm{mxem} / \mathrm{y}$ as an upper bound for all source sites combined (1078).

Some commenters recommended determining individual site-specific TEDEs rather than establishing a $100 \mathrm{mrem} / \mathrm{y}$ maximum TEDE where institutional controls or restrictions are no longer effective $(137,585,776)$. One recommended applying the $100 \mathrm{mrem} / \mathrm{y}$ maximum to all decommissionings whether to restricted or to unrestricted use (688).

Commenters said that the proposed draft is not clear as to when the NRC might terminate a license at a site at greater than a $100 \mathrm{mrem} / \mathrm{y}$ maximum TEDE (901, 1092). One agreed with the proposed continuance of the license if the annual TEDE exceeds $100 \mathrm{mrem} / \mathrm{y}$ (315).

\subsubsection{Other Issue Related Comments}

Commenters stated that the actual dose received is what is of "concern" irrespective of whether the site is decommissioned to restricted or to unrestricted use $(30,573)$.

One commenter stated that open-ended environmental or cultural restrictions requiring more stringent implementation of the rule are inappropriate and not scientifically based ( 850$)$.

Commenters suggested that the NRC assure that licensing fees are not so prohibitive as to preclude the restricted use option or prevent continued licensing when sites do not meet the unrestricted use criteria (708, 838).

\subsection{Notification and Public Participation, \$20.1406}

\subsubsection{Public Notifications}

Several commenters supported the proposed requirements for public participation $(20,132,143,513,564,695,966,1099)$; one supported the concept but not the proposed method (598). Others opposed the requirements for public notifications as proposed $(322,678,683,879)$, and one said that other processes are available for public notifications if necessary (939). 
Two commenters recommended that public notifications should be required only where the decommissioning plan involves other than routine activities (17) or meets some threshold condition (132).

One commenter recommended providing for wider public notice than through newspaper and Federal Register announcements (100), one said to provide workshops or hearings for "input by persons residing in the vicinity of the site..." (1021), and one suggested consideration of several specific kinds of notifications or announcements of SSAB meetings (1100). Another said that public notification should not be at the NRC's discretion as provided in proposed paragraph $20.1406(a),(719)$.

One commenter suggested modification of the proposed draft to require the NRC to notify and solicit input from the state government for the decommissioning site, and have that government "perform public outreach as it deems appropriate" (732).

\subsubsection{Use of Site Specific Advisory Board}

Many commenters endorsed the establishment of site-specific advisory boards (SSABs) as proposed $(20,36,37,73,80,99,141,390,538,561,586,737,920$, 964, 1099), and one supported their establishment if some threshold condition was met (132). Two commenters suggested requiring SSABs for all "significant" decommissionings $(516,541)$, and one suggested requiring them whenever residual radioactivity is higher than background $(992,996)$. One commenter recommended convening the SSAB only if the limit in the rule cannot be met (119).

Many commenters opposed the establishment of SSABs for various reasons such as availability of other avenues for public review, unworkability of the provisions, potential lack of an endpoint to decommissioning, or politicization of the issues $(47,173,229,284,320,422,424,442,533,539,564,567,598$, $677,679,724,767,879,882,954)$.

Some commenters said that the NRC, or some third party other than the licensee, e.g., a state board of health, should establish the SSABs (108, 538, 600, 652). Others stated that the NRC should "seek its input" from the state government involved rather than from SSABs $(731,733)$.

Some commenters said that the SSAB's roles and procedures need better definition or guidelines $(643,920)$, and one said that the board should be "truly" representative (99). One said that the NRC must closely monitor and review the "formation" of the SSABs (457).

One commenter recommended involving the SSAB at an earlier time than proposed in the draft rule (442), while another suggested limiting SSAB membership to those "expressing an interest" when "notices are promulgated" (561). One commenter asked whether the NRC has considered maintaining the SSAB "in some form" even after the license is terminated "as part of the oversight..."(1036). 
One commenter suggested changing the proposed wording to be in a positive sense so that the SSAB would be convened when the licensee proposes to decommission to restricted use, rather than when proposing not to meet the requirements for unrestricted use (124).

\subsubsection{Other Issue Related Comments}

One commenter noted that assuring public health and safety "takes priority" over public education and response to the general public (478).

One commenter stated that "citizens and state or local groups" should be provided with money to hire "inderendent" laboratories to take "measurements" (596). The same commenter recommended this independent testing be performed by national laboratories (604).

One commenter requested that the rulemaking require that all "files" relevant to decommissioning be made publicly available (602) and that a public hearing be held before approval of any decommissioning plan (625).

One commenter recommended deletion of $\$ \$ 20.1406$ and 20.1407 because there should be no need for additional public involvement once the standard is established (908).

One commenter suggested additional requirements for the licensee to provide information and resources to "the community" (373).

\subsection{Site Specific Advisory Board \$20.1407}

\subsubsection{Need for Board}

Some commenters agreed with the proposed requirements for the use of site specific advisory boards $(586,851)$. Some said that the ssABs should be required earlier in decommissioning $(140,442)$; others wanted sSABs to be used for all decommissionings, whether or not to restricted use $(653,736)$.

Other commenters questioned the need for, usefulness of, or role of SSABs (11, $47,65,386,531,564,681,696,727,731,767)$, and one said the SSAB's would likely be politicized, used to promote individual agendas, and diminish regulatory authority and scientific viewpoint (1020). One commenter said that, if there were a need for SSABs, there should be more limitations on their use than the rule proposes (11); another said that the boards should be convened only if the criteria of the rule are not met (119); and one said that if the boards are needed, the requirements might be more appositely set out in part 2 of the NRC's regulations rather than in Part 20 , (229).

Some commenters said that there is no need for the boards because there is ample opportunity available for public participation $(65,229,429,564,767)$, and one suggested that the requirement for the boards be removed from the rule and made 
part of "NRC review documents" and convened subject to "sufficient local interest" (119).

\subsubsection{Responsibilities/Activities}

Some commenters said that the mission of the SSAB should include consensus building in, or "education" of, the local community $(54,390)$; one said that the mission includes deciding on how sites will be used (413). Others said that the board's role should be advisory and not decision-making (438), or that the proposed functions of the SSAB more appropriately belong instead to technical review panels (812). Some said that the designation of the activities and responsibilities of the SSABs should be removed from the rule (696) or put into regulatory guidance (443). One commenter said that the SSABs will politicize decommissioning and deal with non-technical or "perceived" problems instead of technical problems (784).

Some commenters said that more "details" or clarification are needed on the SSABs' activities and responsibilities $(442,809,942)$. One commenter said that the boards should have the authority to investigate issues beyond those contemplated in the proposed rule (133). Another said the board should not be permitted to set more stringent standards (766), while another said that it is not clear to what extent the board has such authorities (758).

Commenters stated that the responsibilities of the SSABs should not supplant local jurisdictional rights (133), should be set by state boards of health or environment $(600)$, or should be defined by the communities already involvert in site clean-up (143).

One commenter said that the rule should establish procedures for the durat.jon and dissolution of the SSAB (476); another said that the SSAB should not be dissolved until the site is "restored" (516), and a third said the it is rot clear that the SSAB would be dissolved after decommissioning as "anticipated" (317).

One commenter recommended replacement of "are not technically achievable" in $\$$ 20.1407(a) with "can not be justified by cost-benefit analysis" (337). Others suggested revision of proposed $\$ 20.1407(a)(2)(c)$ [(a)(2)(iii)] to read "will not impose..." rather than "will impose..." (483) and replacement of "undue" with "unnecessary or excessive health and safety requirements" (492).

\subsubsection{Membership}

Commenters questioned the ability to assemble ideally composed, qualified, or objective SSABs on a timely basis (11, 1013, 1099), or said that guidelines are needed on representation on the boards (920). Others said that the proposed makeup of the SSABs would politicize decommissioning (173), and that the size and makeup of the board should not be in the rule (443). One commenter suggested allowing SSABs with fewer members for "smaller" sites (807). 
Some commenters said that it is not credible to have SSABs staffed and funded by licensees $(175,786,920)$, or that the nominations to the SSABs should be conducted or determined by a state or federal outside convener $(392,538)$. One stated that government and local groups should be permitted to offer nominations and that membership should include "diverse segments" of the community (134). Others said that the membership of the boards should "look like, or be "truly" representative of, the community $(99,145,920)$. One commenter said that the board membership should consist of elected officials or their designees (839). one commenter suggested various parties to include as board members (997), and one agreed that it is appropriate for the NRC to be represented on the SSABs (54).

One commenter said that non-local experts should be allowed to serve as SSAB members (654), while another said that board membership should not include interest groups from outside of the local area (682).

One commenter said that SSAB members should be technically competent (851), and one said that having non-technical members on a committee that makes technical recommendations will result in "solving" non-technical and "perceived" problems (784). One commenter said that the SSABs do not "appear" qualified to advise on technical matters and asked what the "exact role" of the NRC representative to the SSAB is (1035).

One commenter proposed rewriting $\$ 20.1407$ (c)(2) to read "Be selected from organizations which represent these interests and..." (494).

One commenter suggested that meeting times for the SSAB be convenient for working members (1100).

\subsubsection{Independence and Support}

Some commenters said that the licensee should fund the SSAB $(142,538,546)$, but a party independent of the licensee should convene the board $(140,592,594$, 724,786 ). Others said that the SSAB should be appointed by and report to the $\mathrm{NRC}$ or to relevant state and local governments $(518,538,564)$. One suggested inclusion of provisions in the rule for funding independent technical assistance to the SSAB (135), while another asked if supplementary studies would be funded (1099).

Some commenters objected to the proposed requirements for the licensees to fund and support the SSABs $(228,438,564)$. One said that such support was not an effective use of the licensees' resources (228). Commenters said that SSAB members should have no direct financial interest in the decommissioning or ties to the licensee (145). Others stated that funding and staffing of the Si $\mathrm{ABs}$ by the licensee was not credible or could be seen as compromising SSAB independence $(175,944)$. 
One commenter said that the proposed makeup of the SSAB could result in politicization of "the issue" and serve as a "springboard for individual agendas" (173).

Some commenters said that the SSABs should have access to all pertinent documents and other relevant information $(144,521,546)$.

\section{8 .5 Reporting/Use of Recommendations}

Some commenters said the rulemaking should make clear that the SSAB's function is advisory and not decision making and that final decisions lie with the NRC or with the Agreement States and not with the $\operatorname{SSAB}(10,438,458)$. Commenters said that the SSAB should advise the NRC as well as the licensee $(140,142)$, or should report only to the NRC or to the relevant state or local government (518).

One commenter said that the proposed timing for the consideration of recommendations of the SSAB confiict with other existing requirements in the NRC's regulations, e.g., 10 CFR 50.82(a), (412), and recommended changes to the proposed rule to resolve these conflicts (415). One commenter stated that requiring licensees to be subject to third-party recommendations might be illegal under state or federal laws (435).

One commenter stated that the rulemaking should provide for regulatory hearings to appeal any "strong" SSAB disagreement with regulatory decisions (10). Others said that the licensee's responsibility to implement the SSAB's recommendations, or how they will be used, are not well defined $(531,731)$.

One commenter stated that the rulemaking should ensure that local communities can "influence" the remedial and control "actions" (805)

\subsubsection{Other Issue Related Comments}

Commenters said that the conditions for the use of SSABs should be made clear in the statement of considerations for the proposed rule (8), that the SSABs might be confused by the requirements of the proposed rule and make recommendations beyond the purpose of their stated duties (989), or that "anti-nukes" on SSABs can "block progress" (4). One commenter was concerned that the SSABs might "supplant" the responsibilities of local officials (536).

One commenter recommended a national workshop for "affected parties" to "negotiate [with licensees] their own national guidelines for SSABs" (395). Another suggested holding a conference of people involved in previous cleanups to "enhance the NRC's knowledge of public participation" (524). One commenter asked how "groups not directly represented on the SSAB" would "be involved" (1099).

One commenter suggested that, where SSABs are used, the NRC should consider "categorical exemptions" under NEPA, or similar requirements, limiting 
administrative or judicial relief "once the process is concluded" (806). Another said that if SSABs are used they should become the sole vehicle for public participation (899).

One commenter said that the NRC should assume all responsibilities for the functioning of the SSABs and should clearly define their authority and role in the NRC's decision making (564). One commenter said that the language of proposed $\$ 20.1407(a)(2)(c)[(a)(2)(i i i)]$ is "too broad," but suggested no substitute wording $(886)$.

\subsection{Minimization of Contamination, \$20.1408}

\subsubsection{General}

Some commenters agreed with the proposed requirements for minimizing contamination and waste $(21,89,662,1003)$, and some said that those requirements, plus additional such requirements should be included in the rule $(139,148,186,530)$. One said that a prohibition "on contamination of ground water" should be included (149).

Other commenters disagreed with the criteria as proposed, or thought the requirements unreasonable, because other existing requirements or programs amply cover the issues $(285,537,578,593,854,884,950)$.

Commenters said that the rule should "recommend" or require that wastes sent to LLRW sites be kept to a minimum $(711,849)$.

One commenter suggested changing the wording of proposed $\$ 20.1408$ (c) so as not to imply that contamination control programs are not already in place (912).

One commenter said that thorough pre-operational and pre-construction "site characterization" would "help [meet] decontamination objectives" (1023).

\subsubsection{Acceptability Criteria}

One commenter supported the proposed criteria, provided certain practices (e.g., incineration) are excluded (740). And one disagreed with the criteria as proposed $(948)$.

\subsubsection{Backfit Analysis}

Two commenters said that the additional proposed requirements on contamination and waste should be subject to the NRC's policy on backfit analysis $(287,946)$. One said that these requirements are not needed because backfit of this sort is sufficiently covered by other effective regulations (854). 
One commenter objected to allowing three years to update radiation protection programs and wants such updating "now" (113).

\subsubsection{Appropriateness in Part 20}

One commenter said that the waste minimization criteria should be in 10 CFR Part 20 (186). Others disagreed $(64,474,537,593,900,950)$. Some commenters said that these criteria belong in other parts of the NRC's regulations (120, 497, 644) or should be incorporated as license conditions rather than in the regulation $(120,497)$. One said that the section on waste minimization should be deleted entirely (217).

One commenter recommended deletion of proposed $\$ 20.1408$ (a) because it deals with new license applications and "there should be none" for reactors (730).

\subsubsection{Other Issue Related Commenta}

One commenter said that the proposed requirements for minimizing waste are inconsistent with the other proposed decommissioning requirements and will result in the generation of large volumes of waste (327).

\subsection{Implementation}

\subsubsection{Regulatory Guldance/Better Explanation of Rule's Provisions}

Many commenters noted that informed decisions on the proposed rule can be made only if the NRC issues timely guidance or related information (e.g., the GEIS) for review before or with the publication of the proposed rule 179, 128, 272, $352,406,408,539,542,557,569,574,579,642,670,686,755,792,793,799$, $808,840,857,911,974,1059,1063)$.

Many commenters noted various needs for more explanation, in the statement of considerations, or in the rule, in support of the bases for, or the application of, the proposed criteria $18,299,324,325,331,332,347,411,510,754,778$, $800,801,810,901,935,941,982,1029,1031,1061,1082,1087,1088,1097$, 1101).

Several commenters requested guidance on the application of some terms (e.g., "critical group," "typical individual," "prohibitively expensive," "reasonably achievable"), (15, 63, 357, 418, 426,449,453,675, 791,818, 867, 951).

Several commenters said that guidance was needed on demonstrating compliance $(41,51,207,215,318,502,671,672,697,722,753,824)$. Two said that such guidance was particularly needed for "small" sites $(35,570)$.

Some commenters requested guidance on determinations and measurements related to background radiation $(41,75,101,185,280,364,1037)$. 
Some commenters wanted guidance on measurements and assessments of dose (110, $765,811,862,874,1033$ ). One commenter doubts that guidance on survey methods can be developed, tested and distributed by the effective date of the rule (1042). Commenters requested guidance on site "scenario" development and evaluation $(115,353,355,416,765$,$) .$

Some commenters wanted guidance on risk/cost analysis or ALARA assessments (115, $170,358,454,972$ ). Some commenters asked for guidance for "using" restricted use or applying institutional controls $(362,432,940,1091)$.

Some commenters asked for clarification of some definitions $(67,115,1032)$.

One commenter said "there are already too many [regulatory] guides" about the new 10 CFR Part 20 (9), and recommended consolidation and simplification of the regulations (12).

Commenters said that the NRC should provide "educational programs" for the public (398, 399), or training seminars for Agreement state staff (953).

One commenter said there should be guidance for establishing SSABs (920). Another commenter asked for explanation of how regulatory agencies can be assured that 1 icensed companies will continue to exist at sites which do not meet the decommissioning criteria (1024).

\subsubsection{Compatibility/Consistency With Federal/State Requirements}

Several commenters said that the NRC and the EPA should have consistent rules and standards $(18,34,125,366,370,405,547,556,624,795,1076)$. Others said that the various federal-agency or state and local standards should be compatible or consistent $(25,460,498,606,968,970,976,987,1022)$. One said that the NRC should "suspend its process" and cooperate in developing the EPA's rule (725). One said that the rule should clearly state the intent to meet the EPA risk standards for "health and environmental values" (1068). The EPA suggested specific wording, addressing the EPA's role in the decommissioning of nuclear facilities, to include in the preamble to the proposed rule (1086).

Some commenters said that the NRC should be explicit as to what extent the Agreement states will be required to conform to the proposed decommissioning rule $(172,608,1039,1062)$; others said that the states should not be permitted to adopt decommissioning rules more stringent than the NRC's $(290,766,895)$; and one said that if state or local communities adopt standards more stringent than the NRC's, they should be required to "fund the extra effort" (33).

Several commenters said that some aspects of the proposed decommissioning criteria should have to conform to other federal or state criteria (57, 70, 266, $295,436,511,534,640,709,754,761,774,919,833)$, and one said that if the proposed criteria do not so conform, they should be further "justified" (171). 
One commenter endorsed a "unified federal approach" (334), but said that the NRC's rule need not necessarily be framed to "accommodate" the EPA (319) and proposed that, for mixed wastes, the EPA regulate non-radioactive hazards, and the NRC regulate "if radioactivity is dominant" (335). One commenter said that for sites that will not be abandoned the NRC's rule need not be consistent with the EPA's CERCLA requirements which are for abandoned sites (250). One commenter said that the proposed decommissioning criteria seem based more on acceptability to other agencies than on technical merit (943).

Some commenters said that the proposed criteria are not consistent with EPA criteria $(557,982,1080)$; others said that they are not consistent with state standards $(876,985)$, or not consistent with other NRC regulations (1004, 1007, 1011). One commenter said that the relationship between the proposed criteria and other environmental standards has been "inadequately considered" $(351,439)$ or unclear (1030). The EPA said that the rule should require that contaminated groundwater meet the specifications of the EPA's Safe Drinking water Act as implemented under the Resource Conservation and Recovery Act (RCRA) and the Comprehensive Environmental Response, Compensation, and Liability ACt (CERCLA), (1083).

One commenter said that radon is a NORM/NARM responsibility of the states and not the NRC (except as an SNM by-product) nor the EPA (1025).

One commenter said that the draft rule should address the issues covered under the Executive Order on Environmental Justice (E.0. 12898, February 11, 1994), (1101).

\subsubsection{Need for Cost Analysis of Requirements}

A number of commenters said that the draft proposed rule lacks needed or proper assessment of costs and benefits $(208,274,387,396,504,523,580,841,959$, $972,974,1043)$.

Many commenters said that the proposed radiological criteria should better considex overall risk and not waste resources by requiring costly remediation of small risks with disproportionately small net benefit or with net harm (554. $575,584,699,752,764,781,787,800,829,873,917,927,952,960,977,979$, 1058).

One commenter agreed with the proposed requirement for additional cleanup after license termination if new information indicated that a real hazard (not perceived and not as the NRC says "reason to believe") would exist. Determination of the need for additional cleanup should be subject to costbenefit analysis (560). 


\subsection{0 .4 Clarity}

One commenter stated that there are too many regulatory guides, and clarity, safety, and understanding seem inversely proportional to the amount of guidance issued (9). Another suggested that the regulations be consolidated and simplifiad for easier understanding (12).

One commenter said that the goal as set out in proposed $\$ 20.1404(a)$ is unnecessarily complex and suggested eliminating $\$ 20.1404(a)(2),(52)$. Another commenter said to clarify that the $3 \mathrm{mrem} / \mathrm{y}$ goal is a default value below which ALARA is judged to be generically satisfied (1079).

A commenter said that the proposed requirements for restricted use are not clear (107).

Another commenter stated that certain terms in the proposed rule (e.g., "reasonable," "prohibitively expensive") lack specilicity or quantification (431).

Still another commenter stated that more clarification should be provided on how to define "large volumes of radioactive waste requiring subsequent disposal" $(810)$.

One commenter said to clarify the extent to which the proposed rule applies to NORM/NARM wastes (1102).

\subsubsection{Flexibility}

Some commenters agreed with the NRC's proposed approach to the need for flexibility in decommissioning $(404,588,815,959)$. One added that the proposed numerical values for the limit and goal might limit flexibility in practice (959, 1047).

Some commenters said that, in applying a generic standard, some flexibility should be allowed for individual site characteristics $(231,338,697,797,810)$ and for actual risks (232). One stated that, in implementing generic standards, flexibility should be limited to "unique characteristics of the site and waste" (74). Another said that the rule should explicitly allow for site-specific alternatives to the proposed criteria (323).

One commenter said that national and international criteria, applied as recommended by the Health Physics Society, would provide the flexibility for accommodating site-specific factors (638). Another said that a dose-limit approach with the ALARA principle permits flexibility to provide protection and also to conserve resources (744). One commenter said that the proposed rule incorporates adequate flexibility to allow for site-specific implementation of the generic radiological criteria (1028). 
One commenter agreed that the proposed approach of considering the total exposure from all pathways allows more flexibility than would be achieved through the setting of individual path limits (87).

One commenter suggested that the rulemaking make clear that the proposed rule allows the flexibility to isolate contaminated materials on site (672).

One commenter said to discuss in the statement of considerations for the proposed rule the flexibility provided by the limit/goal concept when applied to the wide range of NRC licensees $(368)$.

One commenter said that the "flexibility" of the proposed standard "complicates the [decommissioning] issue further" (866).

\subsection{0 .6 Other Issue Related Comments}

One commenter stated that the NRC should accept no new decommissioning plans until the new rule becomes effective (112).

Another commenter stated that the NRC should have inspectors on site to monitor decommissioning $(630)$.

One commenter recommended that 10 CFR Parts 30, 40, and 50 be amended to cross reference the new decommissioning rules in 10 CFR Part 20, (739).

One commenter recommended use of "default" criteria for simple decommissioning projects when it would be a waste of time to derive sits-specific criteria to meet the dose limits (835).

One commenter suggested deletion of the reference to instrument capabilities in $\$ 20.1402$ because it is an inappropriate example of inability to clean to indistinguishable from background (122).

\subsection{Miscellaneous}

Several commenters commended the NRC's enhanced participatory rulemaking (114, $168,350,409,461,513,603,647,669,734,958,969,1074)$. Others characterized the proposed rulemaking in terms such as well-balanced, needed, reasonable, addressing legitimate concerns, eliminating uncertainty, or expediting decommissioning $(83,125,400,637,1008)$. Two commenters requested an extension of the comment period on the staff draft $(302,611)$.

Two commenters said that the NRC's conclusion that the proposed criteria will protect both people and the environment is correct $(90,583)$ and one agreed with the position that further reductions in dose should not be required after decommissioning and release to unrestricted use (91). One commenter agreed that historically or environmentally unique areas or cultural issues might require special attention (712). 
One commenter said that the proposed generic criteria are not needed because current procedures are "workable" (241); another said that the proposed criteria will make it impractical to comply with other proposed requirements to complete decommissioning within 18 months (230).

One commenter was "disappointed" with the NRC for "having developed these unacceptable [too lenient] criteria" (745) and recommended the abolishment of the NRC (749). Another "demand[ed]" an international "Blue Ribbon Committee" to investigate all "nuclear" activities (756). One commenter did not want a decommissioning rule without prior cessation of the production of all manmade radioactive wastes (869); another wanted cessation of production of radioactive materials except for some medical use (203). One commenter said, "the NRC relies too much on the licensees themselves. [sic] " (590), and that licensees should be financially liable for "all offsite contamination" (620) including "[f]allout from accidents like Chernoble" (634); another said that "contractors who benefited" [from the nuclear industry] should be held financially liable for waste problems (204). One commentex said that by setting an "extremely low limit" in the rule, cleanup contractors will be "driven to develop their technology" (666). One commenter expressed dissatisfaction about issues ranging from waste disposal and dose limits to ALARA, but did not suggest how the decommissioning criteria should be written (38).

Two commenters objected to "the general inflammatory tone" of the draft [the implication that licensees might delay decommissioning to await less expensive technologies] $(956,983)$. One commenter conjectured that the NRC sets standards that are impossible to meet in order to continue collecting licensing fees (5).

One commenter said that the technical and practical considerations presented in the workshops were not used in formulating the decommissioning criteria (258); others said that the workshop comments were well summarized (394) and were "thoughtfully considered" in developing the proposed rule (990).

One commenter said that recycle/reuse of radioactive materials should be considered "in the context of these decommissioning regulations" rather than separately as proposed (433); another said that the NRC's analysis for the rule is "prudently conservative" even though not specific about recycle/reuse (601). One commenter said that the potential for recycling should be included in "release scenarios" for future use (300). The EPA said that the proposed rule should include criteria for recycle/reuse of materials from decommissioned sites $(1.084)$.

One commenter requested that in the statement of considerations for the proposed rule the "risks implied by 15 mrem [sic] be explained" (103) and also to "explain more about restricted use" (104). One commenter did not understand the discussion of the NRC's authority over the expenditure of funds saved by avoiding "unnecessary decommissioning activities" in the statement of considerations (481).

Some commenters supported comments from others $(237,254,383,385,1017)$. 
One commenter predicted that the proposed decommissioning criteria will not be supported by the Generic Environmental Impact Statement (GEIS), (245).

One commenter asked how regulatory agencies can "be assured" that licensed companies will continue to "exist" to "remain under license indefinitely" at sites that cannot meet the decommissioning critexia (1024).

The commenter withdraws a paragraph of its previously-submitted comment [Docket \# 48, page A.3, 2nd full paragraph] that contains inaccurate information and asks that the paragraph "be stricken from the administrative record" (1065).

Under the new name Nuclear Energy Institute (NEI), the commenter summarizes and reiterates comments previously submitted under the names NUMARC and USCEA [summarized in this report under Docket Nos. 31 and 61] (1073). 


\section{APPENDIX A}

TEXT OF RULE FROM STAFF DRAFT 


\section{REVISION OF 10 CFR PART 20 PROPOSED BY TIIE NRC STAFF}

For the reasons set out in the preamble and under the authority of the Atomic Energy Act of 1954, as amended, the Energy Reorganization Act of 1974, as amended, and 5 U.S.C. 553, the NRC is proposing to adopt the following amendments to 10 CFR Part 20.

PART 20 - RADIOLOGICAL CRITERIA FOR DECOMMISSIONING

Subpart $A$

20.1003 Definitions

The definition of "background radiation" is revised to read as follows:

Background radiation means radiation from cosmic sources; naturally occurring radioactive material, including radon (except as a decay product of source or special nuclear material); and global fallout as it exists in the environment from the testing of nuclear explosive devices or from past nuclear accidents like Chernobyl which contribute to background radiation and are not under the control of the licensee. "Background radiation" does not include radiation from source, byproduct, or special nuclear materials regulated by the Commission.

Critical Group means the group of individuals reasonably expected to receive the greatest exposure to residual radioactivity for any applicable set of circumstances.

Decommission means to remove a facility or site safely from service and reduce residual radloactivity to a level that permits (1) release of the property for unrestricted use and termination of the 1 icense, or (2) release of the

$$
\text { A- } 1 \text {. }
$$


property under restricted conditions and termination of the license.

Readily Removable means removable using non-destructive, common, housekeeping techniques (e.g. washing with moderate amounts of detergent and water) that do not generate large volumes of radioactive waste requiring subsequent disposal or produce chemical wastes that are expected to adversely affect public health or the environment.

Residual Radioactivity means radioactivity in structures, materials, soils, groundwater, and other media at a site resulting from activities under the licensee's control. This includes radioactivity from all licensed and unlicensed sources used by the licensee, but excludes background radiation. It also includes radioactive materials remaining at the site as a result of previous burial at or discharged from the site in accordance with 10 CFR Part 20.

Site Specific Advisory Board (SSAB) means a committee constituted by the licensee to provide advice to the licensee on decommissioning.

Subpart E Radiological Criteria for Decommissioning

\subsection{Scope}

(a) The criteria in this subpart apply to the decommissioning of facilities licensed under Parts 30,40,50,60,61,70, and 72, as well as other facilities subject to the Commission's jurisdiction under the Atomic Energy Act and the Energy Reorganization Act. For high-level and low-level waste disposal facilities ( 10 CFR Parts 60 and 61), the criteria apply only to ancillary surface facilities that support radioactive waste disposal activities. For uranium mills, the criteria apply to decommissioning of the 
$01 / 26 / 94$ (DRAFT)

facility but not to the disposal of uranium mill tailings (Appendix $A$ of 10 CFR Part 40).

(b) The criteria in this subpart do not apply to sites already covered by a decommissioning plan approved by the Commission before [insert effective date of rule].

(c) Once a site has been decommissioned and the license terminated in accordance with the criteria in this proposed rule, the Commission would require additional cleanup only if, based on new information, it determines that residual radioactivity remaining at the site could result in significant public or environmental harm.

20.1402 Concepts

The Goal for decommissioning a site is to reduce the concentration of each radionuclide which could contribute to residual radioactivity at the site to a level which is indistinguishable from background. Since this may not be achievable in all situations, due, for example, to instrument capabilities, the Commission will consider that the decommissioning goal has been met if the cumulative Total Effective Dose Equivalent (TEDE) to the average member of the critical group from all radionuclides that could contribute to residual radioactivity and are distinguishable from background does not exceed $3 \mathrm{mrem}$ (0.03 mSv) per year.

The Limit for release of a site is $15 \mathrm{mrem} / \mathrm{y}(0.15 \mathrm{mSv} / \mathrm{y})$ TEDE for residual radioactivity distinguishable from background. If doses from residual radioactivity are less than $15 \mathrm{mrem} / \mathrm{y}$ TEDE, the Commission will terminate the license and authorize release of the site for unrestricted use following the licensee's demonstration that the residual radioactivity at the site has been reduced to as close to the goal as reasonably achievable. 
The Commission expects the licensee to make every reasonable effort to reduce residual radioactivity to levels which will allow unrestricted release of the site. However, the Commission will consider terminating a license in cases where restrictions must be imposed on the use of the site to assure that public doses are maintained below the $15 \mathrm{mrem} / \mathrm{y}(0.15 \mathrm{mSv} / \mathrm{y})$ TEDE limit, provided the licensee:

(1) can demonstrate that residual radioactivity at the site is ALARA and that further reductions in residual radioactivity necessary to comply with the $15 \mathrm{mrem} / \mathrm{y}$ TEDE limit for unrestricted use are not technically achievable, would be prohibitively expensive, or would result in net public or environmental harm,

(2) has made adequate provisions for institutional controls to reduce annual TEDE from residual radioactivity distinguishable from background to the average member of the appropriate critical group to 15 mrem $(0.15$ mSv) TEDE,

(3) has provided sufficient financial assurance to enable an independent third party to assume and carry out responsibilities for any necessary control and maintenance of the site, and

(4) has reduced the residual radioactivity at the site so that the TEDE from residual radioactivity would not exceed $100 \mathrm{mrem}$ ( $1 \mathrm{mSv}$ ) per year even if the restrictions applied in the termination were no longer effective in limiting the possible scenarios or pathways of exposure.

The Commission will not normally consider terminating a license under circumstances where the TEDE to the average member of the critical group from residual radioactivity at the site would exceed $100 \mathrm{mrem}$ ( $1 \mathrm{mSv}$ ) per year if the site were to be released for unrestricted use. 


\subsection{General Provisions}

(a) When calculating TEDE, the licensee shall base estimates on the greatest annual TEDE dose expected within the first 1000 years after decommissioning. Estimates shall be validated using actual measurements to the maximum extent practical.

(b) When determining ALARA under 20.1404(b) or 20.1405(a), the licensee shall consider all significant risks to humans and the environment resulting from the decommissioning process (including transportation and disposal of radioactive wastes generated in the process), and from residual radioactivity remaining at the site following termination of the license.

(c) During decommissioning, all readily removable residual radioactivity shall be removed from the site or disposed of on site in accordance with 20.2002 of this part.

20.1404 Radiological Criteria for Unrestricted Release

(a) The goal for decommissioning is to reduce the residual radioactivity in structures, materials, soils, groundwater, and other media at the site to meet the following conditions:

(1) the concentration of a radionuclide that could contribute to residual radioactivity is indistinguishable from the background radiation concentration for that radionuclide; and

(2) for all radionuclides that could contribute to residual radioactivity and are distinguishable from background radiation, the cumulative TEDE to the average member of the critical group from all 
such radionuclides does not exceed $3 \mathrm{mrem}(0.03 \mathrm{mSv})$ per year.

(b) A site will be considered acceptable for unrestricted use if the residual radioactivity that is distinguishable from background radiation results in a TEDE to the average member of the critical group that does not exceed 15 mrem ( $0.15 \mathrm{mSv}$ ) per year, and is as close to the decommissioning goal as reasonably achievable.

20.1405 Criteria for License Termination Under Restricted Conditions

A site will be considered acceptable for license termination under restricted conditions if:

(a) The licensee can demonstrate that further reductions in residual radioactivity necessary to comply with the provisions of 20.1404 are not technically achievable, would be prohibitively expensive, or would result in net public or environmental harm; and

(b) The licensee has made provisions for institutional controls that provide reasonable assurance that the TEDE from residual radioactivity distinguishable from background to the average member of the critical group will not exceed $15 \mathrm{mrem}(0.15 \mathrm{mSv})$ TEDE per year. Institutional controls shall be enforceable by a responsible government entity or in a court of $\mathrm{law}$ in response to suits by affected parties; and

(c) The licensee has provided sufficient financial assurance to enable an independent third party to assume and carry out responsibilities for any necessary control and maintenance of the site. Acceptable financial assurance mechanisms are: (i) funds placed into an account segregated from the licensee's assets and outside the licensee's administrative control as described in $\$ 30.35(f)(1)$; (ii) surety method, insurance, or other guarantee method as described in $\$ 30.35(f)(2)$; or (iii) a 
$01 / 26 / 94$ (DRAFT)

statement of intent in the case of Federal. State, or local government licensees, as described in $\$ 30.35(f)(4)$; and

(d) Residual radioactivity at the site has been reduced so that if the institutional controls were no longer in effect, the TEDE from residual radioactivity distinguishable from background to the average member of the critical group is as low as reasonably achievable and there is reasonable assurance that the TEDE to that member would not exceed 100 mrem ( $1 \mathrm{mSv}$ ) per year.

\subsection{Notification and Public Participation}

(a) Upon the receipt of a decommissioning plan from the licensee, or a proposal by the 1 icensee for restricted release of a site pursuant to 20.1405, or whenever the Commission deems such notice to be in the public interest, the Commission shall:

(1) notify local and state governments in the vicinity of the site and any Indian Nation or other indigenous people that have treaty or statutory rights that could be affected by the decommissioning.

(2) publish a notice in the Federal Register and in a forum, such as local newspapers, which is readily accessible to individuals in the vicinity of the site and solicit comments from affected parties.

(b) For decommissioning where the licensee does not propose to meet the conditions for unrestricted release pursuant to 20.1404, the licensee shall convene a Site Specific Advisory Board (SSAB) as described in 20.1407 for the purpose of obtaining advice from affected parties regarding the proposed decommissioning. 
$01 / 26 / 94$ (DRAFT)

20.1407 Site Specific Advisory Board

(a) The SSAB should provide advice to the licensee, as appropriate, on:

(1) whether there are ways to reduce residual radioactivity to a level necessary to comply with the provisions of 20.1404 which are technically achievable, would not be prohibitively expensive, and would not result in net public or environmental harm;

(2) whether provisions for institutional controls proposed by the 1 icensee:

(a) will provide reasonable assurance that the TEDE from residual radioactivity distinguishable from background to the average member of the critical group will not exceed $15 \mathrm{mrem}(0.15 \mathrm{mSv})$ TEDE per year,

(b) will be enforceable, and

(c) will impose undue burdens on the local community or other affected parties.

(3) Whether the licensee has provided sufficient financial assurance to enable an independent third party to assume and carry out responsibilities for any necessary control and maintenance of the site.

(b) The decommissioning plan submitted by the licensee in accordance with 10 CFR Parts $30.35,40.42,50.82,70.38$, or 72.54 shall include the recommendations of the $S S A B$ and the licensee's proposed analys is and disposition of this advice.

(c) Membership of the SSAB shall, to the extent that representatives are

$$
A-8
$$


willing to participate:

(1) Reflect the full range of interests in the affected community and region, and be composed of individuals who could be directly affected by residual radioactivity at the decommissioned site,

(2) Be selected from individuals nominated by organizations which represent these interests, and

(3) Include representatives from the licensee; local and state governments; persons residing in the vicinity of the site; citizen, environmental, environmental justice, and other public interest groups; and Indian Nation or other indigenous people that have treaty or statutory rights that could be affected.

(d) The SSAB shall consist of approximately 10 members plus an ex officio representative selected by the Commission.

(e) Licensee notification to the Commission of intent to decommission in accordance with $30.36(b), 40.42(b), 50.82(a), 70.38(b)$ or 72.54 shall specify whether the licensee intends to decommission in accordance with 20.1405. Licensees proposing to decommission in accordance with 20.1405, shall submit a plan for establishing and supporting an SSAB.

(f) The licensee shall be responsible for the establishing the SSAB and the developing appropriate SSAB operating procedures with the advice of the SSAB.

(g) The licensee shall provide adequate administrative support for SSAB activities and shall provide the SSAB access to studies and analyses that are readily available to the 1 icensee and are pertinent to the proposed 
decommissioning.

(h) Meetings of the SSAB shall be open to the public. The licensee shall provide adequate public notice of the location, time, date, and agenda for the meetings at least two weeks in advance of each meeting. All records generated or reviewed by the SSAB shall become part of the docket, and shall be available for public inspection.

\subsection{Minimization of Contamination}

[NOTE: IT MAY BE MORE APPROPRIATE TO PLACE THESE REQUIREMENTS IN PARTS $30,40,50$, ETC. INSTEAD OF PART 20]

(a) Applicants for licenses after [insert effective date of rule], shall describe in the application how facility design and procedures for operation will minimize contamination of the facility and the environment, facilitate eventual decommissioning, and minimize the generation of radioactive waste.

(b) Applicants for license amendments that involve a substantial modification of the licensed facility or operating procedures after [insert effective date of rule], where applicable, shall describe how the facility or procedural modifications minimize contamination of the facility or the environment, facilitate eventual decommissioning, and minimize generation of radioactive waste.

(c) Each licensee subject to the decommissioning provisions of 10 CFR Parts $30.35,40,42,50.82,70.38$, or 72.54 shall, within three years of the effective date of this rule, incorporate into its radiation protection program procedural modifications to minimize contamination of the facility or the environment, facilitate eventual decomissioning, and minimize generation or radioactive waste. 
$=$ 


\section{APPENDIX B - COMMENTER IISTING}

The following commenters responded to the Federal Register Notice.

Docket commenter

1

UCLA School of Medicine

Carol S. Marcus, Ph.D., M.D.

Harbor-UCLA Medical Center

1000 Carson Street

Torrance, CA 90509

2

Stan A. Huber Consultants, Inc.

Stan A. Huber

200 North Cedar Road

New Lenox, IL 60451

3

Peter Bailey

1667 Baltrusol P1

West Palm Beach, FL 33414-5904

4

Georgia Department of Natural Resources

Jim Hardeman

4244 International Pkwy. Suite 114

Atlanta, GA 30354

5

Ohio Citizens for Responsible Energy, Inc

Susan L. Hiatt

8275 Munson Road

Mentor, OH 44060-2406

6

E.I. Du Pont De Nemours \& Co.

Leonard R. Smith

Medical Products Department

549 Albany street

Boston, MA 02118

7

Carol Cain

3476 Washington Way

Atlanta, GA 30340

8

Ogden Environmental and Energy Services

Kenneth N. Fleming CHP

1009 Commerce Park Drive, Suite 100

Oak Ridge, TN 37830

9

Jerry J. Cohen

3417 Tice Creek Dr. \#5

Walnut Creek, CA 94595

10

Chem-Nuclear Systems, Inc.

William B. House

140 Stoneridge Drive

Columbia, SC 29210 
Fuel Cycle Facilities Forum

David G. Culberson

Nuclear Fuel Services

1205 Banner Hill Rd

Erwin, TN 37650

12

New Jersey Dept. of Environmental Protection and Energy

Robert J. Stern, Ph.D., Chief

Division of Environmental Safety, Health

Trenton, NJ 08625-0415

13

Peter Loysen Associates

Peter Loysen

Health and Safety Engineering

287 Long Point Road

Crownsville, MD 21032

14

Ohio Department of Health

Robert E. Owen, Chief

$246 \mathrm{~N}$. High street

Columbus, OH 43266-0118

15

Stanford Linear Accelerator Center

Kenneth R. Kase

Slac, Mail stop 48

P.O. Box 4349

stanford, CA 94309

16

Karl J. Novak

Rd 2 Box 132

Clearville, PA 15535

17

Fawn shillinglaw

1952 Palisades Dr.

Appleton, WI 54915

18

Kennecott Uranium Company

Michael H. Gibson

505 South Gillette Avenue

Gillette, WY 82717

19

Citizens Research \& Environmental Watch

Mary Jane Williams

P.O. Box 2478

Concord, MA 01742

20

Stone \& Webster Engineering Corporation

R.B. Bradbury

245 Summer street

Boston, MA 02210 
Georgians Against Nuclear Energy Glenn Carroll

P.O. Box 8574

Atlanta, GA 30306

B. Koh \& Associates, Inc Barry Koh, Ph.D.

10211 A South Dolfield Road

Owings Mills, MD 21117-3653

23

Westinghouse Electric Corporation

stephen A. Green, Manager

Westinghouse Building

Gateway Center

Pittsburgh, PA 15222

Wisconsin Electric Power Company

Bob Link.

231 W. Michigan

Milwaukee, WI 53201-2046

U.S. Council for Energy Awareness

Mark A. Doruff, Chairman

1776 I street, N.W.

washington, DC 20006-3708

Public Service Company of Colorado

Donald $w$. Warembourg

16805 Weld County Road 19-1/2

Platteville, CO 80651

Dow Chemical Company

Hayden Schoen

1261 Building

Midland, MI 48667

Rio Algom Mining Corporation

Bill Ferdinand

6305 Waterford Boulevard Suite 325

oklahoma City, OK 73118

Atlantic Richfield Company

Ronald S. Ziegler

Bluewater Uranium Mill Site

Grants, NM 87020

Siemens Power Corporation

James B. Edgar

Nuclear Division

2101 Horn Rapids Road

Richland, WA 99352-0130 
31

32

33

34

35

36

37

38

39

40

41
Nuclear Management and Resources Council

Thomas E Tipton

1776 Eye Street, N.W. Suite 300

Washington, DC 20006-3706

American Mining Congress

James E. Gilchrist

$1920 \mathrm{~N}$ street N.W. Suite 300

Washington, DC 20036-1662

Utility Decommissioning Group

Joseph B. Knotts, Jr

1400 L Street, N.W.

Washington, DC 20005-3502

Institute for Energy and Environmental Research

Arjun Makhijani, Ph.D.

6935 Laurel Avenue

Takoma Park, MD 20912

Georgia Power

J.T. Beckham, Jr.

40 Inverness Center Parkway

Birmingham, AL 35201

Southern Nuclear Operating Company

Dave Morey

Post Office Box 1295

Birmingham, AL 35201

Melanie Moorehead

1507 Houston St, \#234

Austin, TX 78756

Nevada Department of Human Resources

John Vaden

Health Division

505 E. King street, Room 101

Carson City, NV 89710

David B. Ottley

2620 S. Everett Pl.

Kennewick, WA 99337

Wyoming Mining Association

Marion Loomis

Hitching Post Inn

P.O. Box 866

Cheyenne, WY 82003

Jackson R. Ellis

$100 \mathrm{~N}$ Irving P1. \#129

Kennewick, WA 99336 
B\&W Fuel Company Kathrym S. Knapp

P.o. Box 11646

Lynchburg, VA 24506-1646

No letter was assigned to this docket number.

Environmental Coalition on Nuclear Power Judith H. Johnsrud, Ph.D.

433 Orlando Avenue

state College, PA 16803

The Childhood Cancer Research Institute Dianne Quigley Concord Professional Center

747 Main Street

Concord, MA 01742

Sierra Club

Jesse L. Riley

854 Henley Place

Charlotte, NC 28207

Department of the Army

Cary Jones

U.S. Army Corps of Engineers

Washington, DC 20314-1000

Western States Legal Foundation

Michael J. Veiluva

1440 Broadway, Suite 500

Oakland, CA 94612

49

Fuel Cycle Facilities Forum

Duplicate of number 11

Consumers power

James S. Rang

Big Rock Point Plant: 10269 US-31 North

Charlevoix, MI 49720

51

Washington Department of Health

John L. Erickson

Airdustrial Center, Bldg 5

Olympia, WA 98504

MHB Technical Associates

Peter M. Strauss

1723 Hamilton Avenue suite $\mathrm{K}$

San Jose, CA 95125 
BP Chemicals

H.M. Blythe

Ft. Amanda Road

Lima, OH 45802-0628

54

Nuclear Information and Resource Service

Mary olson

142416 th street, N.W. Suite 601

Washington, DC 20036

55

Sierra Club Pennsylvania Chapter

P.O. Box 606

Harrisburg, PA 17108

56

Conference of Radiation Control Program Directors

william P. Dornsife

Commonwealth of Pennsylvania

Department of Environmental Resources

P.O. Box 8469

Harrisburg, PA 17105-8469

E.I. Du Pont De Nemours \& Co. (Inc)

Duplicate of number 6

58

Physicians for Social Responsibility

Lawrence Egbert, M.D.

4009 Herschel Avenue

Dallas, TX 75219

59

Yankee Atomic Electric Company

D.W. Edwards

580 Main street

Bolton, MA 01740-1398

60

Public Citizen

Bill Magavern

215 Pennsylvania Avenue SE

Washington, DC 20003

61

U.S. Council for Energy Awareness

Marvin S. Fertel

1776 I street, NW

Washington, DC 20006-3708

62

New York state Energy office

Eugene J. Gleason

Two Rockefeller Plaza

Albany, NY 12223

63

GPU Nuclear Corporation

B. A. Good

Route 441 South

Middletown, PA 17057-0480 
64

65

66

67

68

69

70

71

72

73

74

Sequoyah Fuels

John H. Ellis

P.O. Box 610

Gore, OK 74435

James L. Perkins

Rt 1 Box 423

Wayne, ME 04264

Unocal Corporation

Mark A. Smith

1201 West 5th Street

Los Angeles, CA

\section{Greenpeace}

Rod McCoy

2013 th Street N.E.

Atlanta, GA 30309

Florida Power Corporation

Rolf C. Widell

University of Massachussetts Lowell

Clayton S. French

1 University Avenue

Lowell, MA 01854

Donald E. Dunning

11536 Gates Mill Drive

Knoxville, TN 37922

Rockwell International Corporation

P.D. Rutherford

Rocketdyne Division

6633 Canoga Avenue

Canoga Park, CA 91309-7922

Fluor Daniel

Corporate Hdqrts Bldg.

Paul Speidel

Irvine, CA 92730

Michigan Department of Public Health

George W. Bruchmann,

$3423 \mathrm{~N}$. Logan/Martin L. King Jr Blvd.

Lansing, MI 48909

New York Power Authority

W.A. Josiger

123 Main Street

white Plains, NY 10601 
Kerr McGee Corporation Edwin T. still, DVM

Kerr-Mcgee Center

Oklahoma City, OK 73125

76

Commonwealth Edison

Martin J. Vonk

1400 Opus Place

Downers Grove, IL 60515

77

Nuclear Metals, Inc.

Eric B. Andersen

2229 Main Street

Concord, MA 01742

78

Arkansas Department of Health

Greta J. Dicus

4815 West Markham street

Little Rock, AK 72205-3867

79

The Washington state Department of Health

Duplicate of number 51

80

Neutron Products, Inc.

J.A. Ransohoff, President

22301 Mt. Ephraim Road

Dickerson, MD 20842

81

Virginia Power

M.L. Bowling

5000 Dominion Blvd

Glen Allen, VA 23060

82

Nevada Agency for Nuclear Projects

Robert R. Loux

Nuclear Waste Project office

Capitol Complex

Carson City, NV 89710

83

Corinne Carey

2213 Riverside $\mathrm{Dr} \mathrm{NE}$

Grand Rapids, MI 49505

84

Conference of Radiation Control Program Directors

Gary Robertson

Washington Department of Health

Division of Radiation Protection

Airdustrial Center, Bldg 5

Olympia, WA 98504-7827

85

Clean water Fund of North Carolina

Dr. Carl Rupert

P.O. Box 1008

Raleigh, NC 27602 
Illinols Department of Nuclear safety

Thomas $w$. Ortriger, Director

1035 Outer Park Drive

Springfield, It 62704

87

Texas Department of Health

Ralph S. Heyer

1100 West 49 th street

Austin, TX 78756-3189

88

Cliff Groff

902 N. Keller Ave.

Kennewick, WA 99336

89

California Department of Health Services

Steven A. Book, Ph.D.

$714 / 744$ P street

Sacramento, CA 94324-7320

90

Department of Energy

Raymond F. Pelletier

Washington, DC 20585

Idaho National Engineering Laboratory

Philip D. Wheatley

P.O. Box 1625

Idaho Falls, ID 83415

State of Nebraska Department of Health

Harold $R$. Borchert, Director

301 Centennial Mall South

Lincoln, NB 68509-5007

ORISE

James D. Berger, Director

P.O. Box 117

Oak Ridge, TN 37831-0117

Health Physics Society

Kenneth L. Mossman, President

8046 E. Kalil Drive

Scottsdale, AZ 85260

95

South Carolina Department of Health and Environmental Control

Virgil R. Autry, Director

2600 Bull street

Columbia, SC 29201

Western States Legal Foundation

Michael J. Veiluva

1440 Broadway, Suite 500

Oakland, CA 94612 


\section{APPENDIX B}

97

Yakama Nation

Jim Russell, Manager

P. 0. Box 151, Fort Road

Toppenish, WA 98948

98

Nuclear Energy Institute

Joe F. Colvin, Executive Vice President

1776 I street NW suite 400

Washington, DC 20006-3708

99

NES, Inc

William J. Manion, President

44 Shelter Rock rd

Danbury, CT 06810

100

U.S. Environmental Protection Agency

Margo T. Oge, Director

Office of Radiation and Indoor Air

Washington, DC 20460 
APPENDIX $C$

COMMLNT REFERENCES

$$
-
$$$$
\text { COMMENT REFERENCES }
$$ 


\section{APPENDIX C - COMMENT REFERENCES}

This appendix can be used to determine the origin of each comment and where each comment is used in the summary of comments on the staff Draft. The listed information includes a comment number, the particular summary sections (issues) to which it contributes, the name or abbreviated name of the commenter, the docket number of the letter containing the comment, and the page of the letter on which the comment begins.

About half of the comments are used in more than one summary section, but the comment number is unique and remains with the comment in each summary section where it is used. The last name of the commenter is listed or, if an organization, the full or abbreviated name. For example:

Comment Report

Number Section

292.3 .4

2.5 .2
Docket

Number

Page

E.I. DU PONT DE NEMOURS \& CO.

6

A2

In this example, comment number 29 is used in sections 2.3 .4 and 2.5 .2 of this report. The name of the commenter is listed; the letter is docketed as number 6 , and the comment begins on page 2 of the first appendix to that letter. If no alphabet character is used, the number refers to the page of the basic letter; A, B, C, etc. refer to the successive appendices of a letter.

As explained in section 1.2 , there were 1,075 comments categorized with 1,533 applications of them in the various issues. Because certain comment numbers were not assigned, the last comment number listed is higher than the actual number of comments.

Thus, every comment is assigned a single rumber, retains that same number in each issue where it is summarized, and can be traced to a page in its docketed source letter.

The following pages contain a column listing of these data per comment number. 
$2.3 \cdot 5$

$2.5 \cdot 2$

UCLA SCHOOL OF MEDICINE

1

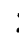

2.3.

UCLA SCHOOL OF MEDICINE

1

$2 \cdot 3 \cdot 5$

UCLA SCHOOL OF MEDICINE

1

4

2.8.

UCLA SCHOOL OF MEDICINE

2 


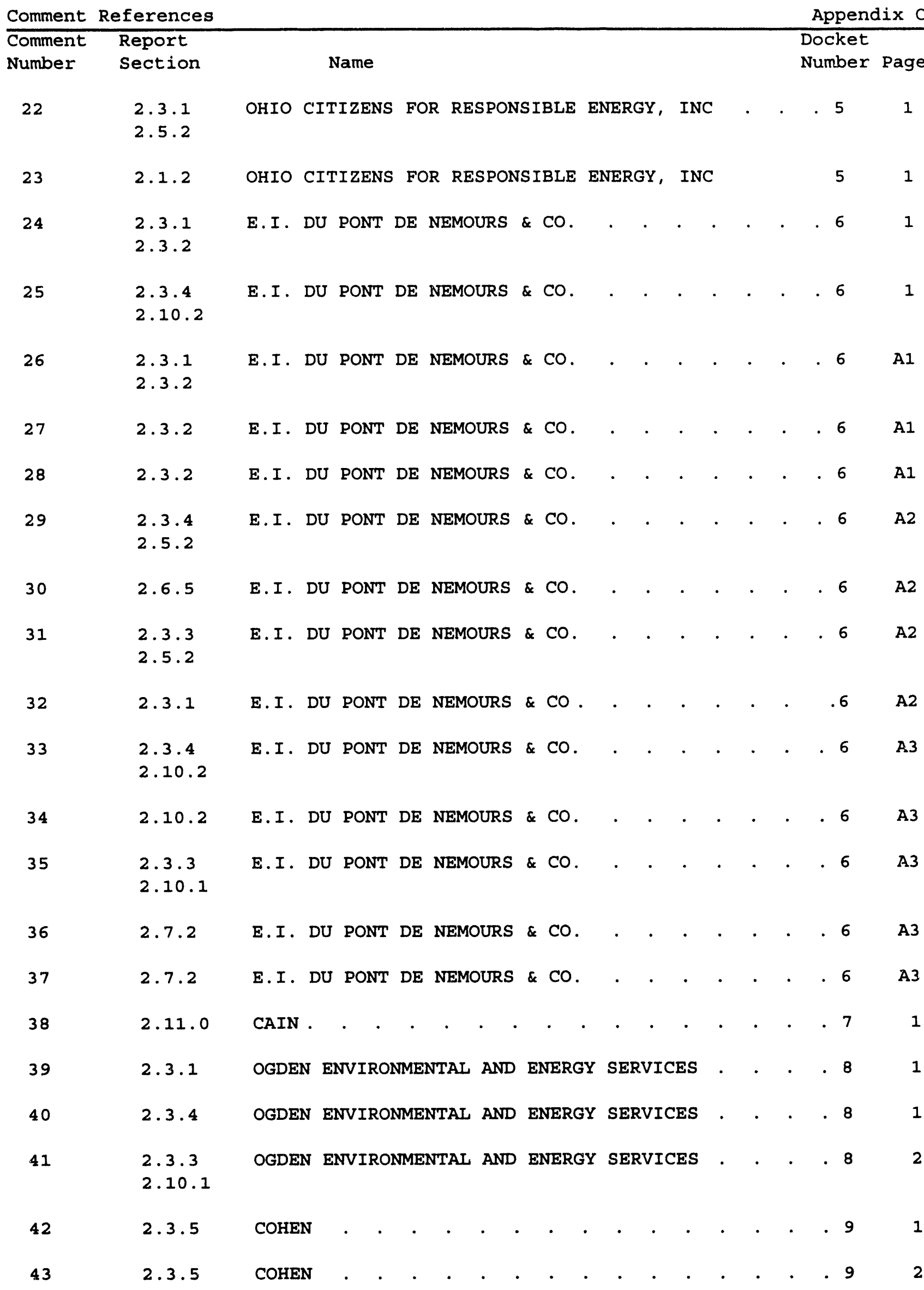




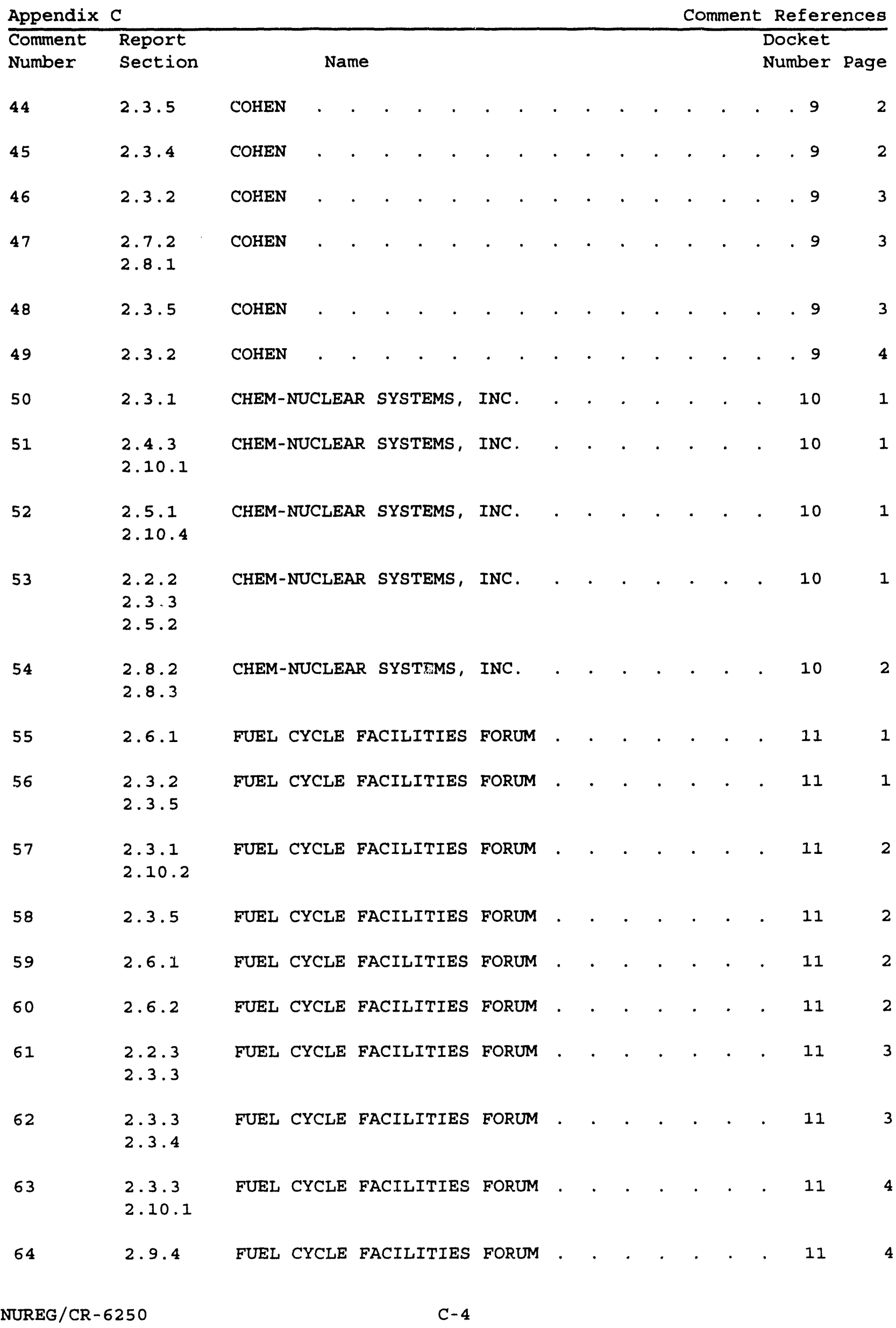




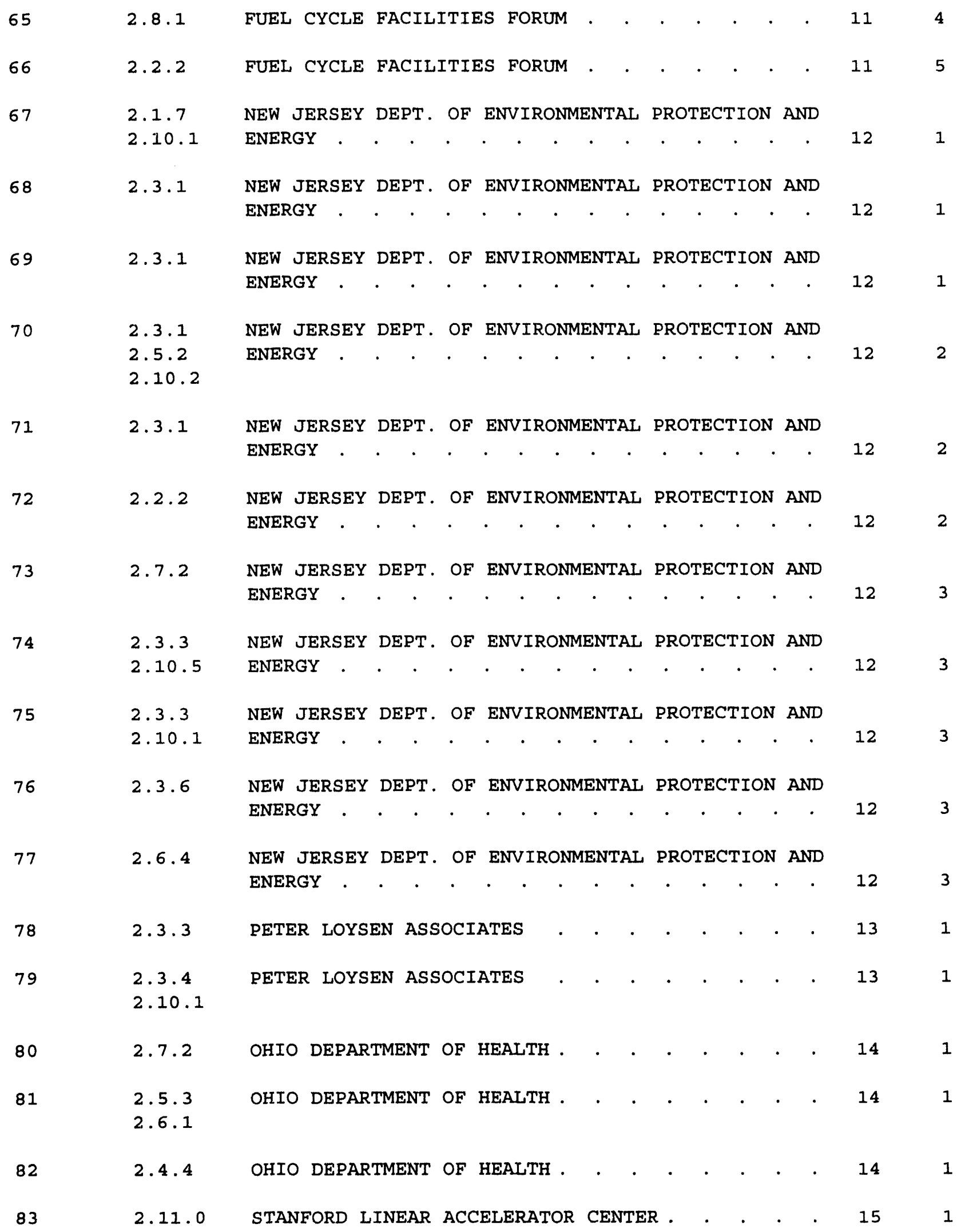




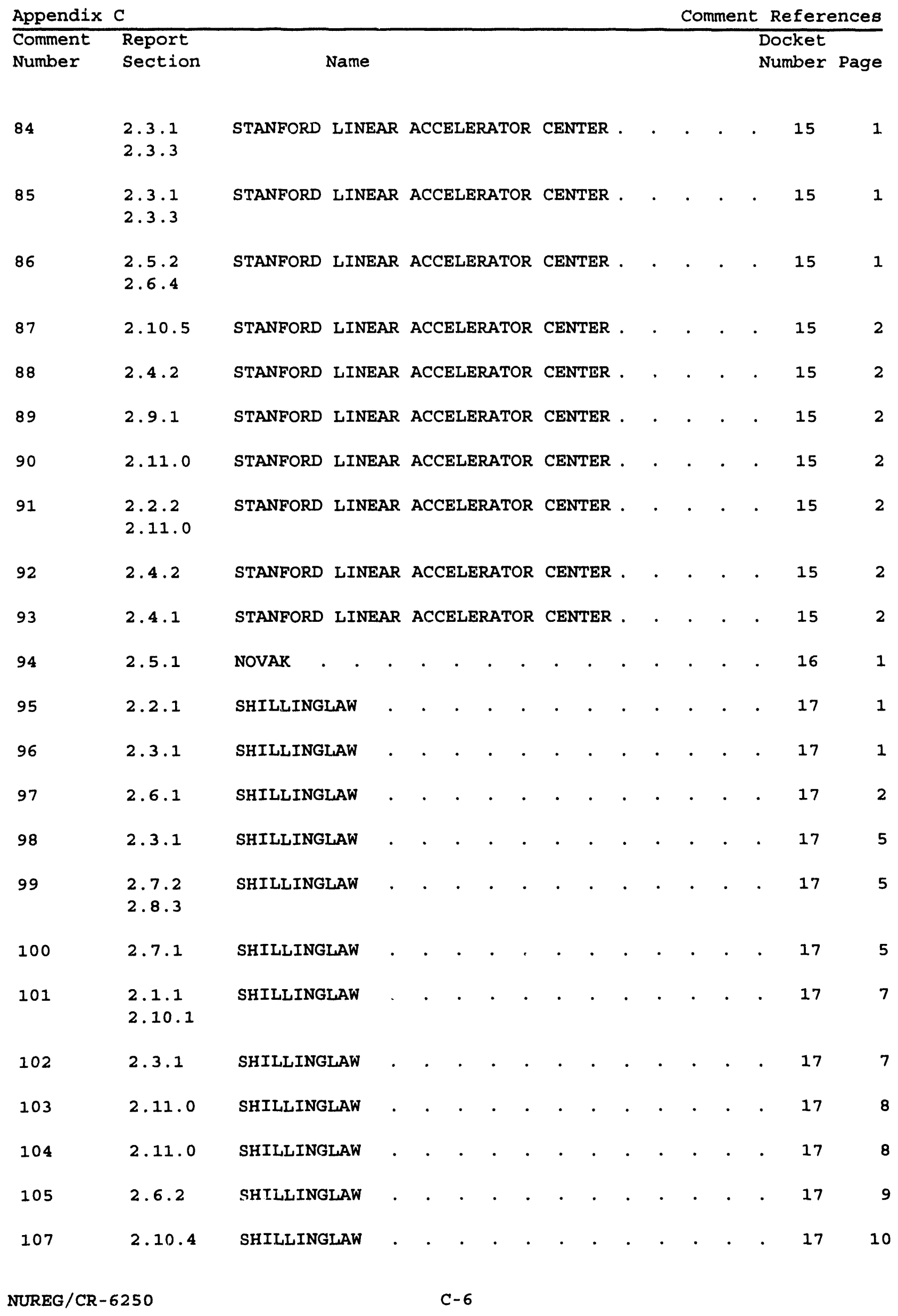




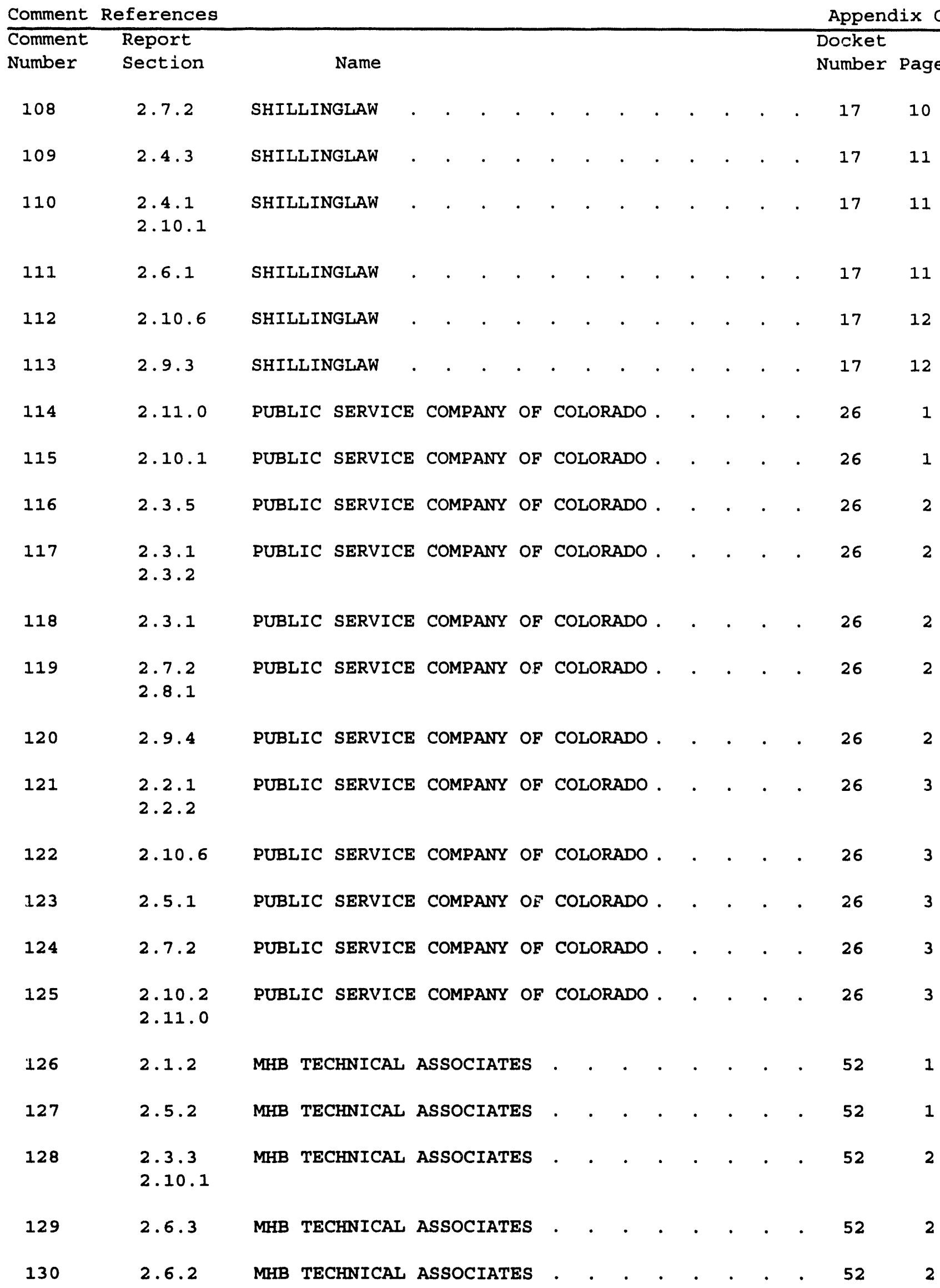




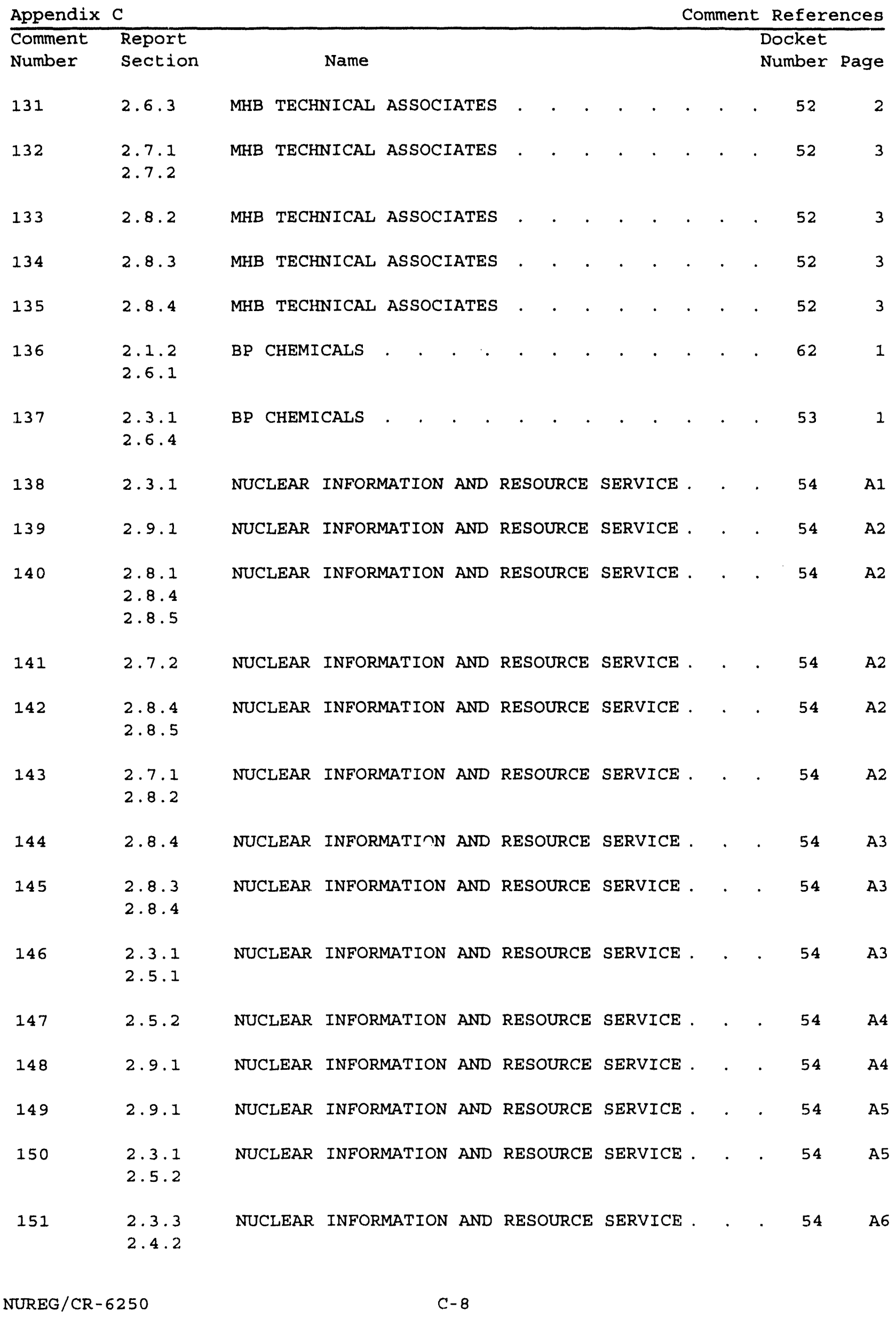




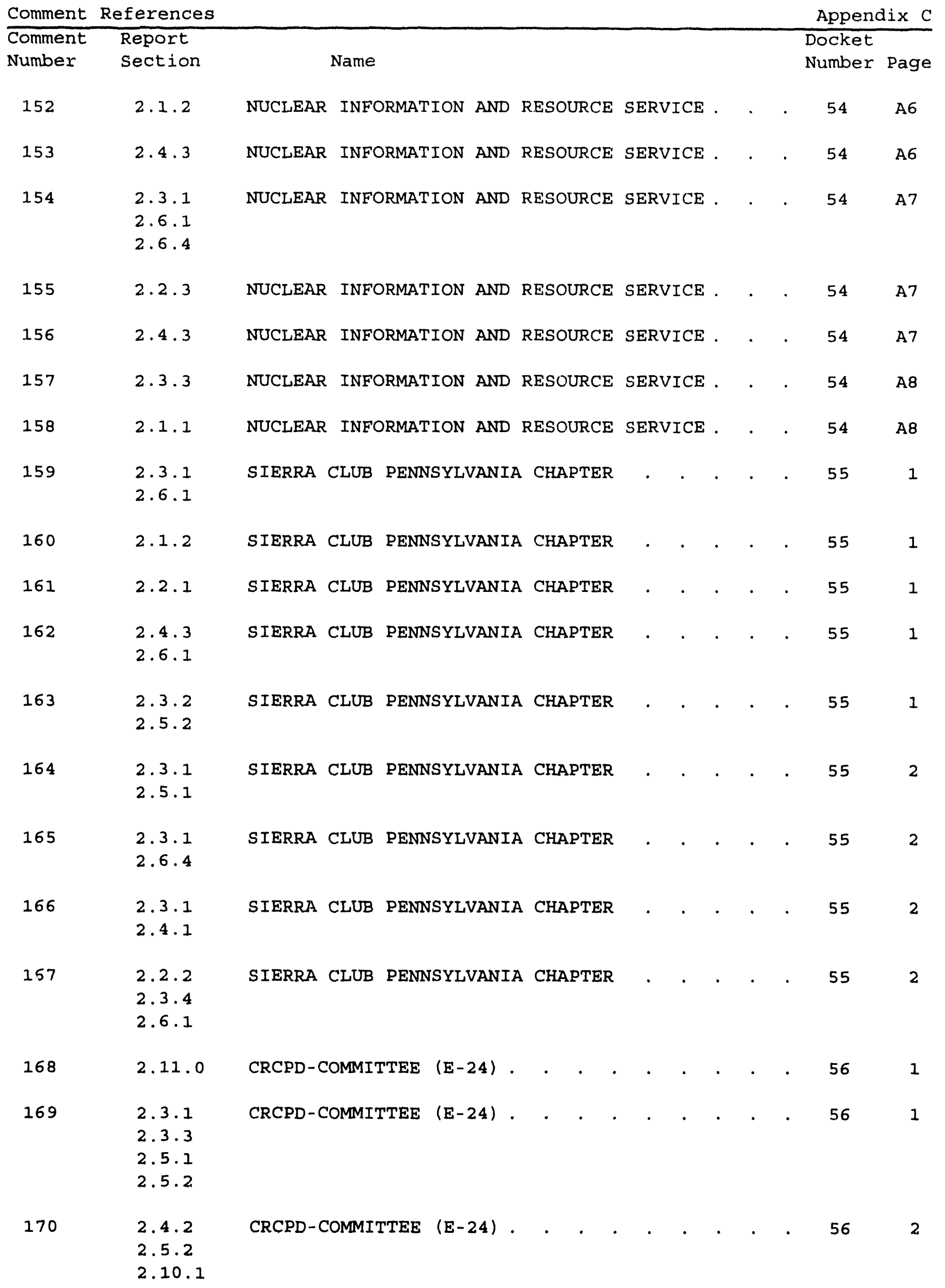


Appendix C

Comment

Number

171

172

173

174

175

176

177

178

179

180

181

182

183

184

185

186

201

202

203

204
$2 \cdot 5 \cdot \frac{1}{2 \cdot 2}$

2.10 .2
Comment References Docket

Number Page

CRCPD-COMMITTEE $(E-24)$. . . . . . . . . . $56 \quad 2$

2.10.2 CRCPD-COMMITTEE (E-24)

2.7 .2

CRCPD-COMMITTEE (E-24)

2.8 .3

2.8 .4

2.4 .2

CRCPD-COMMITTEE (E-24)

2.5 .2

2.8 .3

2.8 .4

CRCPD-COMMITTEE (E-24)

56

2.6.2 CRCPD-COMMITTEE (E-24)

2.3.1 CRCPD-COMMITTEE (E-24).

2.2 .2

CRCPD-COMMITTEE $(E-24)$

CRCPD-COMMITTEE (E-24).

2.2 .2

$2 \cdot 6 \cdot 3$

2.4 .3

CRCPD-COMMITTEE (E-24)

CRCPD-COMMITTEE (E-24)

2.2 .3

CRCPD-COMMITTE

$(E-24)$

2.6 .4

$2 \cdot 4 \cdot 3$

CRCPD-COMMITTEE (E-24) .

2.1 .5

CRCPD-COMMITTE

$(E-24)$

CRCPD-COMMITTEE (E-24)

2.1 .1

2.1 .5

2.10 .1

\section{9 .1}

2.9 .4

CRCPD-COMMITTEE (E-24).

\section{2 .2}

2.6 .1

PHYSICIANS FOR SOCIAL RESPONSIBILITY .

1

2.6 .3

$2.4 \cdot 3$

PHYSICIANS FOR SOCIAL RESPONSIBILITY

1

2.11 .0

PHYSICIANS FOR SOCIAL RESPONSIBILITY

1

2.6 .3 2.11 .0
PHYSICIANS FOR SOCIAL RESPONSIBILITY

1 
Comment References

Number section

205

206

208

209

210

211

212

213

214

215

216

217

218

219

220

221

222

225

226

227

228

$2 \cdot 3 \cdot 1$

2.3 .4

2.5 .2

2. 3.4

2.10 .3

2.3 .3

2.3 .1

$2.5 \cdot 2$

2.3 .4

2.4 .2

2.5 .2

2. 3.1

2.4 .2

2.1 .5

2.4 .3

2.10 .1

2.5 .1

2.9 .4

2.4 .3

2.6 .1

2.4 .3

2.2 .3

$2 \cdot 3 \cdot 4$

2.3 .4

2.4 .3

$2 \cdot 3 \cdot 4$
$2 \cdot 3 \cdot 1$

YANKEE ATOMIC ELECTRIC COMPANY

YANKEE ATOMIC ELECTRIC COMPANY

YANKEE ATOMIC ELECTRIC COMPANY

YANKEE ATOMIC ELECTRIC COMPANY

2.2.2 YANKEE ATOMIC ELECTRIC COMPANY

DOW CHEMICAL COMPANY

DOW CHEMICAL COMPANY

2.4.3 DOW CHEMICAL COMPANY

2.8 .4
Appendix C

Docket

Number Page

YANKEE ATOMIC ELECTRIC COMPANY . . . . . . 592

YANKEE ATOMIC ELECTRIC COMPANY . . . . . . 592

YANKEE ATOMIC ELECTRIC COMPANY . . . . . . 592

YANKEE ATOMIC ELECTRIC COMPANY . . . . . . 592

YANKEE ATOMIC ELECTRIC COMPANY . . . . . . . 59 A1

YANKEE ATOMIC ELECTRIC COMPANY . . . . . . . . $59 \quad \begin{array}{lll}59 & \text { A1 }\end{array}$

$59 \quad A 1$

$59 \quad$ A2

$59 \quad$ A2

59 A2

$59 \quad A 3$

59 A3

$59 \quad A 3$

$27 \quad 1$

$27 \quad 1$

272

DOW CHEMICAL COMPANY . . . . . . . . . . . 272

RIO ALGOM MINING CORPORATION . . . . . . . . . 28

RIO ALGOM MINING CORPORATION . . . . . . . . . 282

RIO ALGOM MINING CORPORATION . . . . . . . . 282

RIO ALGOM MINING CORPORATION . . . . . . . 28 
Appendix C

Comment Report

Number section

229

2.7 .2

$2 \cdot 8 \cdot 1$

230

231

232

233

234

235

236

237

238

239

240

241

242

243

244

245

246

247

248

249

250

251

252
2.11 .0

2.10 .5

$2 \cdot 2 \cdot 3$

2.3. 5

2. 5.1

2.3 .1

$2 \cdot 5 \cdot 3$

2.11 .0

2.2 .1

2.2 .2

2.2 .3

2.4 .3

2.11 .0

2.3 .1

$2 \cdot 3.3$

2. 3.1

2. 5.1

2.11 .0

$2 \cdot 3 \cdot 3$

$2.3 \cdot 3$

2. 2.2

2.2 .3

2.10 .2

2.3 .1

2.2 .2
2.10 .5

RIO ALGOM MINING CORPORATION .

Comment References

Name

Docket

Number Page

RIO ALGOM MINING CORPORATION .

RIO ALGOM MINING CORPORATION .

RIO ALGOM MINING CORPORATION

KENNECOTT URANIUM COMPANY .

RIO ALGOM MINING CORPORATION .

RIO ALGOM MINING CORPORATION.

KENNECOTT URANIUM COMPANY .

ATLANTIC RICHFIELD COMPANY

ATLANTIC RICHFIELD COMPANY

ATLANTIC RICHFIELD COMPANY

ATLANTIC RICHFIELD COMPANY

3

ATLANTIC RICHFIELD COMPANY

ATLANTIC RICHFIELD COMPANY

KENNECOTT URANIUM COMPANY

ATLANTIC RICHFIELD COMPANY

4

ATLANTIC RICHFIELD COMPANY . . . . . . . . . $29 \quad 4$

ATLANTIC RICHFIELD COMPANY . . . . . . . . . $29 \quad 4$

ATLANTIC RICHFIELD COMPANY . . . . . . . . $29 \quad 5$

KENNECOTT URANIUM COMPANY . . . . . . . . . . . 18

ATLANTIC RICHFIELD COMPANY . . . . . . . . $29 \quad 5$

ATLANTIC RICHFIELD COMPANY . . . . . . . . . 29

ATLANTIC RICHFIELD COMPANY . . . . . . . . . . $\quad 29.6$

ATLANTIC RICHFIELD COMPANY . . . . . . . . . $29 \quad 6$ 


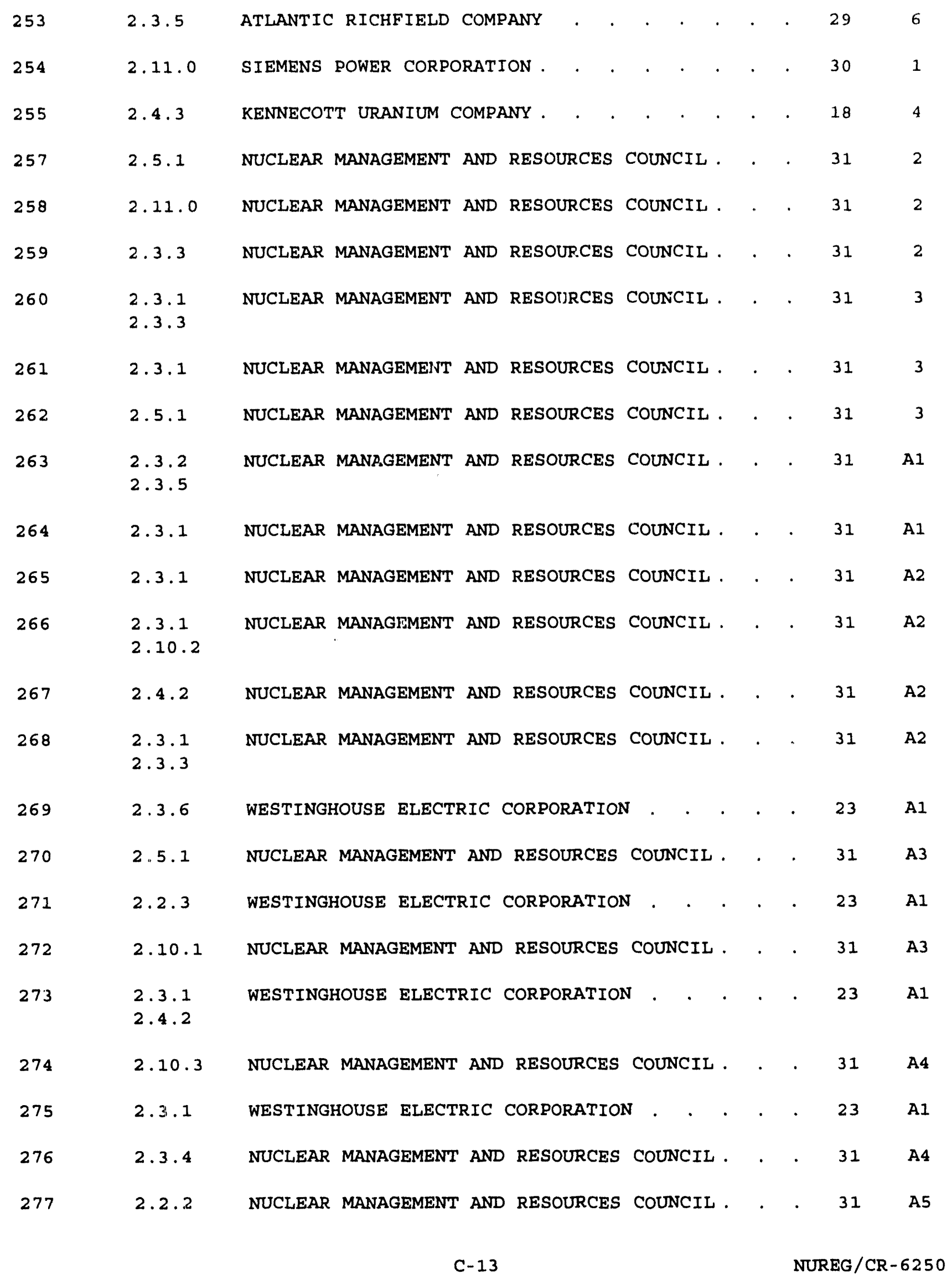


Comment

Number Report section

Name
Docket

Number Page
278

279

280

281

282

283

284

285

286

287

288

289

290

292

293

294

295

296

297

298

299

300
2. 3.1

2.4 .2

2.3 .3

2.3 .4

2.10 .1

2.6 .1

2.3. 1

2.3 .2

2.3. 1

2.3 .5

2.7 .2

2.9 .1

2.3. 1

2.4 .2

$$
2 \cdot 9 \cdot 3
$$

2.2 .2

2.3. 1

2.3.2

2.10 .2

2.4 .2

$2 \cdot 3 \cdot 5$

$2 \cdot 3.1$

2.2.3

2.10 .2

2.3. 1

2.3.5

2.2 .2

$2 \cdot 3 \cdot 1$

2.10 .1

2.11 .0
WESTINGHOUSE ELECTRIC CORPORATION

23

A2

NUCLEAR MANAGEMENT AND RESOURCES COUNCIL .

31

A5

WESTINGHOUSE ELECTRIC CORPORATION

A2

NUCLEAR MANAGEMENT AND RESOURCES COUNCIL .

WESTINGHOUSE ELECTRIC CORPORATION

WRSTINGHOUSE ELECTRIC CORPORATION

23

A3

NUCLEAR MANAGEMENT AND RESOURCES COUNCIL . . . 31

A7

NUCLEAR MANAGEMENT AND RESOURCES COUNCIL . . . 31

A7

WESTINGHOUSE ELECTRIC CORPORATION

23

A3

NUCLEAR MANAGEMENT AND RESOURCES COUNCIL . . . 31 A8

NUCLEAR MANAGEMENT AND RESOURCES COUNCIL . . . 31 A8

WESTINGHOUSE ELECTRIC CORPORATION

23

A3

WESTINGHOUSE ELECTRIC CORPORATION

23

A3

WESTINGHOUSE ELECTRIC CORPORATION . . . . . 23 A4

AMERICAN MINING CONGRESS . . . . . . . . . . 32

AMERICAN MINING CONGRESS . . . . . . . . 32

WESTINGHOUSE ELECTRIC CORPORATION . . . . . . 23 A4

AMERICAN MINING CONGRESS

32

AMERICAN MINING CONGRESS

WESTINGHOUSE ELECTRIC CORPORATION

A4

AMERICAN MINING CONGRESS

2

WESTINGHOUSE ELECTRIC CORPORATION . 


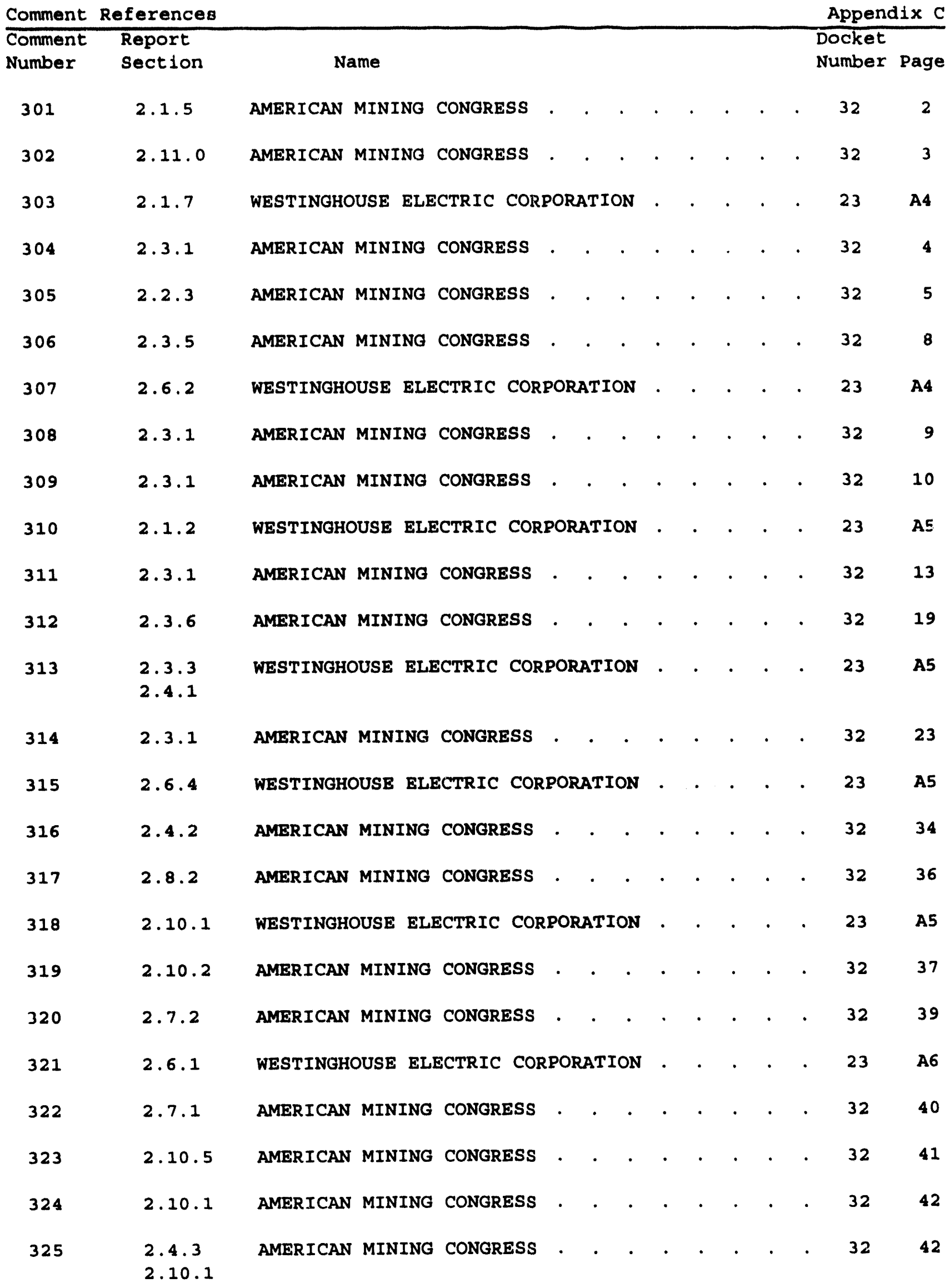




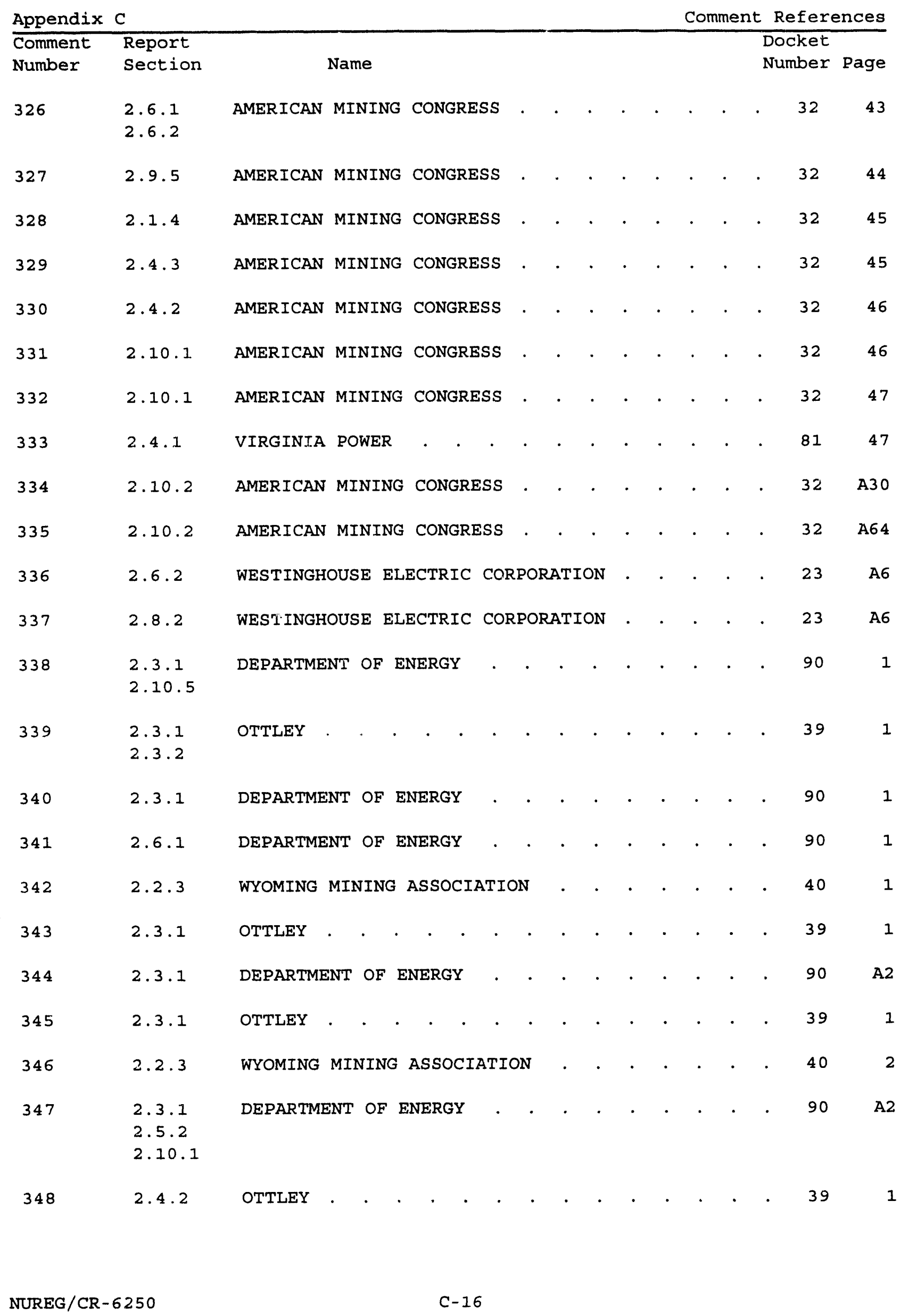


Comment References

Number section
Name
Appendix C

Docket

Number Page
349

$$
2.6 .1
$$

2.6. 2

2.6 .3

350

351

2.11 .0

2.10 .2

DEPARTMENT OF ENERGY

2.10.1 DEPARTMENT OF ENERGY

2.10 .1

DEPARTMENT OF ENERGY

2.3.3 WYOMING MINING ASSOCIATION

2.10 .1

DEPARTMENT OF ENERGY

$2 \cdot 3 \cdot 1$

INSTITUTE FOR ENERG

GY AND

2.10 .1

DEPARTMENT OF ENERGY

2.10 .1

DEPARTMENT OF ENERGY

2.5 .1

\section{INST}

360

361

362

363

364

365

366

367

368

369

370

371

372
2.2.1 DEPARTMENT OF ENERGY

2.2.2 WYOMING MINING ASSOCIATION

2.6 .1 2.10 .1

DEPARTMENT OF ENERGY
WYOMING MINING ASSOCIATION

2.10 .1

2.6 .1

LEPARTMENT OF ENERGY

2.4 .2

2.10 .2

2.2 .2

WYOMING MINING ASSOCIATION

2.4 .3

2.10 .5

DEPARTMENT OF ENERGY

$2 \cdot 3 \cdot 3$

2.10 .2

DEPARTMENT OF ENERGY

$2.3 \cdot 4$

ELLIS

DEPARTMENT OF ENERGY

ENVIRONMENTAL RESEARCH

34

$90 \quad$ A2

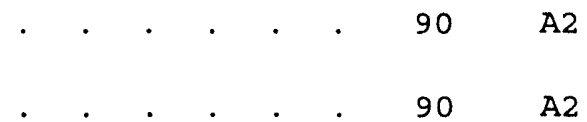

ENVIRONMENTAL RESEARCH

34

A3

A3

2

A3

3

A3

INSTITUTE FOR ENERGY AND ENVIRONMENTAL RESEARCH

34

4

34

2

INSTITUTE FOR ENERGY AND ENVIRONMENTAL RESEARCH

90

A3

90

A4

INSTITUTE FOR ENERGY AND ENVIRONMENTAL RESEARCH

34

3

90

A4

41

1

90

A4 


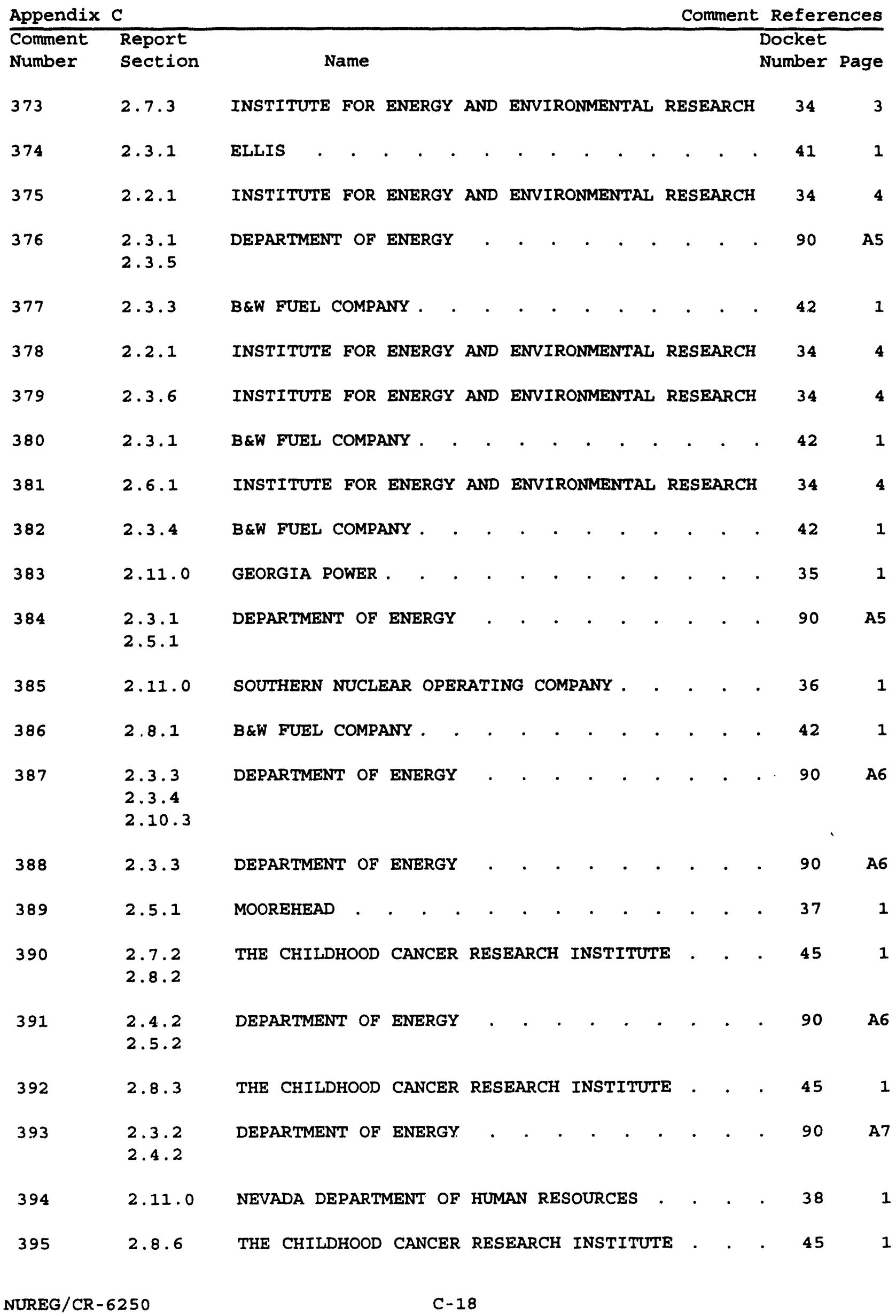


Comment References

Comment Report
Number section

396

$2.3 \cdot 4$

2.10 .3

397

$2 \cdot 3 \cdot 1$

NEVADA DEPARTMENT OF HUMAN RESOURCES

2.10 .1

THE CHILDHOOD

CANCER RESEARCH INSTITUTE

398

399

400

401

403

404

405

406

407

408

409

410

411

412

413

414

415

416

417

418

DEPARTMENT OF ENERGY

$2.10 \cdot 1$

THE CHILDHOOD CANCER RESEARCH INSTITUTE

2.11.0 UTILITY DECOMMISSIONING GROUP

DEPARTMENT OF ENERGY

$2 \cdot 3 \cdot 2$

$2 \cdot 3 \cdot 4$

$2 \cdot 3 \cdot 3$

THE CHILDHOOD

CANCER

RESEARCH INSTITUTE

$2 \cdot 4 \cdot 3$

UTILITY DECOMMISSIONING GROUP

2.10 .2

UTILITY DECOMMISSIONING GROUP

2.10 .1

DEPARTMENT OF ENERGY

2.3 .6

THE CHILDHOOD

CA

ANCE

RESEARCH INSTITUTE

2.10 .1

DEPARTMENT OF ENERGY

2.11 .0

UTILITY DECOMMISSIONING GROUP

$2.4 \cdot 1$

DEPARTMENT OF ENERGY

.

DEPARTMENT OF ENERGY

.

(1)

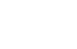

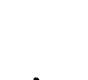

2.3 .6

2.1 .2
Appendix C Docket

Number Page

90

A7

DEPARTMENT OF ENERGY . . . . . . . . . . . 90

A8

2

2

A8

A9

2

2.10 .1

A10

2.3 .2

2.10 .1

453

DEPARTMENT OF ENERGY . . . . . . . .

A10 
Appendix C

Comment Report

Number section

2.4 .1

2.1 .2

2.7 .2

$2 \cdot 1 \cdot 3$

2.7 .2

2.4 .1

2.3 .6

2.10 .1

427

428

429

430

431

432

433

434

435

436

437

438

439

440

441

10.2
2.2.2 DEPARTMENT OF ENERGY

$2 \cdot 3 \cdot 1$

2.8 .1

2.6 .2

2.10 .4

2.6 .2

2.10 .1

2.11 .0

2.5 .1

$2.8 \cdot 5$

2.10 .2

$2 \cdot 4 \cdot 3$

2.8 .2

2.8 .4

2.8 .5

SIERRA CLUB

DEPARTMENT OF ENERGY

SIERRA CLUB

DEPARTMENT OF ENERGY

DEPARTMENT OF ENERGY

DEPARTMENT OF ENERGY

DEPARTMENT OF ENERGY

SIERRA CLUB
Name

Comment References Docket

Number Page

\section{UTILITY DECOMMISSIONING GROUP}

DEPARTMENT OF ENERGY

SIERRA CLUB

UTILITY DECOMMISSIONING GROUP

SIERRA CLUB

UTILITY DECOMMISSIONING GROUP

DEPARTMENT OF ENERGY

SIERRA CLUB

UTILITY DECOMMISSIONING GROUP

UTILITY DECOMMISSIONING GROUP

UTILITY DECOMMISSIONING GROUP

33

90

DEPARTMENT OF ENERGY

90

2.4.3 DEPARTMENT OF ENERGY
A.12

A13

A11

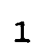

A11

$$
1
$$

6

A11$$
1
$$

A12

$\mathrm{A} 12$

5

A12

2

6

A13

$$
\text { 2.6.2 SIERRA CLUB . }
$$


Comment References

Comment Report

Number section

442

$$
\begin{aligned}
& 2.7 .2 \\
& 2.8 .1 \\
& 2.8 .2
\end{aligned}
$$

443

2. 8.2

$2.8 \cdot 3$

444

445

446

447

448

449

450

451

452

453

454

455

456

457

458

459

460

461

462

463

2.2 .2

2.1.2

2.10 .1

\begin{abstract}
2.4 .2
\end{abstract}
2.6 .2

2.1 .2

2.4 .1

2.10 .1

$$
2.6 .3
$$

2.4 .3

2.7 .2

2.4 .2

2.8 .5

2.3 .6

2.10 .2

2.11 .0

2.2 .1
DEPARTMENT OF ENERGY

DEPARTMENT OF ENERGY

SIERRA CLUB

DEPARTMENT OF ENERGY

DEPARTMENT OF ENERGY

DEPARTMENT OF ENERGY

UTILITY DECOMMISSIONING GROUP

SIERRA CLUB

DEPARTMENT OF ENERGY

DEPARTMENT OF ENERGY

2.10.1 UTILITY DECOMMISSIONING GROUP

SIERRA CLUB

DEPARTMENT OF ENERGY

SIERRA CLUB

UTILITY DECOMMISSIONING GROUP

UTILITY DECOMMISSIONING GROUP

DEPARTMENT OF THE ARMY

PUBLIC CITIZEN

2.3.1 DEPARTMENT OF THE ARMY

UTILITY DECOMMISSIONING GROUP
47

$60 \quad 1$

Appendix $\mathrm{C}$ Docket

Number Page

$90 \quad$ A13

33

7

A14

A14

2

A14

A14

A14

8

2

A14

A14

8

2

A14

2

8

2

1

472

33 
464

$$
2.3 .1
$$

PUBLIC CITIZEN

Number Page

465

DEPARTMENT OF THE ARMY

47

466

2.2 .2

PUBLIC CITIZEN

2.3 .1

467

2.6 .2

UTILITY DECOMMISSIONING GROUP

DEPARTMENT OF THE ARMY

UTILITY DECOMMISSIONING GROUP

UTILITY DECOMMISSIONING GROUP 
Comment References

Comment Report

Number section

489

490

\section{1}

492

493

494

495

496

497

498

499

500

501

502

503

504

2.3 .5
2.10 .3

505

$2 \cdot 3 \cdot 5$

WESTERN STATES LEGAL FOUNDATION .

3

506

$2 \cdot 3 \cdot 1$

WISCONSIN ELECTRIC POWER COMPANY

WESTERN STATES LEGAL FOUNDATION .

WISCONSIN ELECTRIC POWER COMPANY

2. 3.1

2.3 .2

2.4 .2

509

510

WESTERN STATES LEGAL FOUNDATION

PUBLIC CITIZEN

WESTERN STATES LEGAL FOUNDATION .

WESTINGHOUSE ELECTRIC CORPORATION

PUBLIC CITIZEN

WESTINGHOUSE ELECTRIC CORPORATION

Appendix C

Docket

Number Page

$2 \cdot 3 \cdot 1$

WESTERN STATES LEGAL FOUNDATION .

PUBLIC CITIZEN

WESTINGHOUSE ELECTRIC CORPORATION

23

A6

507

$2 \cdot 3 \cdot 1$

2.6 .3

PUBLIC CITIZEN

WESTERN STATES LEGAL FOUNDATION

A2

2

A2

A6

2

A6

A2

3

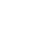




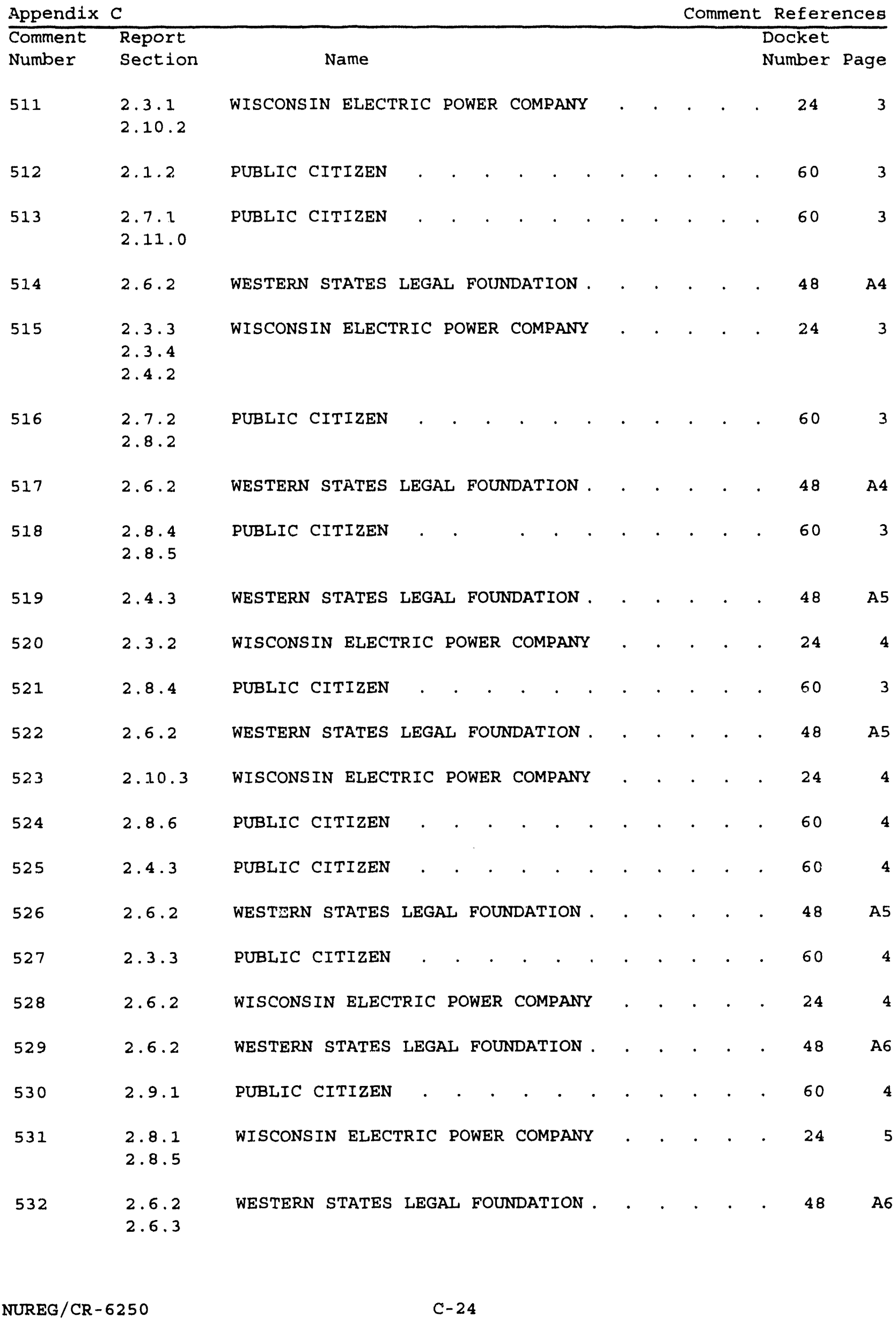




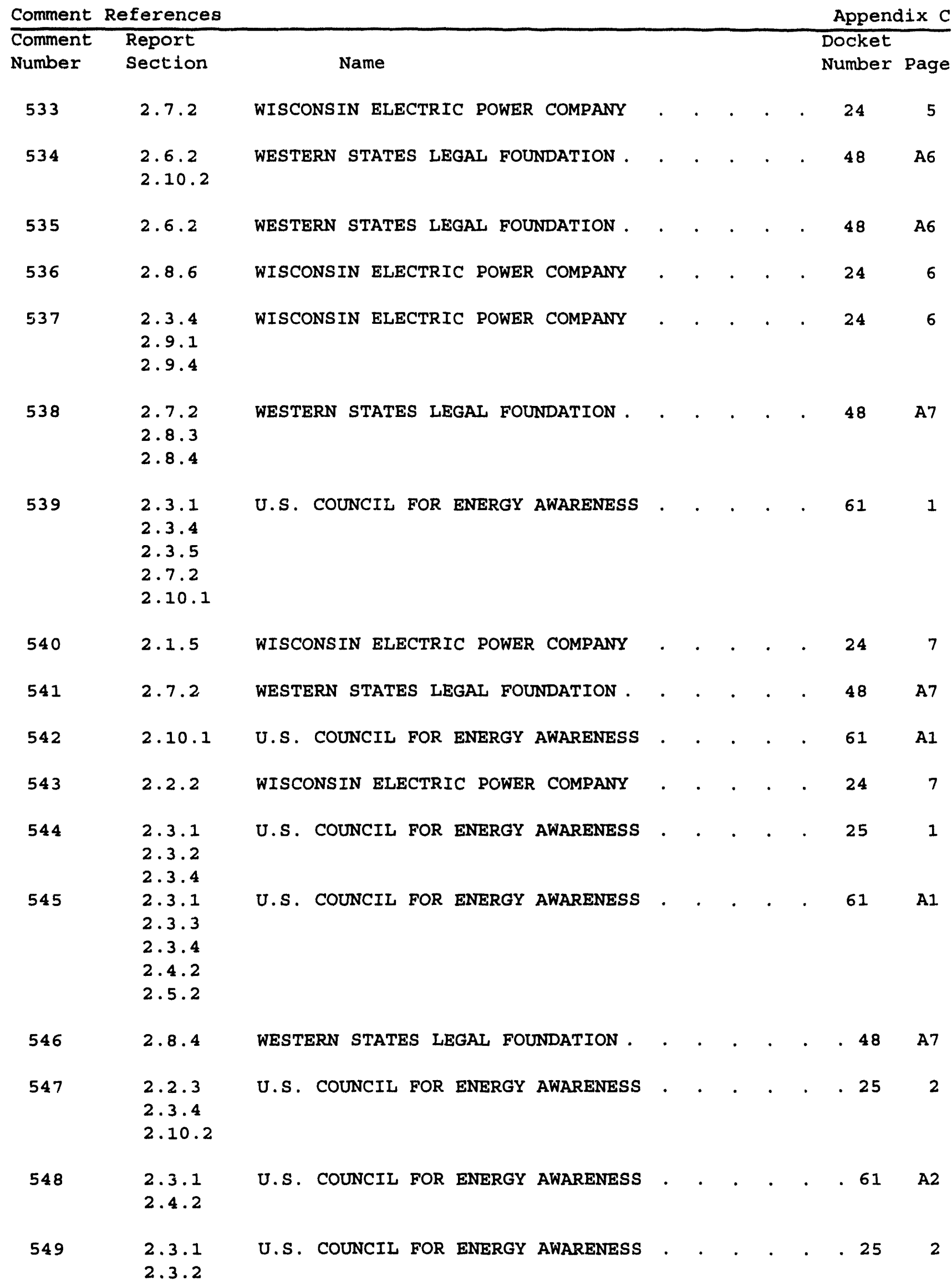


Comment Report

Number section

Name

Comment References Docket

Number Page

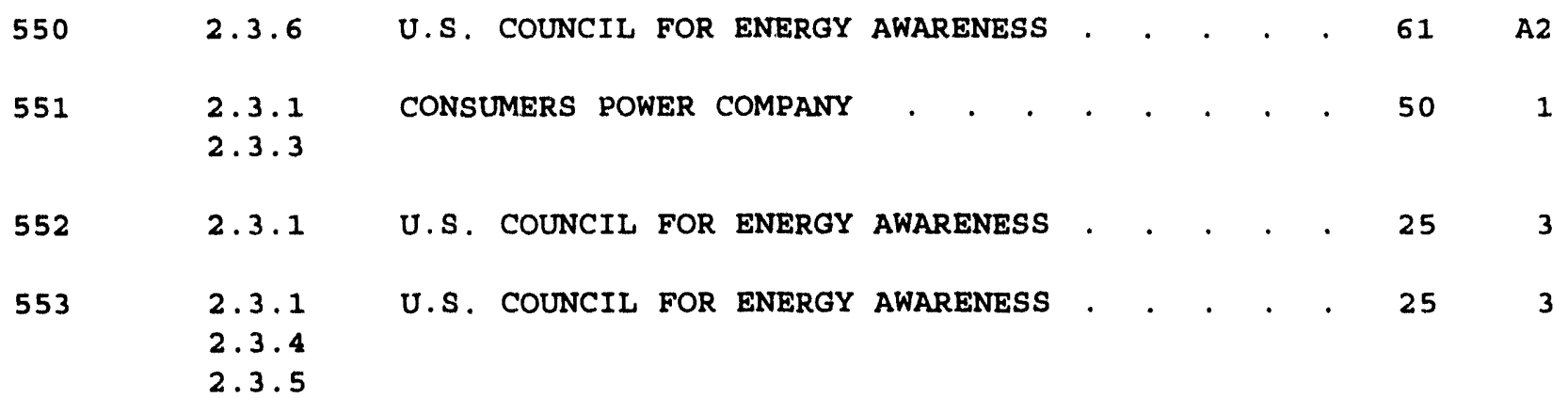

554

$2 \cdot 3 \cdot 4$

U.S. COUNCIL FOR ENERGY AWARENESS

61

A2

2.3 .5

2.5 .2

2.10 .3

555

$2 \cdot 3 \cdot 3$

556

557

558

559

560

561

562

563

564

566

567

568
2.10 .2

2.10.1

2.10 .2

2. 3.1

2.3 .2

2.2 .2

U.S. COUNCIL FOR ENERGY AWARENESS

2.2 .2

2.10 .3

2.7 .2

U.S. COUNCIL FOR ENERGY AWARENESS

CONSUMERS POWER COMPANY

$2 \cdot 3 \cdot 2$

$2 \cdot 3 \cdot 1$

U.S. COUNCIL FOR ENERGY AWARENESS

U.S. COUNCIL FOR ENERGY AWARENESS

2.7 .2

2.8 .1

2.8 .4

2.8 .6

$2 \cdot 4 \cdot 2$

U.S. COUNCIL FOR ENERGY AWARENESS

2.4 .2

U.S. COUNCIL FOR ENERGY AWARENESS

U.S. COUNCIL FOR ENERGY AWARENESS

$2 \cdot 2 \cdot 3$
2.7 .1

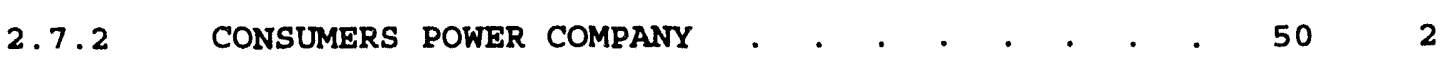

1

3

A3

A3

3

4

A3 
Comment Number

569

570

571

572

573

574

575

576

577

578

579

580

581

582

584

585

586

587

588

589

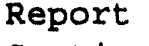

Section

2.10 .1

U.S. COUNCIL FOR ENERGY AWARENESS

Name

Docket

Number page

$$
2.3 .3
$$

2.10 .1

2.1 .5

2. 5.1

U.S. COUNCIL FOR ENERGY AWARENESS

CONSUMERS POWER COMPANY

2.4 .2

2. 5.2

U.S. COUNCIL FOR ENERGY AWARENESS

2.6 .5

U.S. COUNCIL FOR ENERGY AWARENESS

2.10 .1

U.S. COUNCIL FOR ENERGY AWARENESS

2.3 .2

2.10 .3

U.S. COUNCIL FOR ENERGY AWARENESS

$2 \cdot 3 \cdot 1$

CONSUMERS POWER COMPANY

$2 \cdot 3 \cdot 3$

U.S. COUNCIL FOR ENERGY AWARENESS

2.9 .1

U.S. COUNCIL FOR ENERGY AWARENESS

2.10 .1

CONSUMERS POWER COMPANY

CONSUMERS POWER COMPANY

2.10 .3

$2.2 . ?$

U.S. COUNCIL FOR ENERGY AWARENESS

U.S. COUNCIL FOR ENERGY AWARENESS

$2.3 \cdot 1$

2.6.1

2.6 .2

2.6 .4

2.11 .0

U.S. COUNCIL FOR ENERGY AWARENESS

25

U.S. COUNCIL FOR ENERGY AWARENESS

2.10 .3

U.S. COUNCIL FOR ENERGY AWARENESS

$2 \cdot 6.2$

2.6 .4

2.7 .2

2.8 .1

STATE OF WASHINGTON .

U.S. COUNCIL FOR ENERGY AWARENESS

$2 \cdot 4 \cdot 3$

$2 \cdot 10.5$

STATE OF WASHINGTON .

2.4 .3

2.6 .2
U.S. COUNCIL FOR ENERGY AWARENESS 


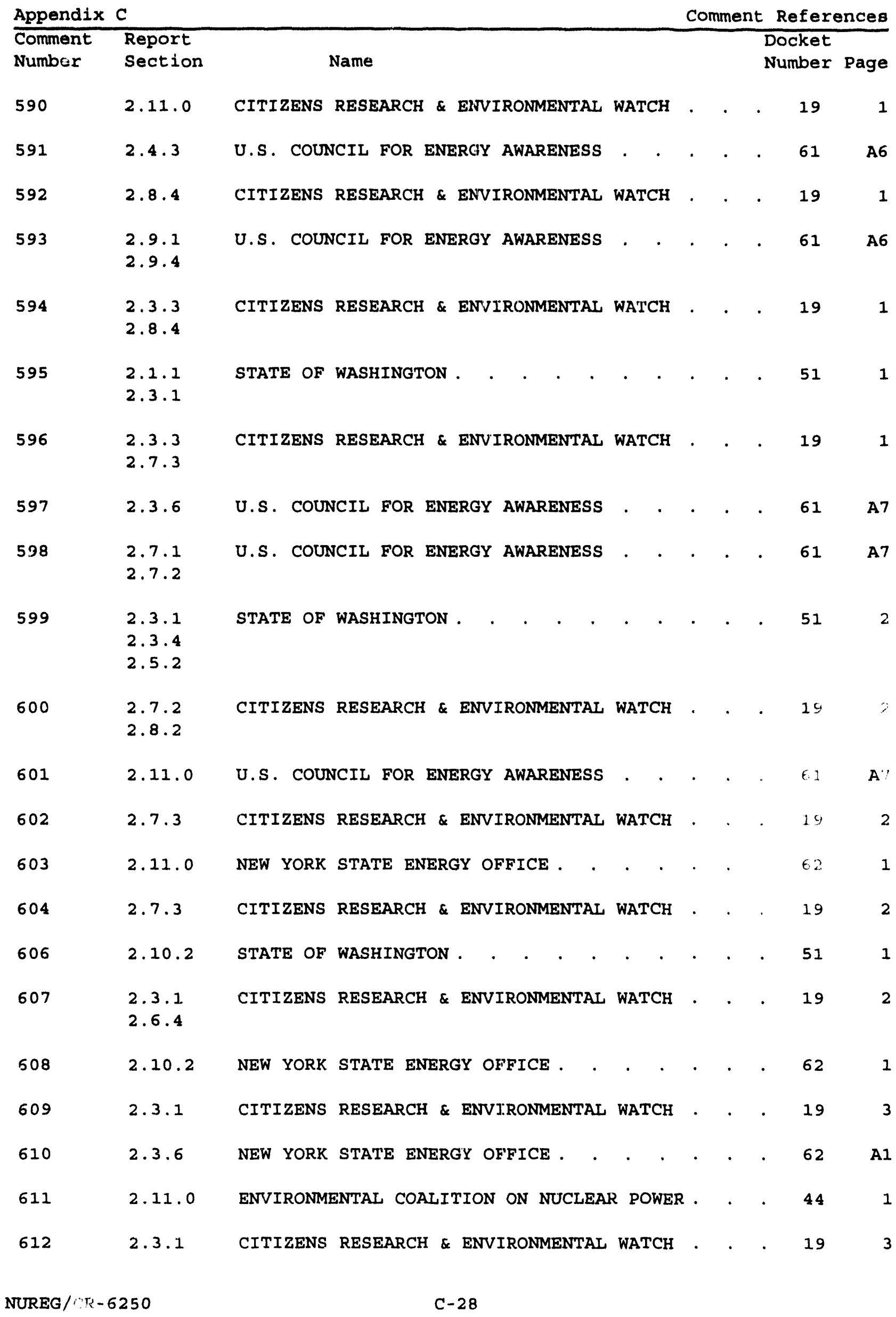


Comment References

Comment Report

Number section

613

2.6 .1

$2 \cdot 3 \cdot 1$

$2 \cdot 2 \cdot 3$

$2 \cdot 6 \cdot 4$

$2 \cdot 3 \cdot 3$

2.1 .2

$2 \cdot 3 \cdot 3$

2.11 .0

2.3. 1

2.4 .2

2. 5.2

622

2.4 .1

$2.3 \cdot 6$

2.10 .2

2.7 .3

2.1 .1

626

627

628

629

630

631

632

633

634

635

636

637
2.5 .2

2.1 .2

2.4 .3

2.10 .6

2.1 .3

2.3 .3

2.4 .3

2.4 .4

2.11 .0

2.1 .4

2.1 .1

2.11 .0
Name

Appendix C

Docket

Number Page

CITIZENS RESEARCH \& ENVIRONMENTAL WATCH . . . 19

NEW YORK STATE ENERGY OFFICE . . . . . . . . 62 A1

ENVIRONMENTAL COALITION ON NUCLEAR POWER . . . $44 \quad 1$

CITIZENS RESEARCH \& ENVIRONMENTAL WATCH . . . 19

CITIZENS RESEARCH \& ENVIRONMENTAL WATCH . . . 194

NEW YORK STATE ENERGY OF'FICE . . . . . . . . . 62 A1

CITIZENS RESEARCH \& ENVIRONMENTAL WATCH . . . 194

CITIZENS RESEARCH \& ENVIRONMENTAL WATCH . . . 1944

NEW YORK STATE ENERGY OFFICE . . . . . . . . . . 62 A2

CITIZENS RESEARCH \& ENVIRONMENTAL WATCH . . . 19

ENVIRONMENTAL COALITION ON NUCLEAR POWER . . . 44

NEW YORK STATE ENERGY OFFICE . . . . . . . . . 62 A2

CITIZENS RESEARCH \& ENVIRONMENTAL WATCH . . . 19

ENVIRONMENTAL COALITION ON NUCLEAR POWER . . . 44

ENVIRONMENTAL COALITION ON NUCLEAR POWER . . . 44

ENVIRONMENTAL COALITION ON NUCLEAR POWER . . . 4443

CITIZENS RESEARCH \& ENVIRONMENTAL WATCH . . . . 19

CITIZENS RESEARCH \& ENVIRONMENTAL WATCH • . . 19

ENVIRONMENTAL COALITION ON NUCLEAR POWER . . . 44

CITIZENS RESEARCH \& ENVIRONMENTAL WATCH • . . 19

CITIZENS RESEARCH \& ENVIRONMENTAL t. 'CH . . . $19 \quad 6$

CITIZENS RESEARCH \& ENVIRONMENTAL WATCH • . . 197

ENVIRONMENTAL COALITION ON NUCLEAR POWER . . . 44

CITIZENS RESEARCH \& ENVIRONMENTAL WATCH . . . 197

STONE \& WEBSTER ENGINEERING CORPORATION . . . 201 

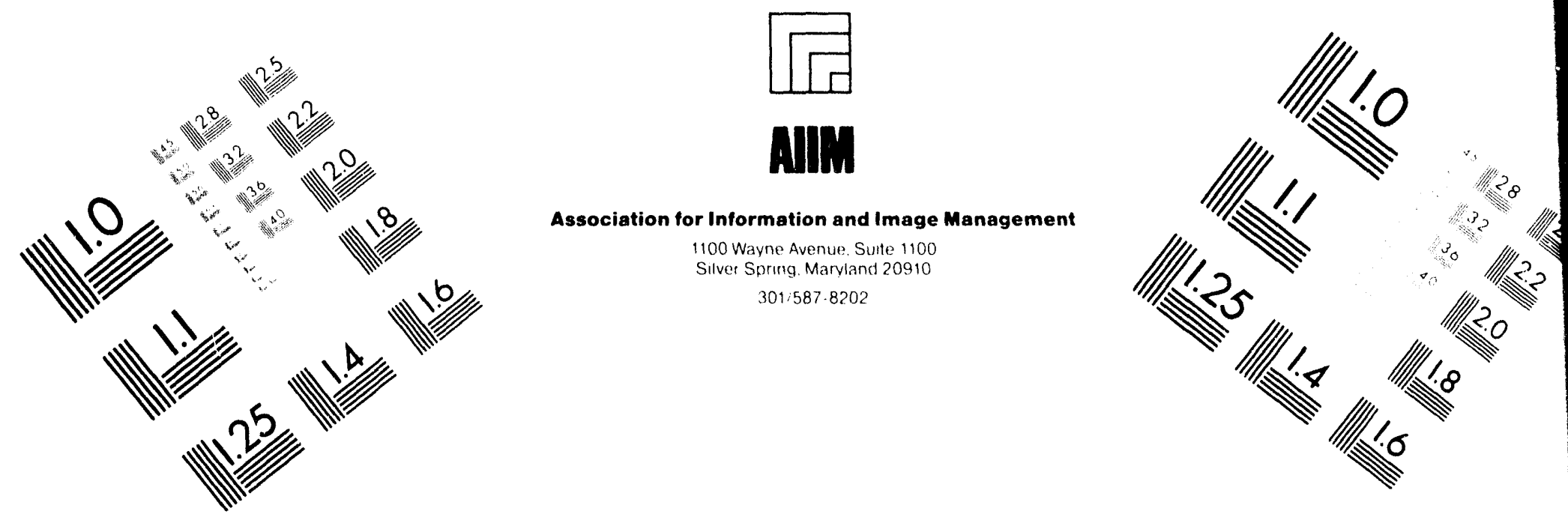

\section{Centimeter}

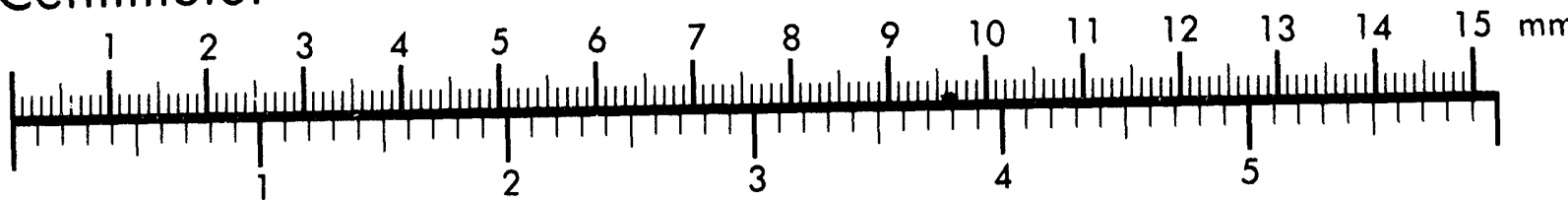

Inches
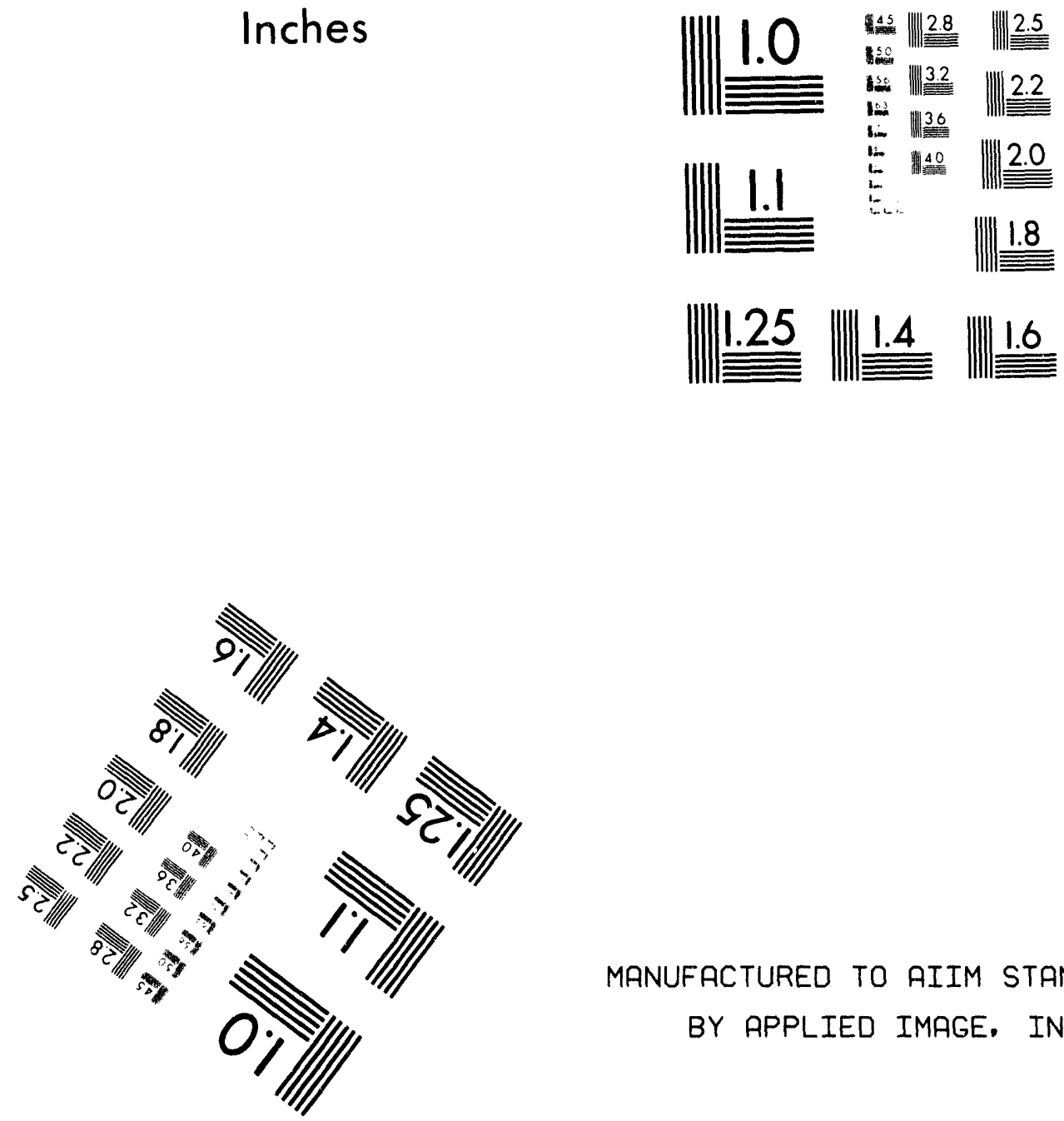

MANUFACTURED TO AIIM STANDARDS

BY APPLIED IMAGE. INC.

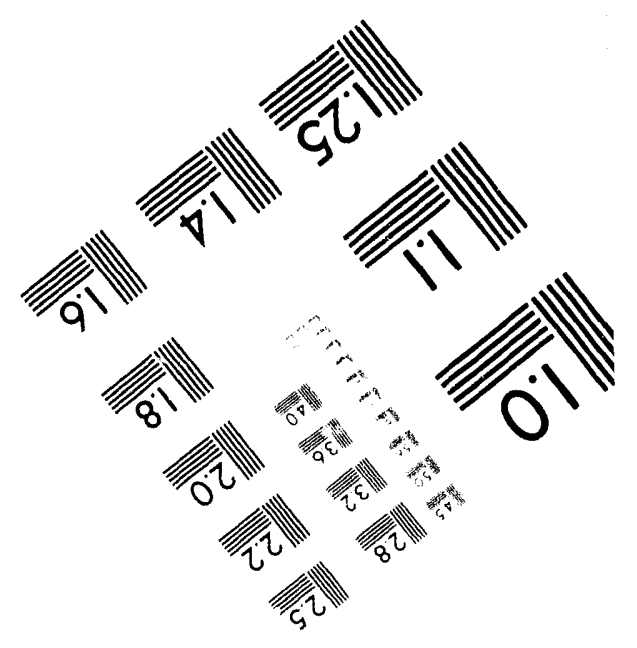



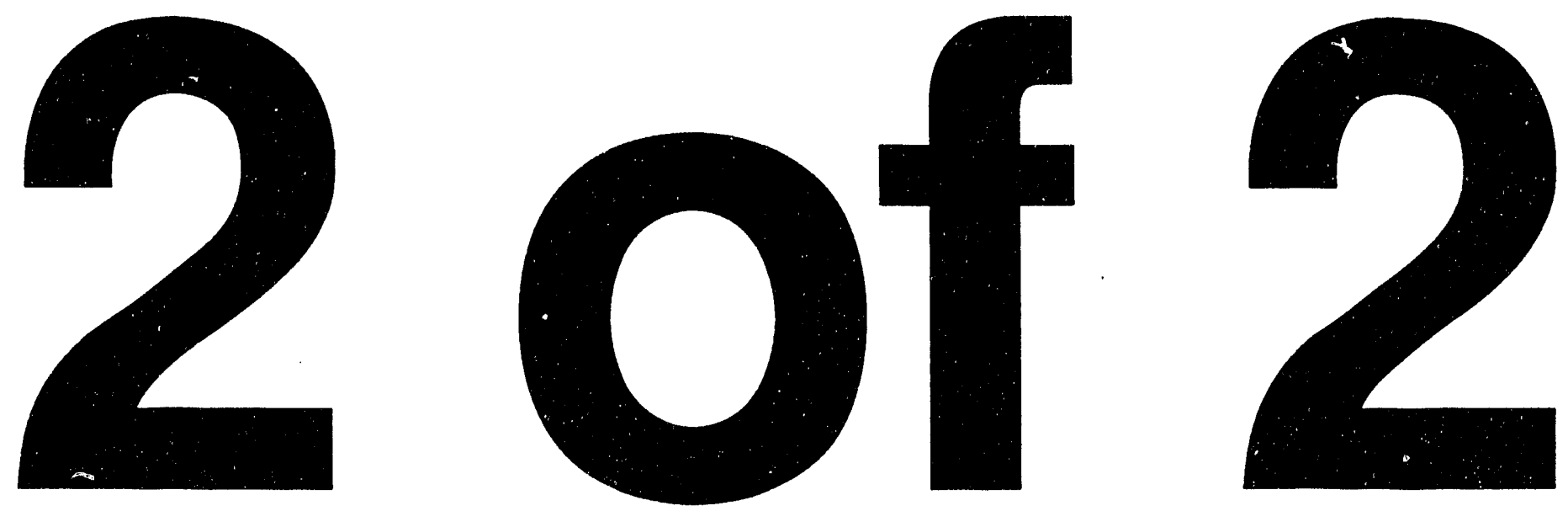
Comment

Report

Number

section

2.3 .1

2.3 .2

2.3 .5

2.4 .2

2.10 .5

$639 \quad 2.3 .1$

$2.3 \cdot 4$

640

2.3 .1

2.10 .2

641

2.5 .1

STONE \& WEBSTER ENGINEERING CORPORATION

642

$2 \cdot 3 \cdot 3$

2.10 .1

643

$2 \cdot 3 \cdot 4$

2.6 .1

2.7 .2

644

$2 \cdot 9 \cdot 4$

STONE \& WEBSTER ENGINEERING COP.PORATION

Comment References

Name

Docket

Number Page

STONE \& WEBSTER ENGINEERING CORPORATION

STONE \& WEBSTER ENGINEERING CORPORATION

STONE \& WEBSTER ENGINEERING CORPORATION

2$$
\text { STONE \& WEBSTER ENGINEERING CORPORATION }
$$

\section{5}

$2 \cdot 1 \cdot 5$

ENVIRONMENTAL COALITION ON NUCLEAR POWER

2.2 .2

STONE \& WEBSTER ENGINEERING CORPORATION

2.11 .0

GEORGIANS AGAINST NUCLEAR ENERGY

2.1 .1

GEORGIANS AGAINST NUCLEAR ENERGY

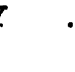

648

649

2.3 .1

GEORGIANS AGAINST NUCLEAR ENERGY

650

2.6 .1

GEORGIANS AGAINST NUCLEAR ENERGY

2.4 .3

GEORGIANS AGAINST NUCLEAR ENERGY

651

2.7 .2

GEORGIANS AGAINST NUCLEAR ENERGY

2.8 .1

GEORGIANS AGAINST NUCLEAR ENERGY

653

654

2.8 .3

655

2.1 .6

$$
\text { GEORG }
$$

ENVIRONMENTAL COALITION ON NUCLEAR POWER . • . $\quad 44 \quad 4$

656

2.2 .2

2.6 .2

657

2.3 .1

GEORGIANS AGAINST NUCLEAR ENERGY

21

3

658

ENVIRONMENTAL COALITION ON NUCLEAR POWER .

$44 \quad 4$ 
$\frac{\text { Comment References }}{\text { Comment Report }}$

Number section
Name
Appendix C

Docket

Number Page
659

660

661

662

663

664

665

666

667

668

669

670

671

672

673

674

675

676

677

678

679

680

\section{3 .1}

GEORGIANS AGAINST NUCLEAR ENERGY

$2 \cdot 3 \cdot 3$

GEORGIANS AGAINST NUCLEAR ENERGY

GEORGIANS AGAINST NUCLEAR ENERGY

$2 \cdot 6 \cdot 3$

2.9 .1

GEORGIANS AGAINST NUCLEAR ENERGY

2.6 .1

GEORGIANS AGAINST NUCLEAR ENERGY

2.2 .3

GEORGIANS AGAINST NUCLEAR ENERGY

GEORGIANS AGAINST NUCLEAR ENERGY

$2 \cdot 3 \cdot 1$

2.11 .0

GEORGIANS AGAINST NUCLEAR ENERGY

2.2 .1

ENT

GEORGIANS AGAINST NUCLEAR ENERGY

GEORGIANS AGAINST NUCLEAR ENERGY

2.11 .0

B. KOH \& ASSOCIATES, INC

2.3 .1

$2 \cdot 3 \cdot 1$

$2 \cdot 3 \cdot 4$

B. KOH \& ASSOCIATES, INC

2.10 .1

2.10 .1

2.10 .5

B. KOH \& ASSOCIATES, INC

22

2

2.2 .2

ENVIRONMENTAL COALITION ON NUCLEAR POWER .

44

5

$2 \cdot 3 \cdot 4$

B. KOH \& ASSOCIATES, INC

22

2

2.4 .3

2.2 .2

2.10 .1

B. KOH \& ASSOCIATES, INC

$2 \cdot 4 \cdot 3$

B. KOH \& ASSOCIATES, INC

2.7 .2

B. KOH \& ASSOCIATES, INC

2.7 .1

B. $\mathrm{KOH} \&$ ASSOCIATES, INC

2.7 .2

B. KOH \& ASSOCIATES, INC

$2 \cdot 3 \cdot 5$

ENVIRONMENTAL COAIITION ON NUCLEAR POWER 


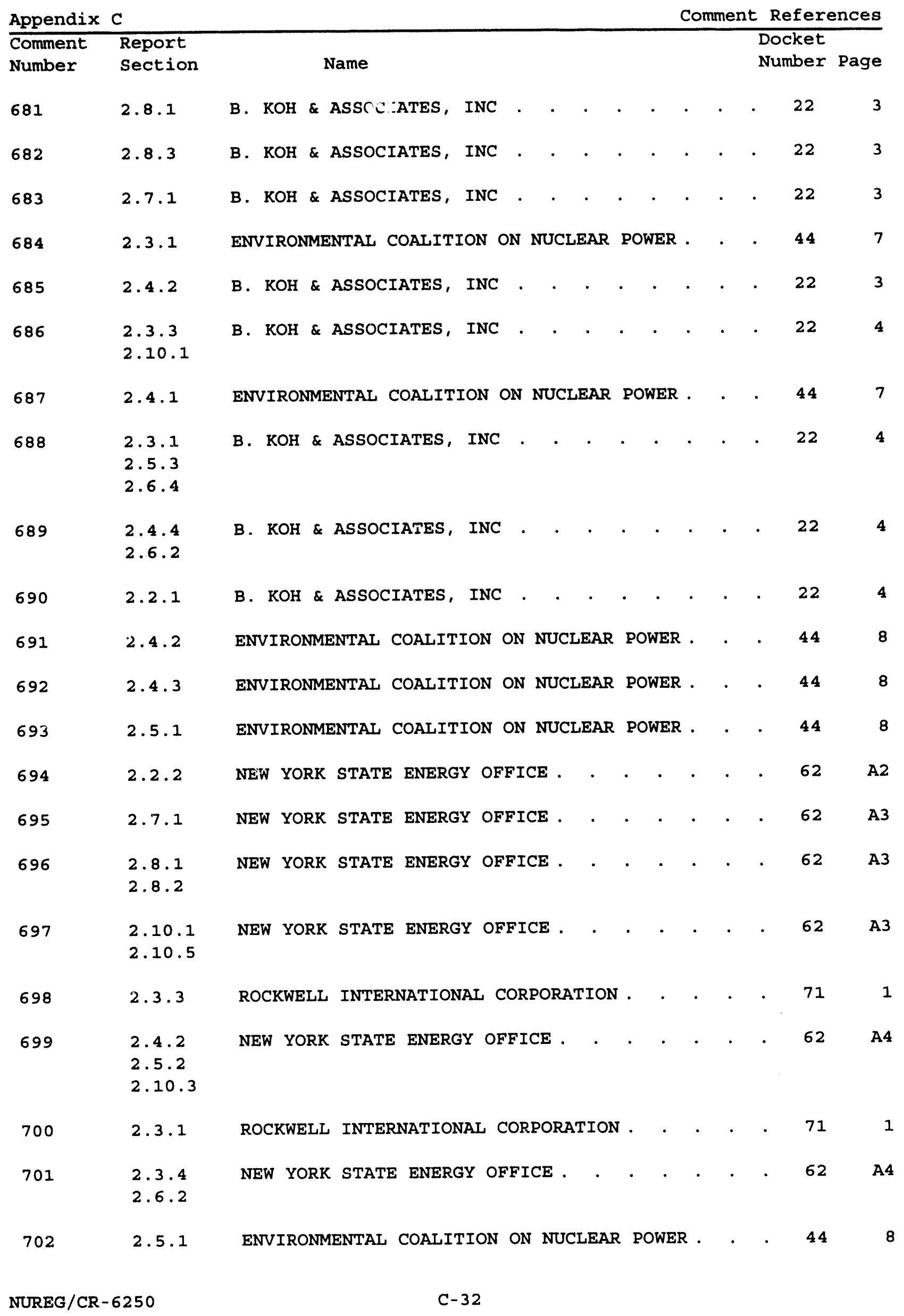


$\frac{\text { Comment References }}{\text { Comment Report }}$

Number section
Appendix C Docket

Number Page
703

705

706

707

708

709

710

711

712

713

714

715

716

717

718

719

720

721

722

723

724

725
2.2 .3

2.2 .3

2.1 .7

$2 \cdot 3 \cdot 3$

2.6 .5

2.3. 1

2. 5.2

2. 10.2

2.3 .1

2.4 .3

2. 4.3

2.9 .1

2.11 .0

2.1 .2

2.1 .7

2.1 .7

2.6 .1

2.2 .2

2. 3.1

2. 4.2

2.7 .1

2. 3.1

2.3 .3

2.4 .2

N

2.10 .1

NEW YORK STATE ENERGY OFFICE

ROCKWELL INTERNATIONAI CORPORATION

$2 \cdot 3 \cdot 3$

2.7 .2

$2.8 \cdot 4$

ENVIRONMENTAL COALITION ON NUCLEAR POWER

NEW YORK STATE ENERGY OFFICE .

A4

NEW YORK STATE ENERGY OFFICE .

62

A4

ROCKWELL INTERNATIONAI CORPORATION .

$71 \quad 2$

NEW YORK STATE ENERGY OFFICE

62

A4

NEW YORK STATE ENERGY OFFICE .

62

A.5

ROCKWELL INTERNATIONAL CORPORATION

2

NEW YORK STATE ENERGY OFFICE

NEW YORK STATE ENERGY OFFICE

NEW YORK STATE ENERGY OFFICE

62

A6

NEW YORK STATE ENERGY OFFICE

62

A6

NEW YORK STATE ENERGY OFFICE

62

A6

NEW YORK STATE ENERGY OFFICE . . . . . . . . . 62

A7

ENVIRONMENTAL COALITION ON NUCLEAR POWER . . . 4499

NEW YORK STATE ENERGY OFFICE . . . . . . . . . . 62 A7

NEW YORK STATE ENERGY OFFICE .

62

A8

ENVIRONMENTAL COALITION ON NUCLEAR POWER .

NEW YORK STATE ENERGY OFFICE

62

A9

2.10 .2 


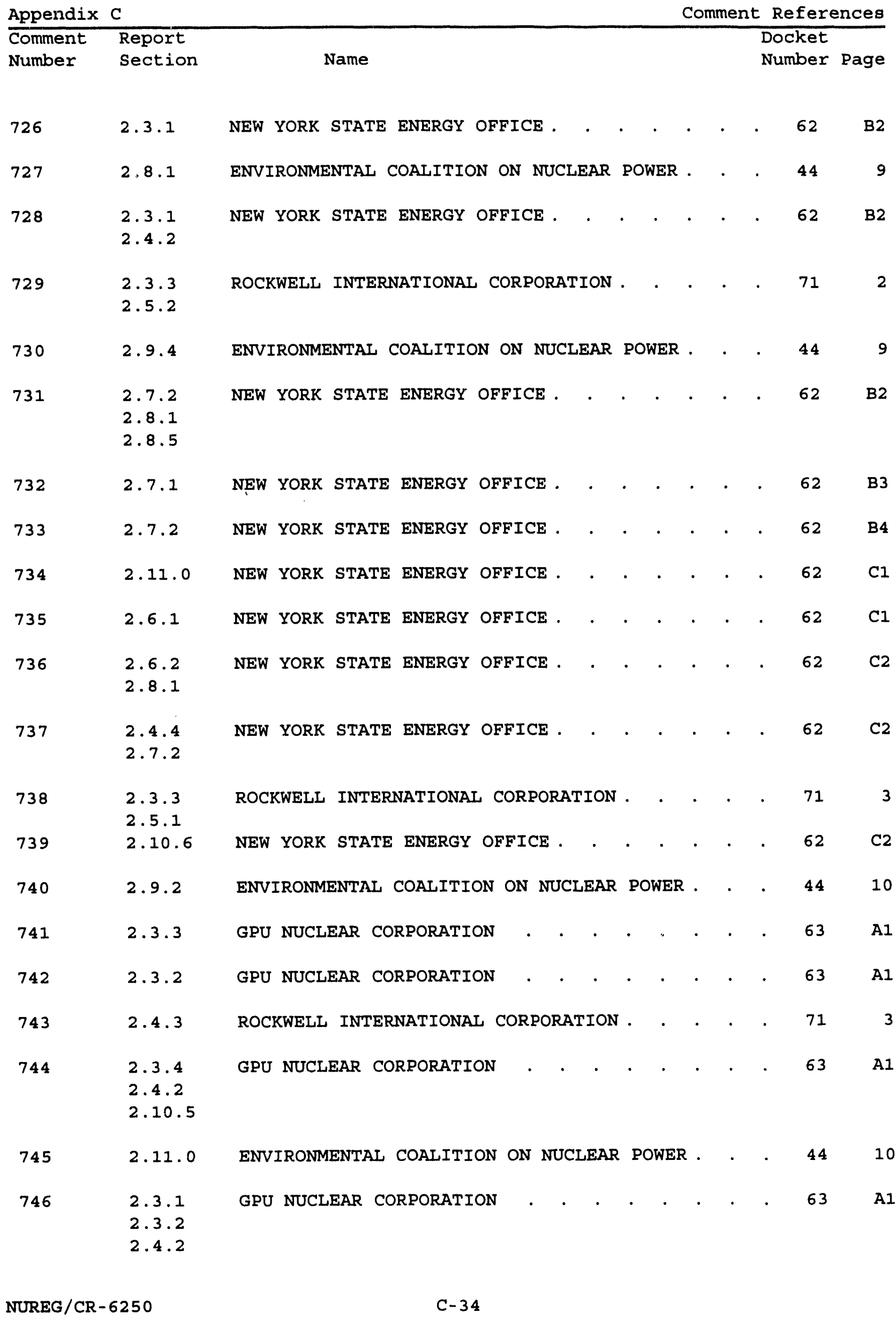


Comment References

Comment Report
Number section

747

748

749

750

751

752

753

754

755

756

757

758

759

760

761

762

763

764

765

2.3 .6

2.3 .3

2.11 .0

2. 3.1

2. 3.2

2.3 .1

2.3 .3

2. 5.2

2.3 .4

2. 4.2

2.10 .3

2.10 .1

2.10 .2

2.11 .0

2.3 .1

2. 5.2

2.8 .2

2. 3.2

2.3 .3

2. 3.4

2. 10.2

$2 \cdot 3 \cdot 1$
$2 \cdot 3 \cdot 1$
$2 \cdot 3 \cdot 2$
$2 \cdot 3 \cdot 3$
$2 \cdot 3 \cdot 4$
$2 \cdot 10 \cdot 2$

2.3 .1

2.4 .2

2.2 .

2.4 .2

2.10 .3

$2.3 \cdot 3$
2.10 .1

2.10 .1

GPU NUCLEAR CORPORATION

CORPORATION

GPU NUCLEAR CORPORATION

GPU NUCLEAR CORPORATION

CAREY

ROCKWELL INTERNATIONAL CORPORATION .

Appendix C

Name

Docket

Number Page

GPU NUCLEAR CORPORATION

$63 \quad A 1$

ROCKWELL INTERNATIONAL CORPORATION

71

3

ENVIRONMENTAL COALITION ON NUCLEAR POWER

$44 \quad 10$

GPU NUCLEAR CORPORATION

63

A1

GPU NUCLEAR CORPORATION

63

A2

GPU NUCLEAR CORPORATION

2.3.1

GPU NUCLEAR CORPORATION

CRCPD COMMITTEE (E-5)

GPU NUCLEAR CORPORATION

2.10 .1

GPU NUCLEAR CORPORATION
63

A4

84

1

63

A4

A3

A4

4

A4 
Appendix $\mathrm{C}$

Comment Report

Number section

766

2.8.2

2.10 .2

767

768

769

770

771

772

773

774

775

776

777

778

779

780

781

782

783

784

785

2. 8.1

$$
2.3 .1
$$

2.4 .4

2.3 .6

2.2 .2

2.6.1

2. 3.4

2. 4.2

2. 3.1

2. 3.2

2.5.2

2.3 .1

2.6 .2

2.6 .4

2.3 .4

2. 10.1

2. 3.1

2.3 .4

2.1 .1

2.3 .1

2.3 .4

2.8. 2

2.8 .3

2.1. 2
2.7.2 GPU NUCLEAR CORPORATION

CRCPD COMNITTEE (E-5)

GPU NUCLEAR CORPORATION

CRCPD COMMITTEE $(E-5)$

SEQUOYAH FUELS

FLUOR DANIEL

SEQUOYAH FUELS

\subsubsection{SEQUOYAH FUELS}

2.3.1 FLUOR DANIEL

2.4.3 SEQUOYAH FUELS

FLUOR DANIEL

CRCPD COMMITTEE

$(E-5)$

SEQUOYAH FUELS

2.10 .3

FLUOR DANIEL

PERKINS
Comment References Docket

Number Page

$63 \quad \mathrm{A4}$

63

A4

1

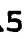

2

2

2

1

3

3

1

2

3

1 PERKINS . . . . . . . . . . . . . . . . . 65

CRCPD COMMITTEE $(E-5)$. . . . . . . . . . $84 \quad 2$

FLUOR DANIEL . . . . . . . . . . . . . . . . $72 \quad 7$

1 
$2.8 \cdot 3$

PERKINS .

2.8 .4

2.3 .4 FLUOR DANIEL

2.10 .3

2.3.1 CRCPD COMMITTEE (E-5)

84

2. 4.2

$66 \quad 1$

2.2 .1

UNOCAL CORPORATION

66

2.2 .2

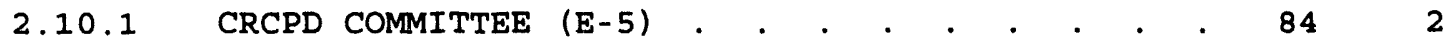

2.10 .1 UNOCAL CORPORATION . . . . . . . . . . . . . . $66 \quad 62$

2.3 .3 UNOCAL CORPORATION . . . . . . . . . . . . . . . 66

2.10 .1

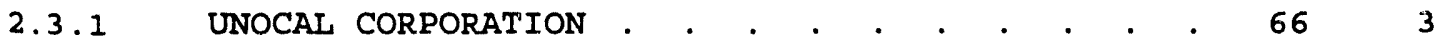

2.10.2 CRCPD COMMITTEE $(E-5)$. $. \quad . \quad . \quad . \quad . \quad . \quad . \quad . \quad 84 \quad 842$

2.3.3 MICHIGAN DEPARTMENT OF PUBLIC HEALTH . . . . $\quad 73$ A1

2.4 .1

2.3 .4

UNOCAL CORPORATION

66

3

2.10 .5

842

2.10.1 MICHIGAN DEPARTMENT OF PUBLIC HEALTH . . . . $\quad \begin{array}{llll}73 & \text { Al }\end{array}$

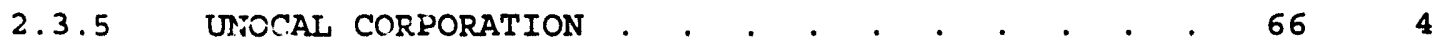

2.10 .1

2.10 .3

2.4 .3

UNOCAL CORPORATION

66

4

2.10 .1

2.4 .3

UNOCAL CORPORATION

66

4

2.3 .3

MICHIGAN DEPARTMENT OF PUBLIC HEALTH

2. 5.2

\section{6 .1}

UNOCAL CORPORATION .

66

$2.8 \cdot 5$

CRCPD COMMITTEE (E-5)

84

2.8 .6

UNOCAL CORPORATION

66 


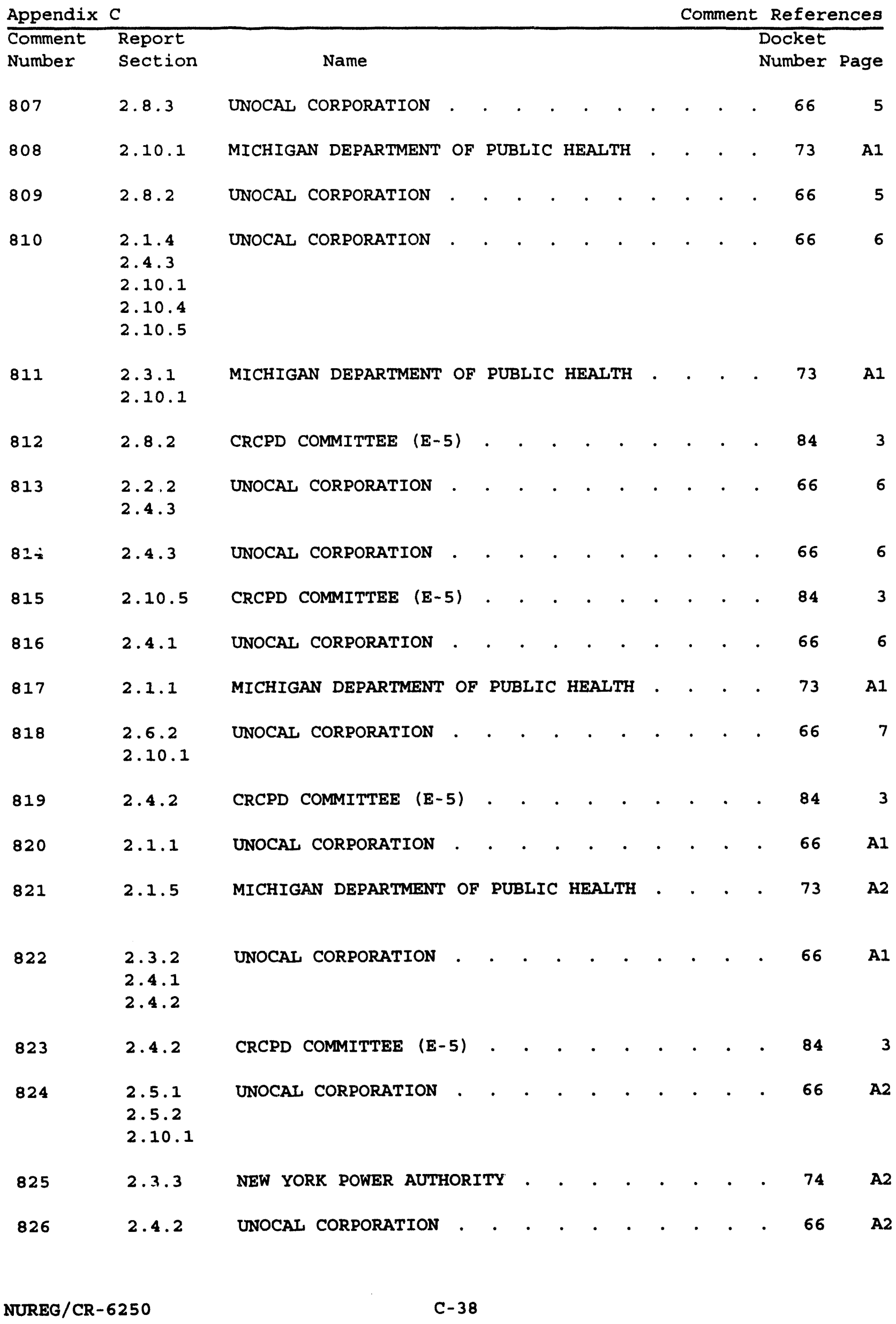


Comment References

Comment Report

Number section

827

2.6 .1

2.6.2

828

829

$2.3 \cdot 1$

2.3 .3

$2.3 \cdot 4$

2. 4.2

2.10 .3

830

2.3 .1

2.5.1

831

832

833

834

835

836

837

838

839

840

841

842

844

845

2.2 .3

2.3 .6

2.3.1

2. 3.2

2. 5.2

2.10 .2

$2 \cdot 3 \cdot 2$

2. 4.2

2.10 .6

2.3.1

2. 5.2

2.3 .5

2. 5.1

$2 \cdot 6.5$

$2 \cdot 8 \cdot 3$

2. 3.1

2.4 .3

2.10 .3

$2 \cdot 3 \cdot 1$

2.3.2

2.4 .2

$2 \cdot 3 \cdot 2$

2.4 .2

CRCPD COMMITTEE (E-5)

UNOCAL CORPORATION

UNOCAL CORPORATION

CRCPD COMMITTEE (E-5)

UNOCAL CORPORATION

UNOCAL CORPORATION

CRCPD COMMITTE

$(E-5)$

NEW YORK POWER AUTHORITY

NEW YORK POWER AUTHORITY

CRCPD COMMITTEE (E-5)

UNOCAL CORPORATION

UNOCAL CORPORATION 
Appendix C

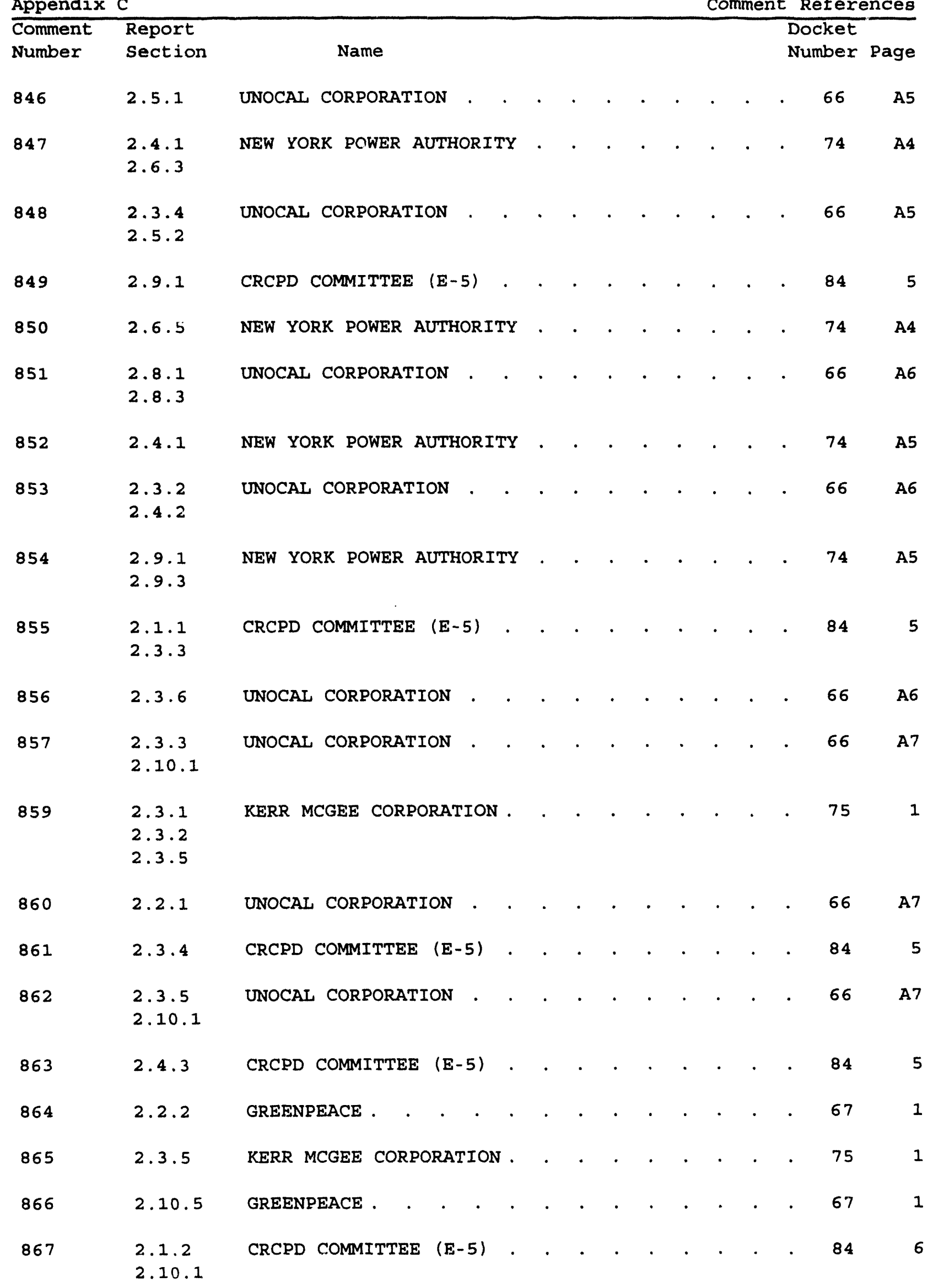


Comment References

Comment Report

Number

Section

$2 \cdot 3 \cdot 1$
2.3 .3
2.5 .1

869

2.11 .0

GREENPEACE

870

871

872

873

874

875

876

877

878

879

880

881

882

883

884

885

886

887

2.3 .1

2.5 .2

2.1 .7

2.10 .3

2.2 .2

2. 10.1

2. 3.1

2.3 .5

2.3 .1

2. 10.2

2.3 .

$2 \cdot 3 \cdot 3$

2. 2.2

2. 7.1

2.7 .2

$2 \cdot 3 \cdot 3$

2. 3.1

2.7 .2

2.3 .1

2.4 .2

2.9 .1

2.3 .1

2.8 .6

2.3 .1

$$
2 \cdot 3 \cdot
$$

2.3.1 FIORIDA POWER CORPORATION

KERR MCGEE CORPORATION

CRCPD SOMMITTEE (E-5)

FLORIDA POWER CORPORATION .

KERR MCGEE CORPORATION

CLEAN WATER FUND OF NORTH CAROLINA

KERR MCGEE CORPORATION .

CRCPD COMMITTEE (E-5)

KERR MCGEE CORPORATION

FLORIDA POWER CORPORATION .

CRCPD COMMITTEE (E-5)

KERR MCGEE CORPORATION

FLORIDA POWER CORPORATION

KERR MCGEE CORPORATION .

FLORIDA POWER CORPORATION

FLORIDA POWER CORPORATION .

KERR MCGEE CORPORATION

FLORIDA POWER CORPORATION .

68

1

84

6

2

75

2

$68 \quad 2$

3

682 
Appendix C

Comment Report

Number

section

2.3 .1

2.3 .2

2.4.2

889

2.4 .2

2.5 .2

890

$2.3 \cdot 1$

2.3 .2

891

2.3.1

2.3. 2

892

$2 \cdot 3 \cdot 1$

2.3 .2

2.5 .2

893

2.3 .1

894

895

896

897

898

899

900

901

902

903

904

905

906

907

908

909

2. 4.1

2.6 .3

2.6 .1

2. 8.6

2.9 .4

2.6 .4 2. 10.1

2.2 .2

2.4 .1

2.3 .3

2.4 .4

2. 4.2

2.6 .2

$$
2.7 .3
$$

2. 3.1
CLEAN WATER FUND OF NORTH CAROLINA.

2.4.2 COMMONWEALTH EDISON.

2.10 .2

FLORIDA POWER CORPORATION

COMMONWEALTH EDISON

COMMONWEALTH EDISON

FLORIDA POWER CORPORATION
Comment References

Docket

Number Page

FLORIDA POWER CORPORATION

68

2

CLEAN WATER FUND OF NORTH CAROLINA

85

2

COMMONWEALTH EDISON

1

COMMONFEALTH EDISON

2

FLORIDA POWER CORPORATION

68

3

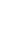

3

2

3

2

2

4

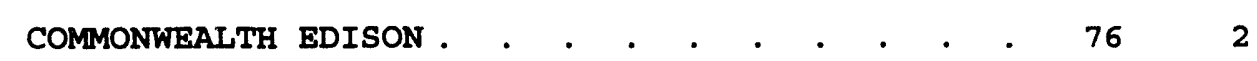

COMMONWEALTH EDISON . . . . . . . . . . . . 76

CLEAN WATER FUND OF NORTH CAROLINA . . . . . 85

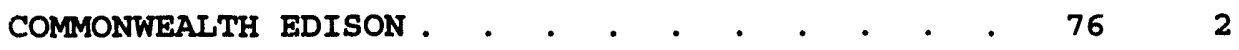

FLORIDA POWER CORPORATION . . . . . . . . . . 684

COMMONWEALTH EDISON . . . . . . . . . . . . . 76

FLORIDA POWER CORPORATION . . . . . . . . . . 68

COMMONWEALTH EDISON . . . . . . . . . . . . . 76

CLEAN WATER FUND OF NORTH CAROLINA . . . . . 85

FLORIDA POWER CORPORATION . . . . . . . . . . . 68

COMMONFEALTH EDISON . . . . . . . . . . . . . 76 


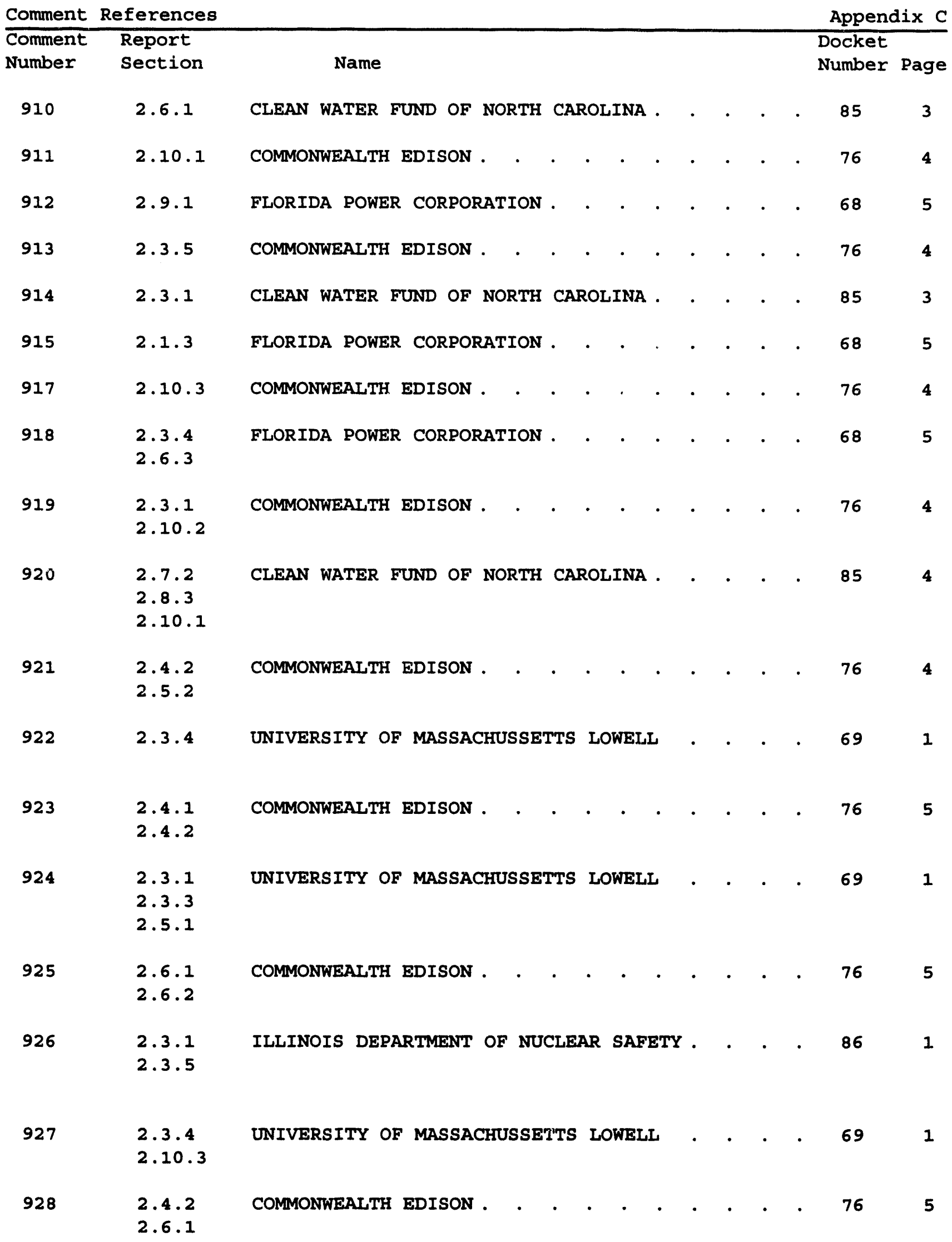




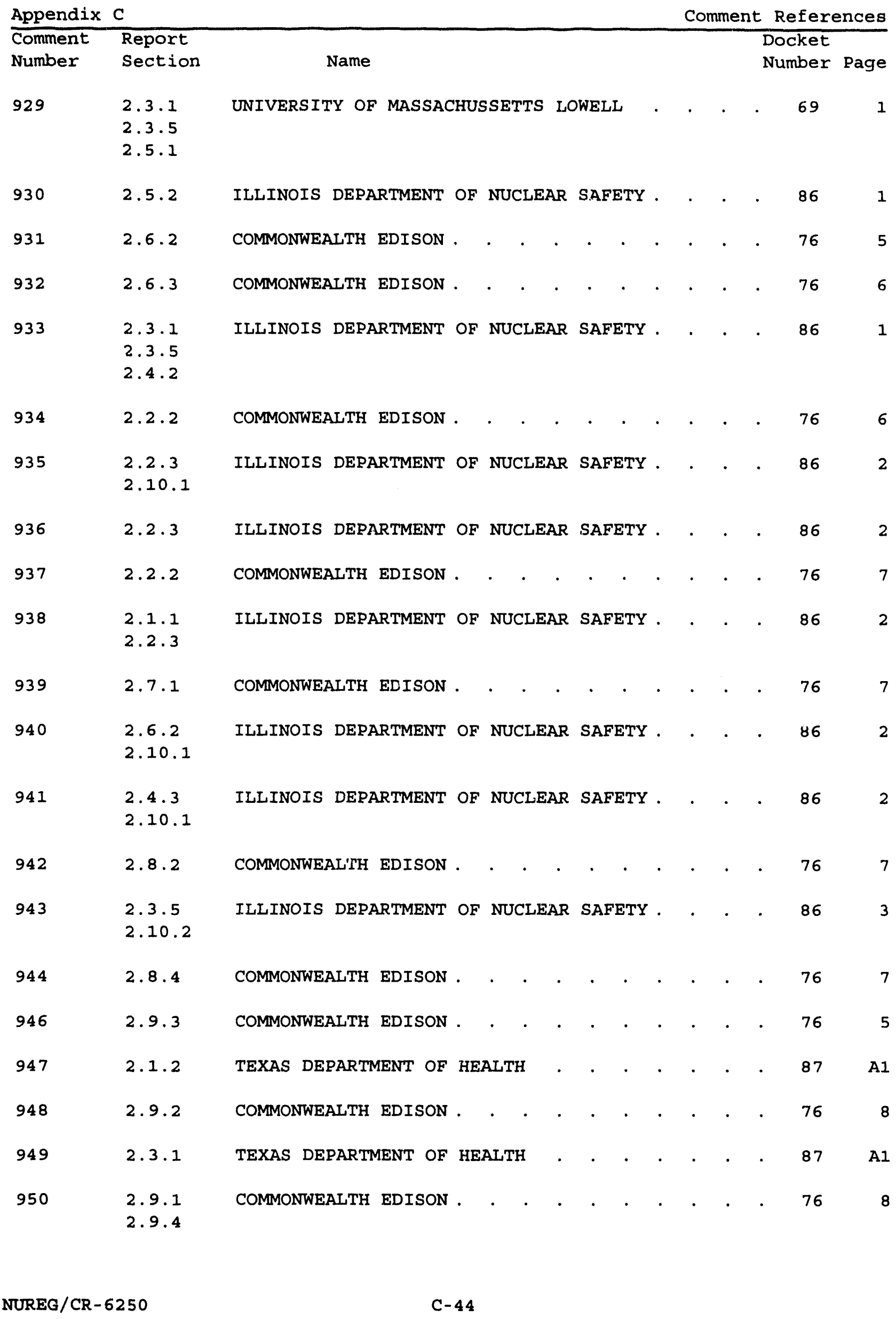


Comment References

Comment Report

Number section

951

952

953

954

955

956

957

958

959

960

961

962

963

964

965

966

967

2. 6.1

2.10 .1

2.3 .4

2.10 .3

2.7 .2

2.3 .1

2.4 .2

2.5 .2

2.11 .0

2.3 .1

2. 4.2

2.11 .0

. 3.1

2.10 .3

2.10 .5

$2.3 \cdot 4$

2.10 .3

2.3 .1

2.5 .1

$2 \cdot 3 \cdot 1$

2.3 .5

2.3 .1

$2 \cdot 5 \cdot 3$

2.6.1

2.7 .2

$2 \cdot 3 \cdot 1$

2.3 .2

2.5.1

2.7.1

2.3 .1
2.10 .1

DUNNING

Name

Appendix C

Docket

Number Page

TEXAS DEPARTMENT OF HEALTH

87

A1

NUCLEAR METALS, INC.

77

1

TEXAS DEPARTMENT OF HEALTH

87

A.1

TEXAS DEPARTMENT OF HEALTH

87

A1

UNIVERSITY OF MASSACHUSSETIS LOWELI

69

2

DUNNING .

GROFF

DUNNING .

70

1

2.1.3 DUNNING .

GROFF

DUNNING .

70

1

GROF

DUNNING .

DUNNING .

2.4 .2

2.5 .2 


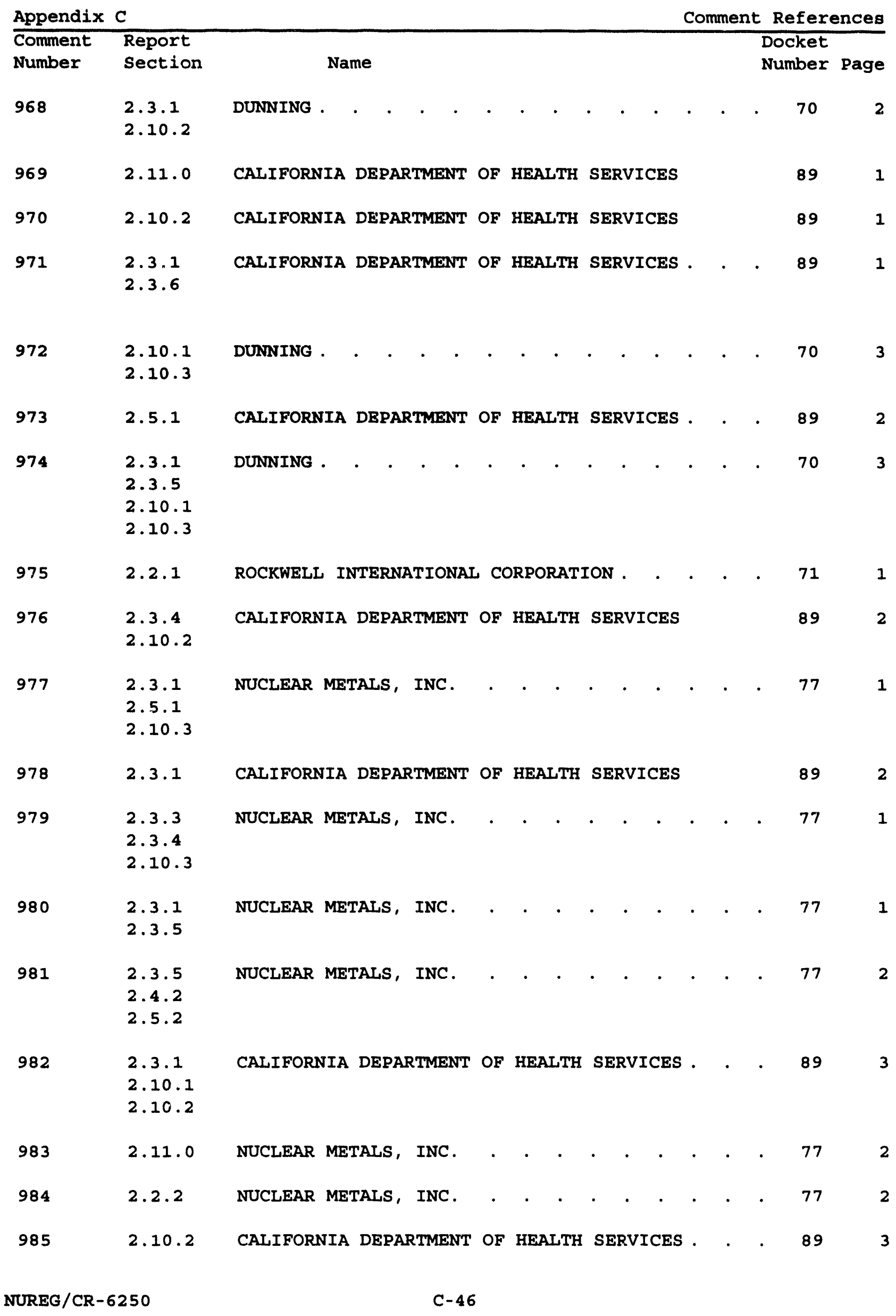




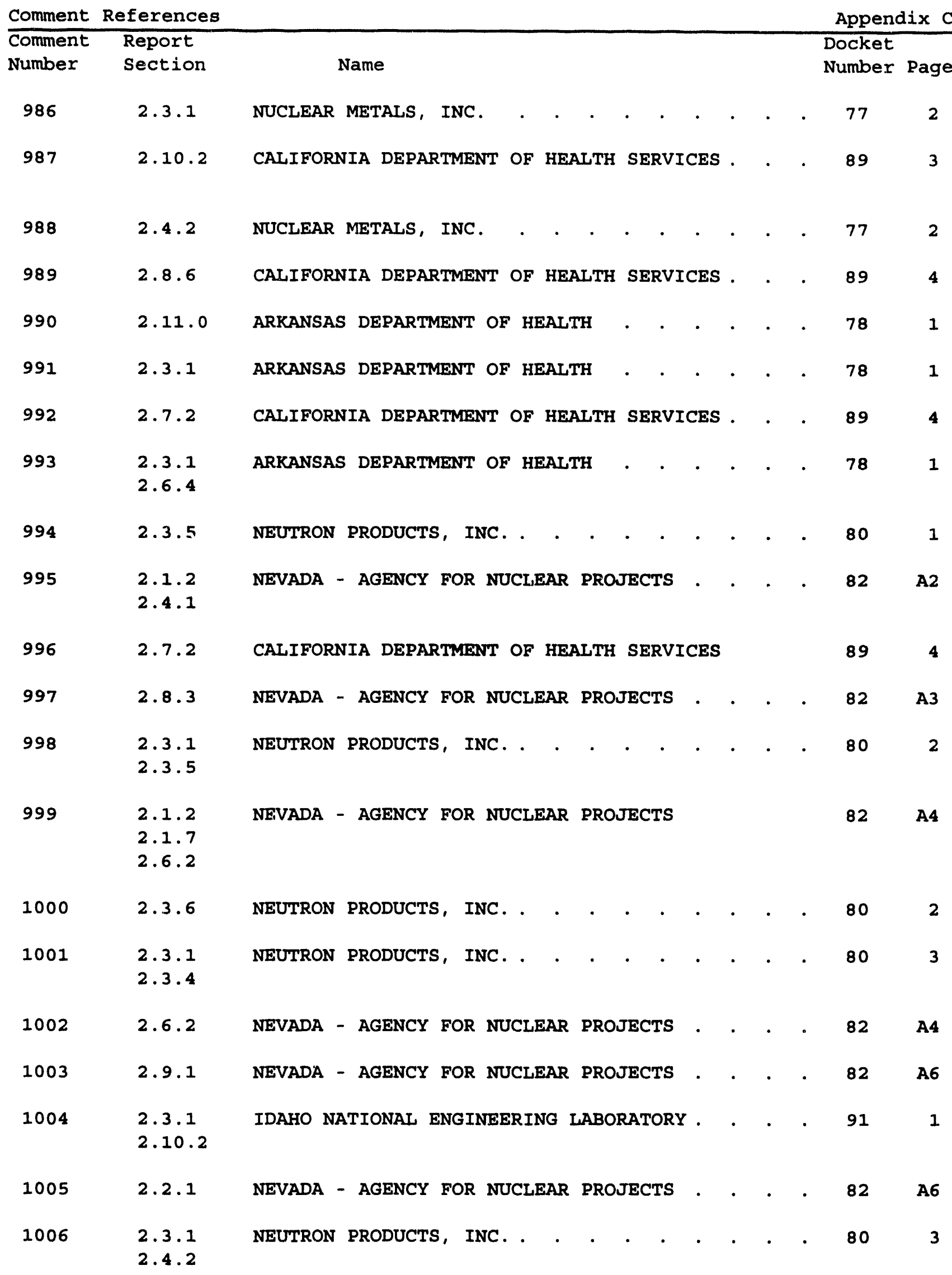


Comment

Report

Number section

Name

Docket

Number Page
1007

2.6 .2

2. 10.2

1008

1009

1010

1011

1012

1013

1014

1015

1016

1017

1018

1019

1020

1021

1022

1023

1024

1025

1026

1027

1028

1029

1030
2.11 .0

2.3 .1

2.2 .3

2. 4.1

2. 10.2

\subsection{1}

$2.8 \cdot 3$

2.4 .2

2.3 .1

$2 \cdot 3 \cdot 4$

2.4 .3

2.11 .0

2.3 .3

2. 3.4

2.3 .1

2. 8.1

2.7 .1

2.10 .2

2.9 .1

2.10 .1

2.11 .0

2.10 .2

2.3 .6

$2 \cdot 6 \cdot 3$

$2.10 \cdot 5$

2.10 .1

2.10 .2

ORISE
IDAHO NATIONAL ENGINEERING LABORATORY

NEVADA. - AGENCY FOR NUCLEAR PROJECTS

A1

IDAHO NATIONAL ENGINEERING LABORATORY .

2

NEVADA - AGENCY FOR NUCLEAR PROJECTS . . . . 82

A2

IDAHO NATIONAL ENGINEERING LABORATORY

91

2

NEVADA - AGENCY FOR NUCLEAR PROJECTS .

82

A2

IDAHO NATIONAL ENGINEERING LABORATORY .

91

2

NEVADA - AGENCY FOR NUCLEAR PROJECTS

82

A2

NEUTRON PRODUCTS, INC.

5

IDAHO NATIONAL ENGINEERING LABORATORY .

VIRGINIA POWER

81

STATE OF NEBRASKA DEPARTMENT OF HEALTH

92

A1

STATE OF NEBRASKA DEPARTMENT OF HEALTH

A1

STATE OF NEBRASKA DEPARTMENT OF HEALTH . . . 92

A1

ST TE OF NEBRASKA DEPARTMENT OF HEALTH

92

A1

STATE OF NEBRASKA DEPARTMENT OF HEALTH

A1

STATE OF NEBRASKA DEPARTMENT OF HEALTH

A1

STATE OF NEBRASKA DEPARTMEYT OF HEALTH

STATE OF NEBRASKA DEPFRTMENT OF HEALTH .

92

A2

STATE OF NEBRASKA DEPARTMENT OF HEALTH

92

A2

STATE OF NEBRASKA DEPARTMENT OF HEALTH

92

A2

ORISE

93

A1

ORISE

93

93

A1 


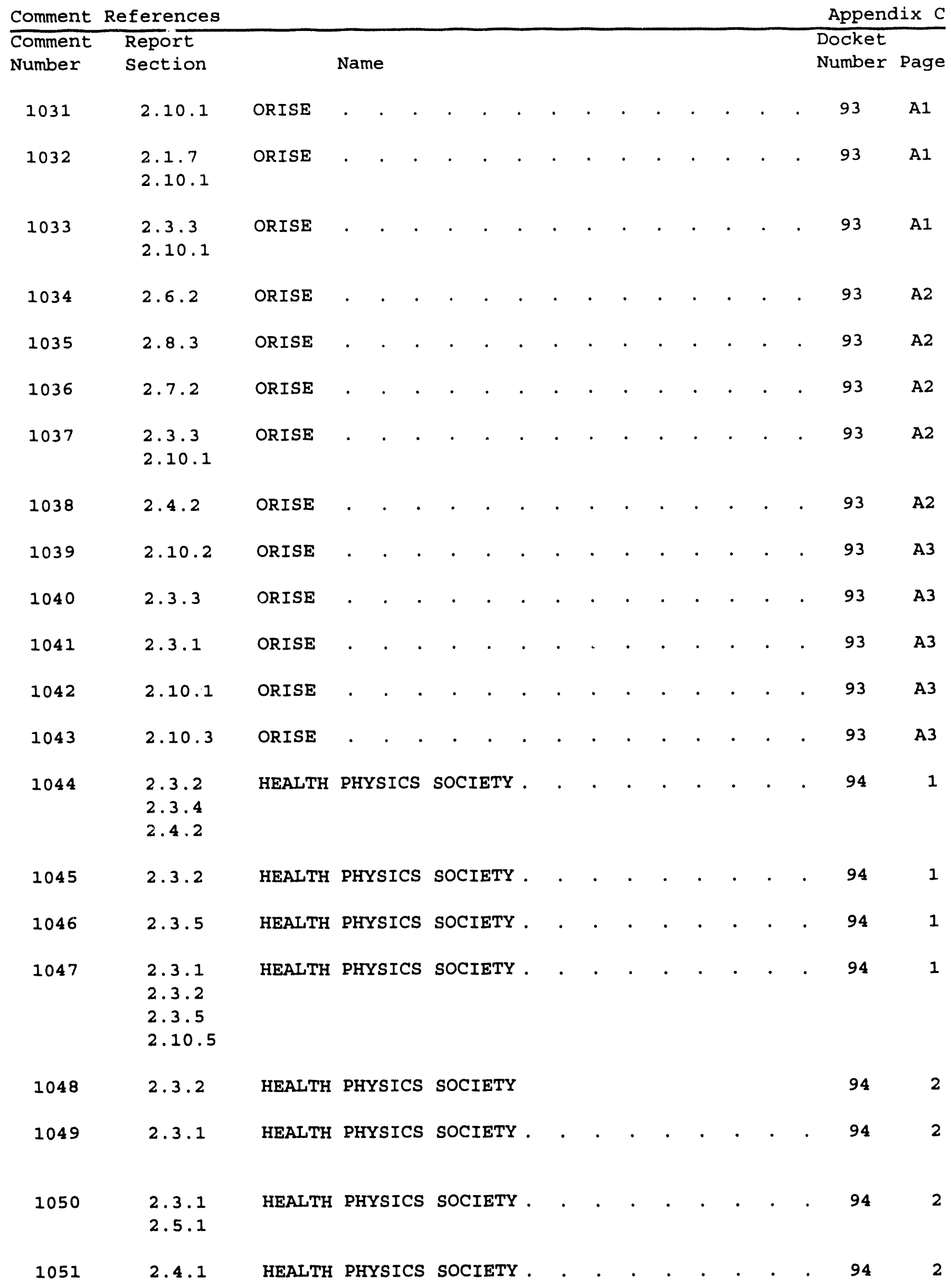


Comment Report

Number Section

Name

Docket

Number Page

1052

$2 \cdot 3 \cdot 3$

HEALTH PHYSICS SOCIETY

$2 \cdot 3 \cdot 4$

HEALTH PHYSICS SOCIETY

1053

1054

$2 \cdot 3 \cdot 4$

2.4 .2

1055

$2 \cdot 3 \cdot 1$

2.2 .2

2.3 .3

1057

2.3. 1

2. 4.2

1058

2.10 .3

1059

2.10 .1

$2.3 \cdot 1$

1060

1061

1062

1063

1064

1065

1066

1067

1068

1069

1070

1071

1072
2. 4.3

2.10 .1

$2.4 \cdot 3$

2.10 .1

2.10 .2

2.11 .0

2. 2.3

2.3 .5

2.2 .3

2. 6.1

2.10 .2

YAKAMA NATION

YAKAMA NATION .

2.3 .2

2.3 .6

$2 \cdot 3 \cdot 3$

2.4 .4

YAKAMA NATION .

YAKAMA NATION

YAKAMA NATION .
THH CAROLINA DEPT OF HEALTH AND

ENVIRONMENTAL CONTROL . . . . . . . . . . 951

SOUTH CAROLINA DEPT OF HEALTH AND

ENVIRONMENTAL CONTROL . . . . . . . . . . 951

SOUTH CAROLINA DEPT OF HEALTH AND

ENVIRONMENTAL CONTROL • • • • • • • • . 95

SOUTH CAROLINA DEPT OF HEALTH AND . . . . . . 95 ENVIRONMENTAL CONTROL

SOUTH CAROLINA DEPT OF HEALTH AND

ENVIRONMENTAL CONTROL . . . . . . . . . . . 95

WESTERN STATES LEGAL FOUNDATION

97

1

YAKAMA NATION .

YAKAMA NATION . 


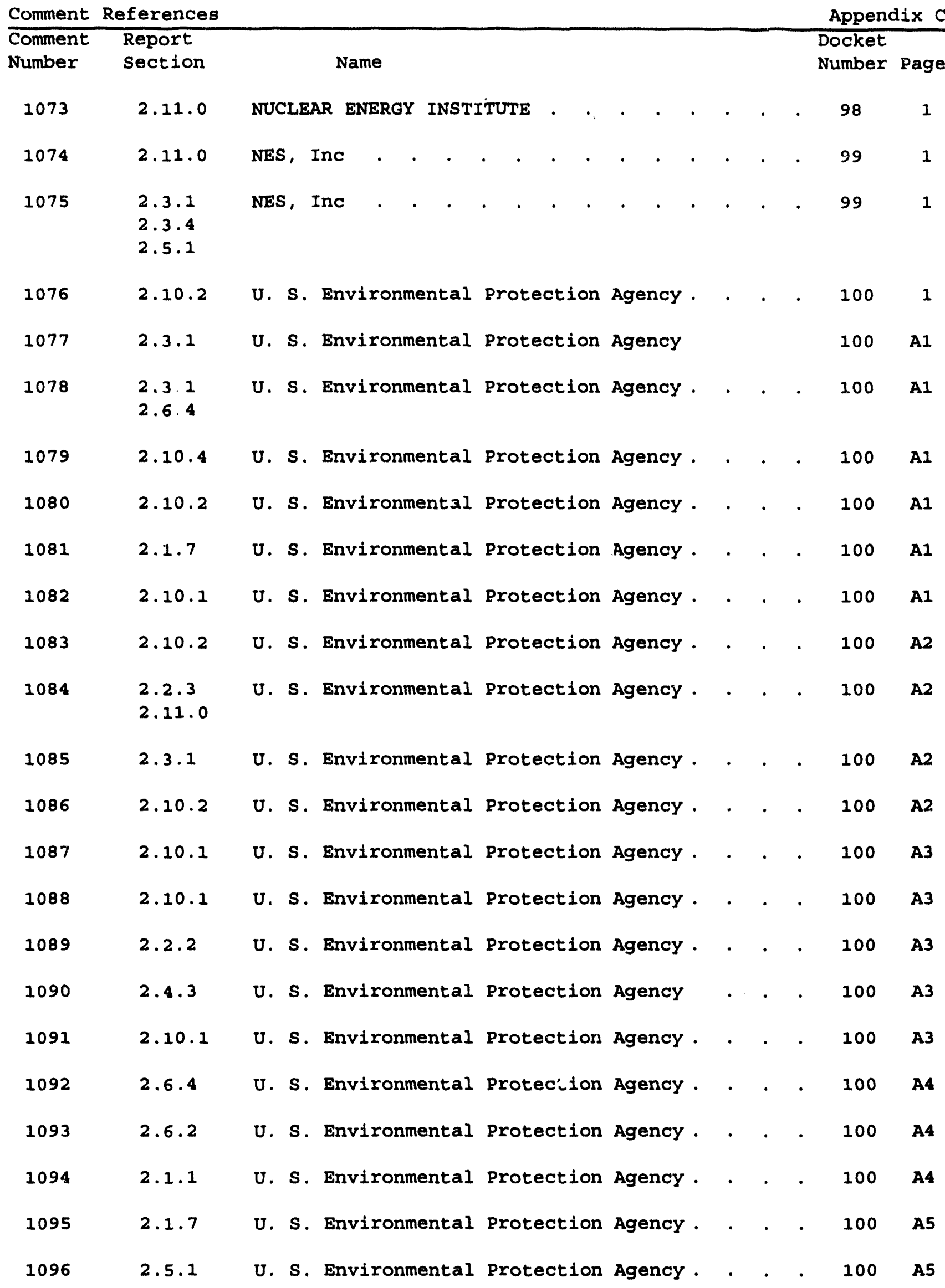


Appendix C

Comment Report

Number section

$2 \cdot 10.1$

U.

1097

1098

1099

2.6 .2

U. S. Ervironmental Protection Agency

U. S. Environmental protection Agency .

$2 \cdot 7.1$

2.7 .2

2.8 .3

2.8 .4

2.8 .6

1100

$2 \cdot 7 \cdot 1$

$2 \cdot 8 \cdot 3$

1101

1102
2. 10.1

2.10 .2

$2 \cdot 10 \cdot 4$
U. S. Environmental protection Agency

U. S. Environmental protection Agency

U. S. Environmental
Comment References

Docket

Number Page

$100 \quad$ A6

$100 \quad$ A6

$100 \quad \mathrm{~A} 6$

100 A6

$100 \quad$ A6

$100 \quad$ A6 

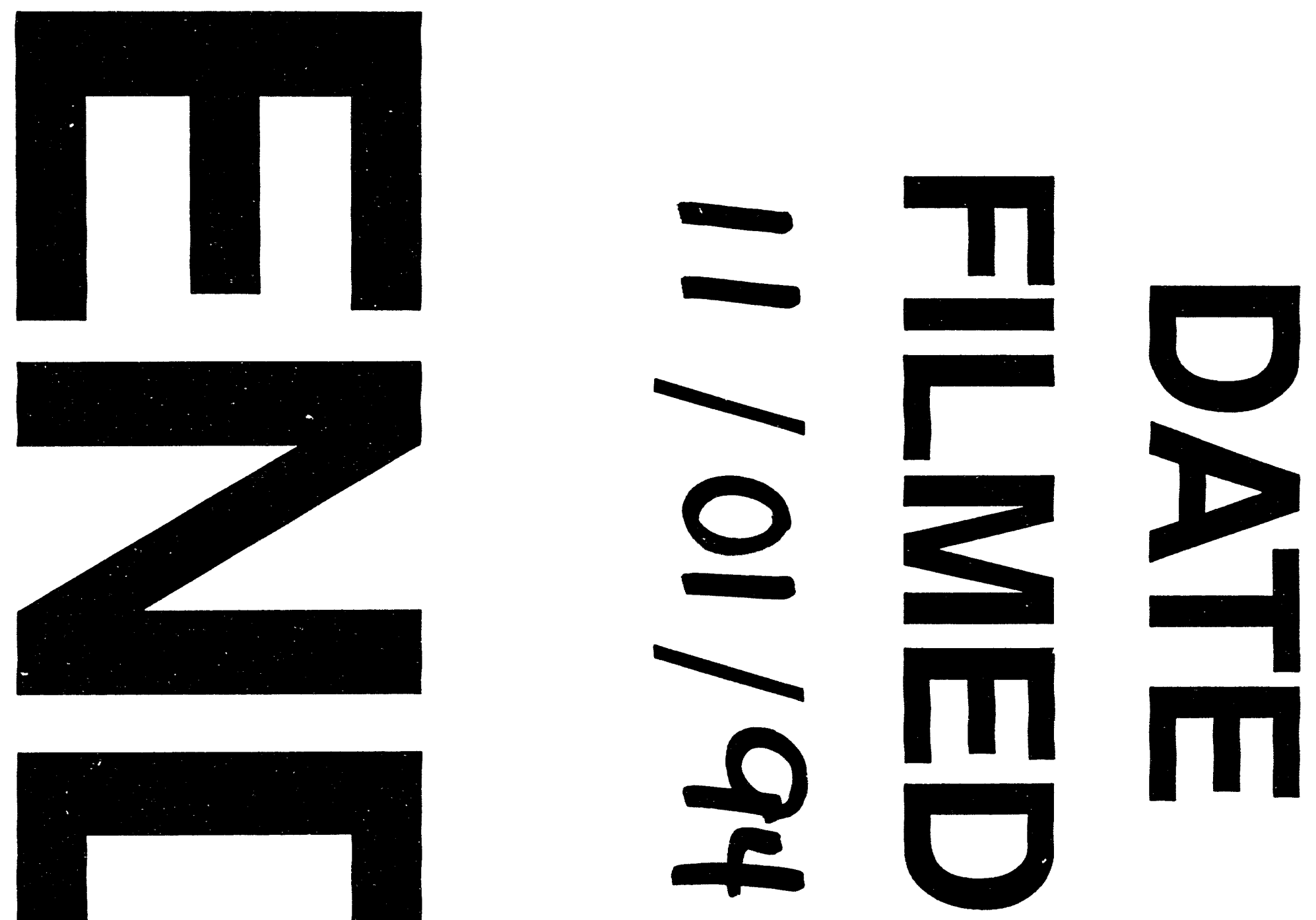
